\title{
Recent progress, fabrication challenges and stability issues of Lead-free Tin- based perovskite thin films in the field of photovoltaics
}

\author{
Author(s) \\ Prerna Mahajan ${ }^{1}$, Ram Datt $^{2}$, Wing Chung Tsoi ${ }^{2}$, Vinay Gupta ${ }^{3}$, Amit Tomar $^{4}$, Sandeep Arya $^{1, \#}$
}

\begin{abstract}
Affiliation(s)
${ }^{1}$ Department of Physics, University of Jammu, Jammu and Kashmir-180006, India

${ }^{2}$ SPECIFIC, Department of Engineering, Swansea University, United Kingdom- SA1 8EN

${ }^{3}$ Department of Mechanical Engineering, Khalifa University of Science and Technology, Masdar campus, Abu Dhabi 54224, UAE

${ }^{4}$ Department of Physics, Central University of Jammu, Rahya Suchani, Samba District, Bagla, Jammu and Kashmir 181143, India
\end{abstract}

\#Email corresponding author: snp09arya@gmail.com 


\begin{abstract}
Lead-halide perovskite materials have fascinated incredible attention among the research communities due to their favorable electrical and optical properties for optoelectronics and photovoltaic application such as significant light absorption coefficient, higher values of diffusion length, carrier mobility, carrier lifetime, etc. However, lead toxicity as well as its low material stability makes it still far from commercialization. Finding of lead ion replacement is therefore needed to form environmental friendly perovskite materials that are called lead-free perovskites. Among different substitutions, tin is the most potential candidate that is also non-toxic. In this review, the recent development of tin-based lead-free perovskite thin films in photovoltaics research area during the period 2014 till now is summarized. Moreover, the technical challenges and the stability issues faced by them are also discussed. Further, it is suggested that more efforts are needed for the advancement of tin-based lead-free perovskite thin films based solar cells to bring up this field as a cost competent technology for long term sustainability.
\end{abstract}

Keywords: Perovskites, tin-based perovskites, lead-free perovskites, photovoltaics, solar cells. 


\section{Introduction}

In 1839, a Russian scientist Gustav Rose reported the mineral $\mathrm{CaTiO}_{3}$ for the first time and named it as perovskite, after the name of a Russian mineralogist, Count Lev Aleksvich Von Perovski. Now, perovskite be defined as a material having chemical formula $\mathrm{ABX}_{3}$ and crystal structure similar to the mineral $\mathrm{CaTiO}_{3}$. The crystal phase however depends upon ionic or elemental radius of the comprised elements i.e. A, B, and X. The perovskites with the formula $\mathrm{APbX}_{3}$ are lead-based perovskite materials having $\mathrm{A}=$ Inorganic cation (Cs), Organic cation (MAmethylammonium, FA- formamidinium), and $\mathrm{X}=\mathrm{Cl}, \mathrm{Br}$, I [1-3]. Organic cation and inorganic cation can form perovskite materials, which are known as organic-inorganic hybrid perovskites. Here, organic cation's size defines the crystal structure being either 2D or 3D [4,5]. Owing to tunable chemical composition and crystal structure, perovskite materials offer versatile properties, such as optical, electrical, ferroelectricity, high conductivity and magnetism, etc. As a result, perovskites are widely applied for the fabrication of light emitting diodes (LEDs), solar cells, memory devices, solid oxide fuel cells, and photodetectors, etc [6-8].

Lead halide perovskites possess indispensable optoelectronic characteristics like direct bandgap, strong optical absorption coefficient, long charge carrier lifetime, high charge carrier mobility and long diffusion length. Further, they do possess high open-circuit voltages caused by photon recycling and as a consequence, they have long charge extraction lengths through multiple absorption-emission events within the perovskite active layer. Due to these features, the lead halide perovskites have been observed to demonstrate an increase in power conversion efficiency (PCE) from 17\% [9] in 2014 to $25.2 \%$ [10] in the last seven years. The metal lead has invaluable intrinsic properties like high density, high melting point, corrosion resistance, ductility, malleability, etc. Till date, a record PCE of $25.2 \%$ was attained based on lead-halide perovskite solar cells [10]. Despite these advantages of lead-based perovskites, there are serious concerns regarding the toxic nature and the instability problems in humid conditions that need to be addressed. It is noticeably mentioned in the stringent directives of European Union that the harmful chemicals should not be employed in electrical and electronic equipments so as to avoid their exposure to people as well as environment. Lead has been recognized as one of the ten harmful substances listed by ROHS. Further, lead halide perovskite solar cells do contain a considerable portion of lead, that is, $33 \%$ by weight [11]. These issues give birth to the development of a different category of perovskites called Lead-Free perovskites which show similar semiconducting characteristics like those of lead-based perovskites. These lead-free perovskites have emerged to be a feasible candidate for their impending utilization as light harvesters to ensure clean and green photovoltaic technology which is extensively crucial for their market approval for future commercialization. In the perovskite formula of $\mathrm{APbX}_{3}$, the $\mathrm{Pb}$ is well replaced by Tin ( $\mathrm{Sn}$ ), Bismuth (Bi), Antimony ( $\mathrm{Sb}$ ), Copper ( $\left.\mathrm{Cu}\right)$, Germanium (Ge), etc. for photovoltaic application as well as crystal formation. All these lead-free perovskites have reported good efficiencies, but there is still an ominous call for the enhancement of their efficiencies and stability within the air [12-15].

Bismuth which is a non-hazardous and non-radioactive element is among one of the most important substitutions in place of lead. In the progress of lead-free perovskite solar cells, bismuth-based lead-free perovskite light absorbers could be the competent light harvester due to its interesting properties and excellent stability towards moisture. But, 
a poor performance and efficiency were achieved with bismuth that may be attributable to the wide bandgap of perovskite light absorber [16]. Therefore, bandgap tuning is essential for the enhancement in the efficiency of bismuth-based lead-free perovskite solar cells. Further, germanium-based lead-free perovskites have also shown some prospectives for being the absorber layer for perovskite solar cells. Ge-based perovskites that were prepared and studied for the evaluation of their potential as a perovskite absorber layer include cations Cs, MA, FA, acetamidinium, guanidinium, trimethylammonium, and isopropylammonium. These materials were observed to possess slightly higher bandgaps that the lead counterparts, but, the problem of material stability is however also present. From the reported results of the Ge-based lead-free perovskite solar cells, it can be clearly seen that such devices exhibited poor $\mathrm{V}_{\mathrm{oc}}$ and the recorded PCE was also very less [17]. Moreover, the other major drawbacks of Ge-based lead-free perovskite materials are the rapid oxidation of $\mathrm{Ge}^{2+}$ in air. Copper-based lead-free perovskites are also a good contender and have received interest among the researchers due to its stability in air [18, 19]. In comparison to the 3D Cu-based perovskites, the 2D perovskites with multi quantum-well electronic structure, presented good electronic, magnetic and dielectric properties [18]. According to a study where Cu-based lead-free perovskite solar cells were fabricated using perovskites $\left(\mathrm{CH}_{3} \mathrm{CH}_{2} \mathrm{CH}_{2} \mathrm{CH}_{2} \mathrm{NH}_{3}\right)_{2} \mathrm{CuBr}_{4}$ and $\left(\mathrm{F}_{-} \mathrm{C}_{8} \mathrm{H}_{8} \mathrm{NH}_{3}\right)_{2} \mathrm{CuBr}_{4}$, the resulting solar cells demonstrated very less PCEs of $0.63 \%$ and $0.51 \%$, respectively [18]. Further, in another study, $\mathrm{Br} / \mathrm{Cl}$ ratio was altered to tune the light adsorption properties of $\mathrm{Cu}$-based lead-free perovskite [19]. But, due to low absorption coefficient and heavy mass for the holes, the PCE obtained was still very low. The other divalent cations like $\mathrm{Sr}^{2+}$ and $\mathrm{Ca}^{2+}$ in the IIA group can also form perovskites [20, 21], which should be much more chemically stable than those of $\mathrm{Sn}^{2+}$ and $\mathrm{Ge}^{2+}$. However, both $\mathrm{MASrI}_{3}$ and $\mathrm{MACaI}_{3}$ have a large bandgap and the lack of lone pair electrons in the outer $\mathrm{s}$ orbital of $\mathrm{Sr}^{2+}$ and $\mathrm{Ca}^{2+}$ makes their electronic structure and bandgap be dramatically different from $\mathrm{MAPbI}_{3}$. Antimony-based lead-free perovskites was also investigated but it possesses deep trap states, thus rendering a bad performance of its devices.

The study on the advancement of lead-free perovskite solar cells has been improved in the last few years. A lot of researchers around the world developed the lead-free perovskite solar cells using different non-hazardous or less venomous metals. Earlier, bismuth- and antimony-based lead-free perovskites have been employed for solar cell applications but attributing to wide band gap or poor morphological features, they showed poor performance. Some researchers also prepared germanium-based lead-free perovskites which showed suitable band gap and good performance, but the rapid oxidation in air destroyed their practical applications. Copper-based lead-free perovskites have also been utilized which also showed lower band gap, but their performance was found to be poor. Consequently, several effectual and competent organic or inorganic electron transport/charge extraction layers are required to enhance the performance of lead-free perovskite solar cells. The design of novel device architecture and use of proficient lead-free new light absorbers are also important for the development of efficient lead-free perovskite solar cells. The introduction of new additives, antisolvents, etc. would also be of great significance toward the development of efficient lead-free perovskite solar cells [22].

Among all the potential replacement candidates, tin has been considered as a suitable substitution for lead in perovskite solar cells due to their similarity in chemical properties. Tin-based lead-free perovskite solar cells have 
shown the highest PCE, and have therefore fascinated the most awareness in the photovoltaic field. Partial or complete replacement of lead with tin is gaining increasing research interest, due to the promise of further narrowing the bandgaps. This enables ideal solar utilization for single-junction solar cells as well as the construction of

all-perovskite tandem solar cells. For all perovskite $\mathrm{Sn}^{2+}$ based tandom solar cells, the researchers have studied mix tin-lead perovskite. Till date, there is no research work related to $\mathrm{Sn}^{2+}$ based tandom solar cell which is lead-free. Tin is less toxic and have potential to replace lead from the $\mathrm{APbX}_{3}$ perovskite structure. Further, the low band gap of this lead-free perovskite makes it a suitable light absorber toward the development of less toxic or lead-free perovskite solar cells. In order to meet the world's ever-increasing power demand, solar photovoltaics are being regarded as one of the most successful approaches. Even though the crystalline silicon primarily leads the worldwide photovoltaic market, however, because of low production expenditure and less material utilization, the market allocate of thin film photovoltaics has also developed enormously during the last decade. Perovskite based solar cells have revealed immense prospective for being a realistic substitute to various solar technologies. Further, the sturdy advancement in exploration and development of perovskites has fortified its scenario for the replacement of present solar cell technologies. To date, various tin-based lead-free perovskites have been synthesized and applied mainly in photovoltaic applications. These perovskites get the attention of the research community which shows the increasing of research articles published in the last two years. In this review, the recent synthesized tin-based leadfree perovskites with their promising photovoltaic applications along with the challenges and stability issues faced by them are highlighted.

\section{Tin (Sn)-based lead-free perovskites}

Among the alternative ion replacements in place of lead, tin ( $\mathrm{Sn})$ is a potential candidate. Tin-based lead-free perovskites exhibit the potency to bring the torch through and turn out to be a leader in an alternative-lacking energy market. For this reason, tin is being believed to be a feasible candidate for bestowing a great deal of desirable impulsion to solar cell physicists beyond just substituting lead in the perovskite lattice. Such growth has however been an outcome of persistent research in the direction of uncovering superior materials and utilizing them in accessible agenda to capitulate solar cells that would resolve the world's energy crisis and give comfort. To facilitate this, the main factor that is to be improved and needs primary focus is efficiency. A maximum PCE of $\sim 35 \%$ is being assumed as per Shockley Queisser Limit [23] in case of single p-n junction exhibiting energy gap $1.34 \mathrm{eV}$. In the world photovoltaic market, one more factor that needs consideration for an enduring subsistence of perovskite in addition to efficiency is stability that is other field for its progress [24]. This is a persuading stage of research as there are sufficient indications that the research scientists have not been competent so far to knock the proper prospective of tin-based lead-free perovskites. As a result, it leaves abundant scope in emergent tin-based lead-free perovskites so as to succumb its maximum efficiency. Several modern research studies have sturdily implied that $\mathrm{Sn}$ could bear out to be a proficient, inexpensive, nontoxic and outstanding alternative for lead in perovskite photovoltaics.

The Sn-based lead-free perovskites exhibit superior light absorption properties [25] and narrowed optical energy bandgap [26], resembling Pb-based perovskites. For conventional organic-inorganic hybrid $\mathrm{Pb}$-based perovskites, the lead $6 \mathrm{p}$ orbital plays an essential function in the band structure arrangement. The $5 \mathrm{p}$ orbital of tin is however not 
as much of dispersive and shallower, resulting in narrow optical energy band gap. The methylammonium, formamidinium and cesium based tin iodides i.e. $\mathrm{MASnI}_{3}, \mathrm{FASnI}_{3}$ and $\mathrm{CsSnI}_{3}$ respectively exhibit direct bandgap with values of approximately $1.20 \mathrm{eV}, 1.41 \mathrm{eV}$, and $1.3 \mathrm{eV}$, those are still narrow and further impressive in comparison to their lead analogs. Tin-based lead-free perovskites experience higher charge carrier mobility than that of lead-based perovskites [27]. Further, in the exposure of ambient air atmosphere, they degrade to $\mathrm{Sn}^{4+}$ and turn out to be an environment friendly $\mathrm{SnO}_{2}$ [28]. As per the experimental reports published for tin-based lead-free perovskites, their efficiency can reach up to $12.96 \%$ [29]. The photovoltaic parameters of various tin-based lead-free perovskites as absorbers in solar cells with different device architectures are summarized in Table 1.

\section{a. MASnX $_{3}$}

Noel et al. [30] described absolutely lead-free solar cell for the first time that was based on methyl ammonium tin iodide perovskite. When equimolar proportion of $\mathrm{CH}_{3} \mathrm{NH}_{3} \mathrm{I}$ and $\mathrm{SnI}_{2}$ were dissolved in DMF (Ndimethylformamide) solution (concentration- $40 \mathrm{wt} \%$ ), $\mathrm{CH}_{3} \mathrm{NH}_{3} \mathrm{SnI}_{3}$ perovskite was formed exhibiting tetragonal crystal structure which is demonstrated in Fig. 1(a). Further from Fig. 1(b), the energy gap was observed to be 1.23 $\mathrm{eV}$ in the absorption spectra. Fig. 1(c) demonstrates the cross-sectional view while Fig. 1(d) demonstrates J-V graph of prepared solar cell devices. The fabricated device resulted in an efficiency reaching over $6 \%$ under 1 sun illumination.

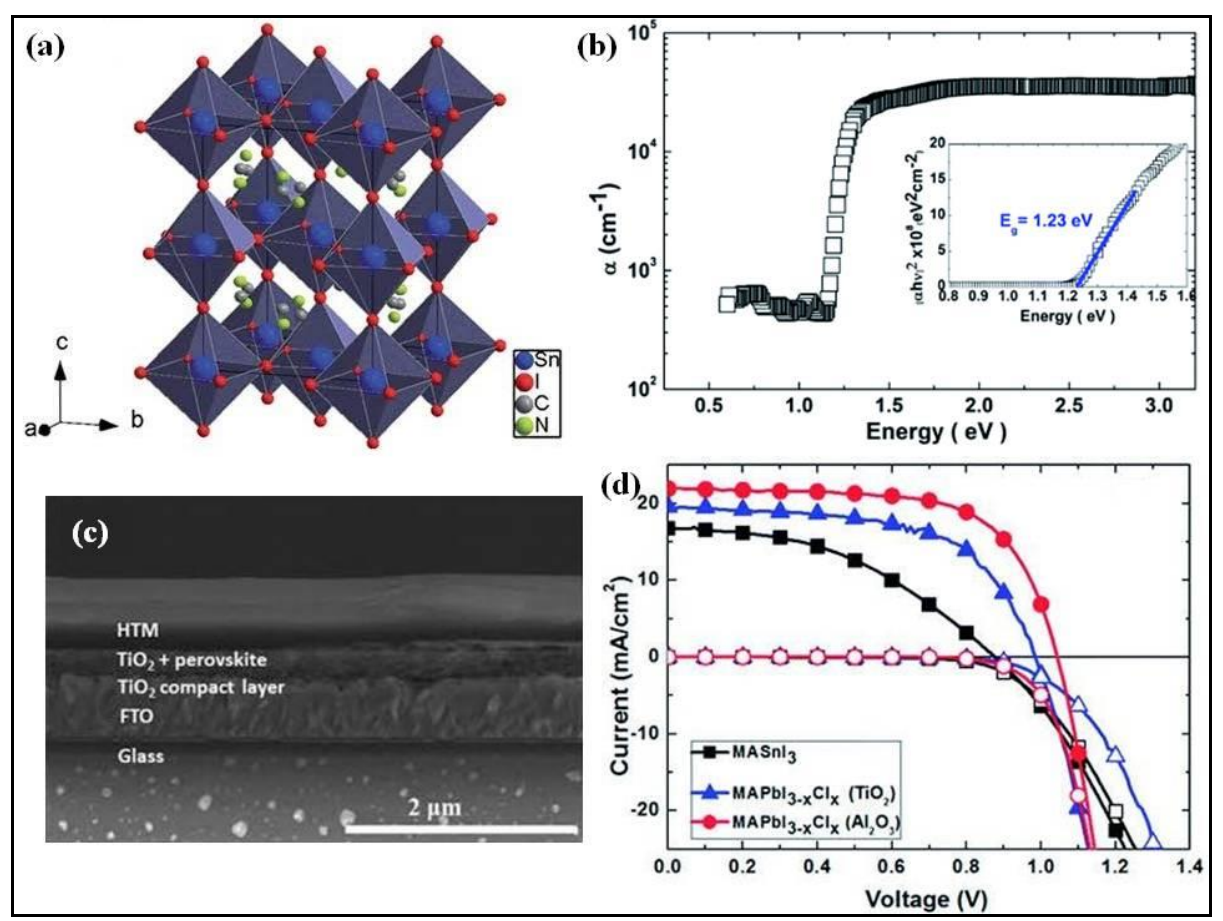

Fig. 1 (a) Simulated crystal structure, (b) absorption profile and the band gap (inset) of $\mathrm{CH}_{3} \mathrm{NH}_{3} \mathrm{SnI}_{3}$, (c) Crosssectional view of prepared solar cell, (d) Current-voltage curves of best fabricated devices. Reproduced from [30] with permission. Copyright 2014, The Royal Society of Chemistry.

$\mathrm{Yu}$ et al. [31] synthesized $\mathrm{MASnI}_{3}$ thin films by hybrid thermal evaporation method. The deposited films were compact, smooth and exhibited homogeneous coverage over the intact substrate that resulted in $\mathrm{V}_{\text {oc }}$ of $494 \mathrm{mV}$ in the 
fabricated solar cell yielding PCE 1.7\%. Hsu et al. [32] prepared $\mathrm{MASnI}_{3-\mathrm{x}} \mathrm{Br}_{\mathrm{x}}$ perovskites and found that in liquidjunction PEC (photoelectrochemical) solar cells, the optimized MASnI ${ }_{0.5} \mathrm{Br}_{2.5}$ demonstrated improved performance and stability exhibiting PCE of $1.51 \%$ which correspond to an increase of $20.8 \%$ in comparison to $\mathrm{MASnI}_{3}$. Song et al. [33] established a successful technique for fabricating $\mathrm{MASnI}_{3}$ based photovoltaic device where the precursor solution was formed when $\mathrm{SnI}_{2}$ and MAI were dissolved in DMSO solution. To this solution, $\mathrm{SnF}_{2}(20 \mathrm{~mol} \%)$ was poured followed by heating of the final solution at $150{ }^{\circ} \mathrm{C}$. A reducing vapor atmosphere was incorporated due to which there was a reduction (>20\%) in the ratio of $\mathrm{Sn}^{4+}$ and $\mathrm{Sn}^{2+}$. This lead to highly censored charge carrier recombination which finally resulted in PCEs of 3.89\% for $\mathrm{MASnI}_{3}$ based solar cell.

Handa et al. [34] reported the formation of encapsulated $\mathrm{MASnI}_{3}$ thin films that displayed long-term stability. The films were prepared by including and excluding $\mathrm{SnF}_{2}$ additive $(20 \mathrm{~mol} \%)$. The film that included $\mathrm{SnF}_{2}$ demonstrated energy gap of $1.25 \mathrm{eV}$. However, in case of the film that excluded $\mathrm{SnF}_{2}$, optical absorption peak undergone blue shift due to Burstein-Moss effect and is because of the formation of various number of unintentionally doped holes. It was also verified by the time-resolved PL results that the luminescence lifetime of $\mathrm{MASnI}_{3}$ is enhanced by the addition of $\mathrm{SnF}_{2}$. Further, the solar cells were fabricated with the films and optical properties were studied to elucidate the photocarrier dynamics. Since the film with $\mathrm{SnF}_{2}$ exhibited longer lifetime, the solar cell incorporating $\mathrm{SnF}_{2}$ additive demonstrated improved performance. Xiao et al. [35] fabricated $\mathrm{MASnIBr}_{2}$ mixed halide perovskite solar cell through $\mathrm{SnF}_{2}$ assisted heterogeneous nucleation resulting in stable and high PCE of 3.70\%. Nguyen et al. [36] fabricated various Sn-based mixed halide $\operatorname{MASn}\left(\mathrm{I}_{1-\mathrm{x}} \mathrm{Br}_{\mathrm{x}}\right)_{3}(0 \leq \mathrm{x} \leq 1)$ based photovoltaic devices. It was confirmed that the rapid nucleation and retarding growth of the crystals of $\mathrm{MASnI}_{3}$ could be managed by variation in the amount of DMSO in DMF solution. When DMF: DMSO ratio was optimized to 4:1, a surface with superior quality and similar grain sizes as well as coverage was obtained in the entire series. Maximum PCE of $3.20 \%$ is attained by the device for $\mathrm{x}=0.67$ by the enhancement of energy bands alignment. A unique two-step chemical method was demonstrated for the first time by Li et al. [37] for fabricating highly crystalline, dense and uniform $\mathrm{MASnI}_{3}$ films with good reproducibility. In the first step, $\mathrm{SnI}_{2}$ and hydrazinium iodide (HAI) were used to deposit $\mathrm{HASnI}_{3}$ (hydrazinium tin iodide) perovskite film. In the second step, a cation displacement approach is used for the transformation of $\mathrm{HASnI}_{3}$ into $\mathrm{MASnI}_{3}$. Fig. 2(a,b) demonstrates the UV-Vis spectra and XRD of the films of $\mathrm{HASnI}_{3}$ as well as $\mathrm{MASnI}_{3}$. SEM images of both films are demonstrated in Fig. 2(c,d). Thus, the two step process involving a cation displacement approach resulted in the formation of high quality $\mathrm{MASnI}_{3}$ film which when used as absorber in solar cell, accomplished a maximum PCE of 7.13\%. Device structure and current-voltage characteristics of fabricated devices are demonstrated in Fig. 2(e,f). 


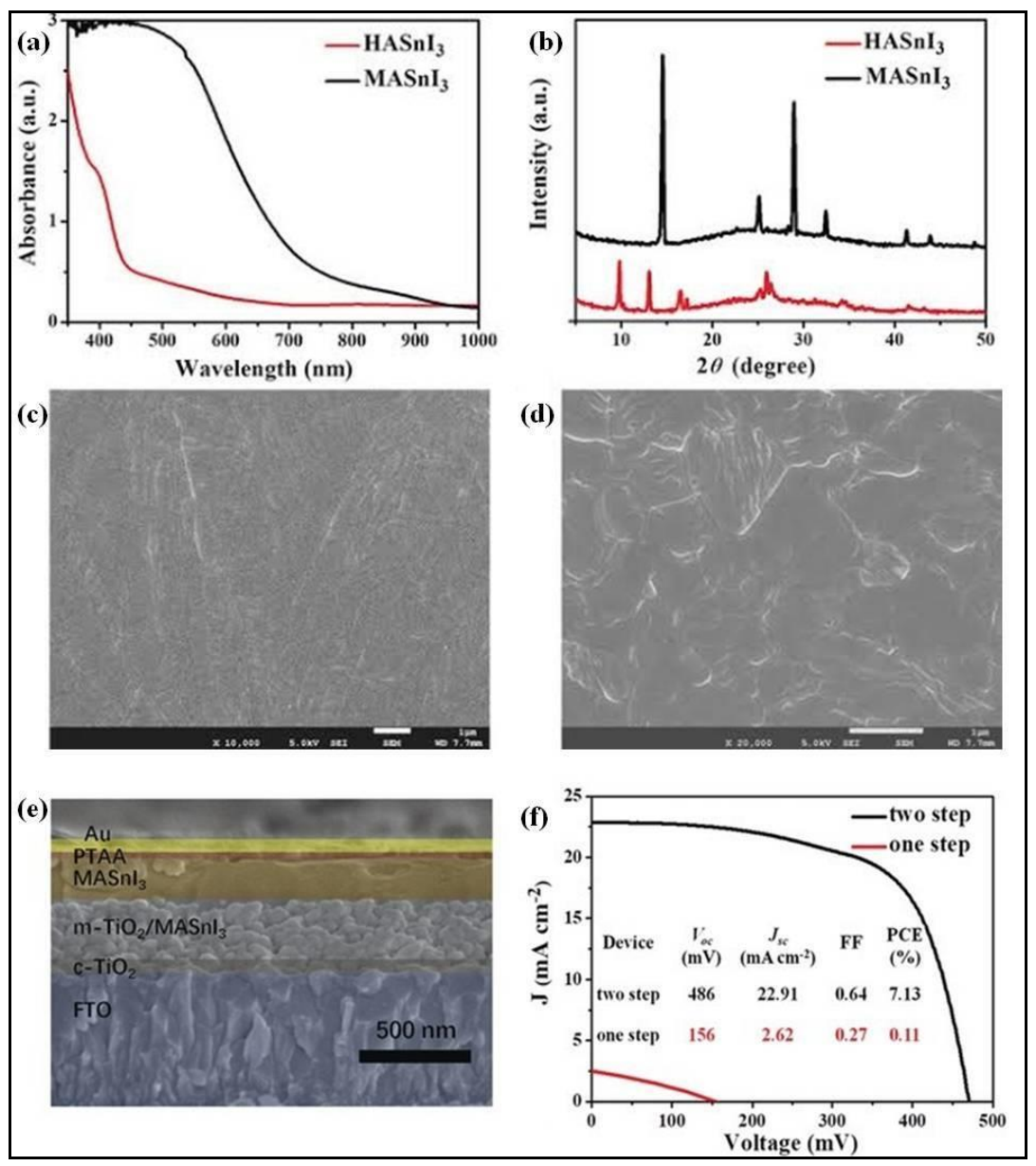

Fig. 2 (a) Optical absorption (UV-Vis) spectra, (b) XRD of $\mathrm{HASnI}_{3}$ and resultant $\mathrm{MASnI}_{3}$ films, (c) SEM image of $\mathrm{HASnI}_{3}$ film, (d) SEM image of resultant $\mathrm{MASnI}_{3}$ film, (e) Device architecture of fabricated device, (f) Currentvoltage graph of studied devices based on one-step or the two-step $\mathrm{MASnI}_{3}$ layer. Reproduced from [37] with permission. Copyright 2019, WILEY-VCH.

To realize highly efficient solar cell devices, it is essential that the perovskite film nucleation as well as crystallization should be controlled well. For this reason, a synthetic strategy has been developed recently by Wang et al. [38] for the fabrication of $\mathrm{MASnI}_{3}$ thin film that involves ion exchange/insertion reactions. The strategy as shown in Fig. 3(a) resulted in highly consistent pinhole-free $\mathrm{MASnI}_{3}$ films by a reaction between $\mathrm{SnF}_{2}$ and MAI. Because of the presence of hefty amount of left $\mathrm{SnF}_{2}$, the unfavourable oxidation was successfully suppressed in the obtained film. The absorption spectra and XRD pattern of $\mathrm{SnF}_{2} /$ PEDOT:PSS films in the reaction at the different time intervals are shown in Fig. 3(b,c). Further, Fig. 3(d,e) demonstrates the SEM of pristine SnF 2 PEDOT:PSS film as well as the one treated by the ion exchange/insertion reaction for $60 \mathrm{~min}$. The resulting solar cell exhibited PCE of $7.78 \%$ (Fig. 3(f,g)) with high reproducibility and excellent stability. This strategy presents an innovative approach for fabricating inexpensive as well as stable tin-based lead-free perovskite solar cells. Fig. 4 demonstrates the performance progress of $\mathrm{MASnX}_{3}$ based photovoltaic cells until now. 

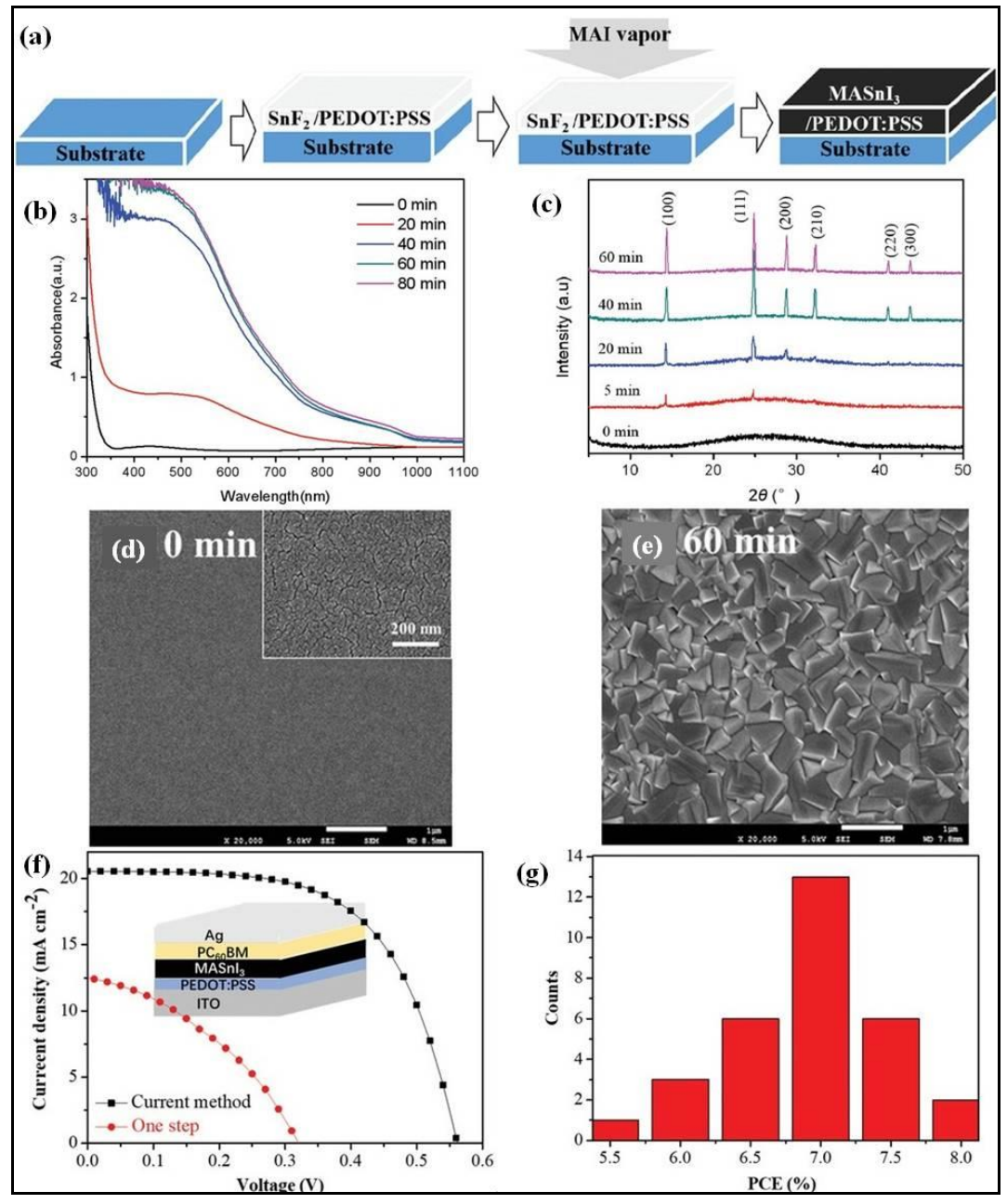

Fig. 3 (a) Schematic diagram of $\mathrm{MASnI}_{3}$ perovskite film via ion exchange/insertion reaction process, (b) UV-vis spectra and (c) XRD of the conversion in the reaction at the different time intervals, (d) Surface SEM images of the pristine $\mathrm{SnF}_{2} / \mathrm{PEDOT}$ :PSS film and (e) treated by the ion exchange/insertion reaction for $60 \mathrm{~min}$, (f) $\mathrm{J}-\mathrm{V}$ characteristics of best solar cells incorporating $\mathrm{MASnI}_{3}$ films prepared by current ion exchange/insertion method and the one-step solution method, (g) Histograms of PCEs for 30 devices via ion exchange/insertion method. Reproduced from [38] with permission. Copyright 2020, WILEY-VCH. 


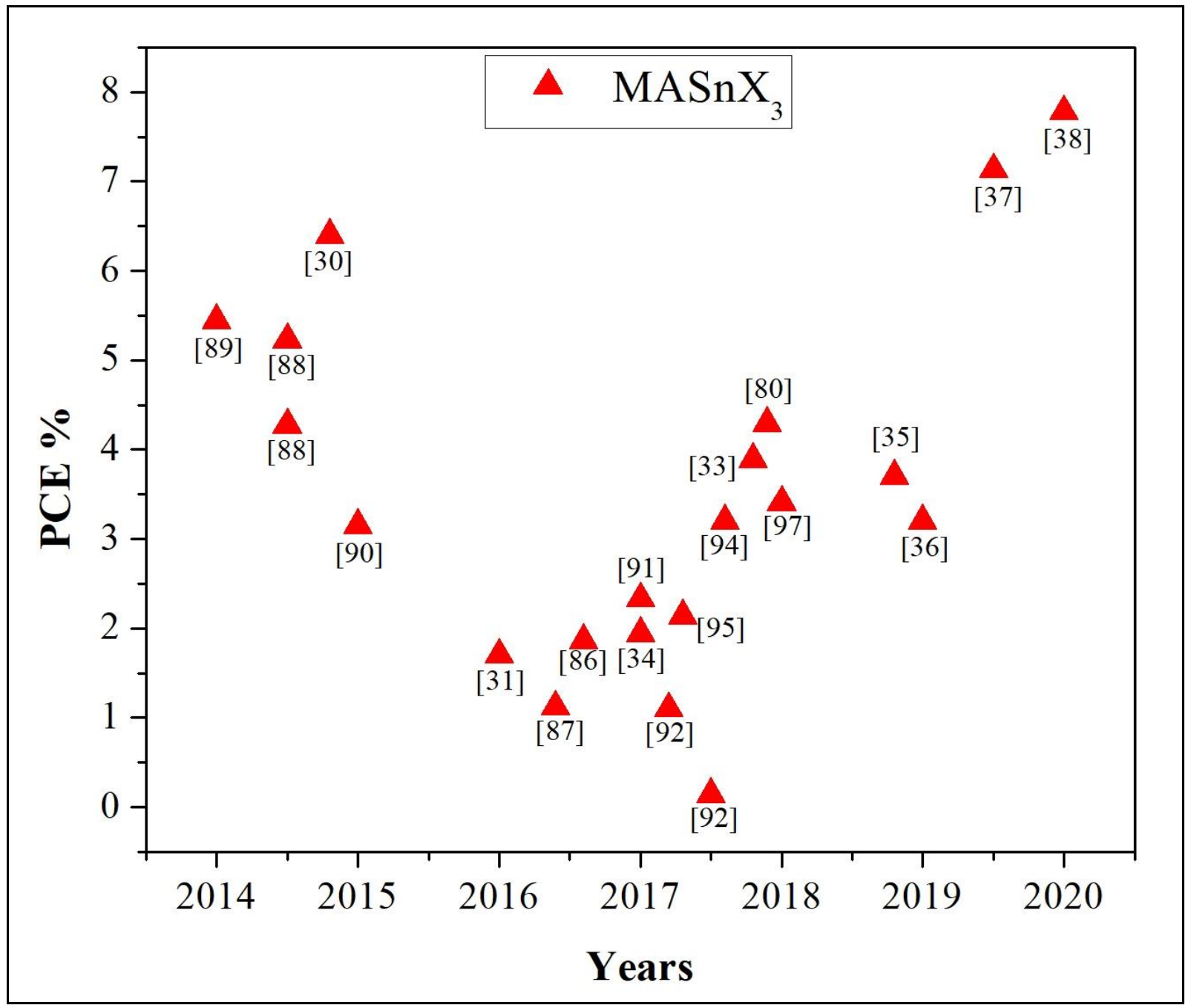

Fig. 4 Efficiency of $\mathrm{MASnX}_{3}$ based solar cells during different years.

\section{b. $\mathrm{FASnX}_{3}$}

Koh [39] et al. utilized $\mathrm{FASnI}_{3}$ as an active layer in solar cell that resulted in PCE of 2.10\%. By mixing stoichiometric amounts of FAI and $\mathrm{SnI}_{2}, \mathrm{FASnI}_{3}$ was prepared which showed energy gap of $1.41 \mathrm{eV}$ allowing the harvesting of light from NIR region that attained higher photocurrents. Liao et al. [40] fabricated stable and environmental friendly $\mathrm{FASnI}_{3}$ based efficient inverted solar cell device incorporating PEDOT: PSS as HSL (hole selective layer) and $\mathrm{C}_{60}$ as ESL (electron selective layer). The addition of $10 \mathrm{~mol} \% \mathrm{SnF}_{2}$ resulted in average PCE of $5.41 \% \pm 0.46 \%$ and maximum PCE of $6.22 \%$. Moreover, steady-state efficiency of $6 \%$ (approx.) was exhibited by the device for over 100 seconds. Zhang et al. [41] reported the preparation of formamidinium based mixed halide perovskite. The FASnI ${ }_{2} \mathrm{Br}$ precursor solution was formed when $\mathrm{SnI}_{2}(373 \mathrm{mg})$ and $\mathrm{FABr}(125 \mathrm{mg})$ were mixed together with $1 \mathrm{ml}$ DMF solution. The resulting perovskite showed energy gap of $1.68 \mathrm{eV}$ and was examined as an absorbing layer for $\mathrm{p}-\mathrm{i}-\mathrm{n}$ heterojunction based photovoltaic cells which were processed at a low temperature. Ke et al. [42] described $\mathrm{FASnI}_{3}$ based photovoltaic device that showed an enhancement in PCE using cascaded $\mathrm{TiO}_{2}-\mathrm{ZnS}$ ETL (electron transport layer). Maximum PCE of 5.27\% was obtained and is attributed to the reduced interfacial 
charge recombination as well as facilitated transfer of electrons reflected by a cascade conduction band structure of $\mathrm{TiO}_{2}$-ZnS ETL.

Zhu et al. [43] demonstrated a two step $\mathrm{SnI}_{2}$ deposition method to adjust the volume expansion as well as for a fast reaction with MAI and FAI. In the first step deposition, a Lewis base was employed as an additive into the solution of $\mathrm{SnI}_{2}$ to convert into $\mathrm{SnY}_{2}$-TMA complexes where $\mathrm{Y}=\mathrm{I}^{-}, \mathrm{F}^{-}$and $\mathrm{TMA}=$ trimethylamine. During second step, the formed complexes were intercalated with FAI to form FASnI. The results show that by successfully forming $\operatorname{SnY}_{2-}$ TMA complexes as an intermediate product, TMA facilitated uniform film formation of $\mathrm{SnY}_{2}$. Consequently dense $\mathrm{FASnI}_{3}$ films were formed having large crystalline domain resulting in PCE of $4.34 \%$ in conventional and $7.09 \%$ in inverted perovskite solar cells. In addition to homogeneous deposition and formation of dense perovskite layers, it is necessary to reduce the $\mathrm{Sn}^{4+}$ content for fabricating proficient $\mathrm{Sn}$-based lead-free perovskite solar cells. For this, Lee et al. [44] employed non-solvent dripping along with solvent-engineering technique. Utilizing $\mathrm{SnF}_{2}$ additive, when $\mathrm{SnF}_{2}$-pyrazine complex was formed, $\mathrm{SnF}_{2}$ was homogeneously dispersed and hence, highly reproducible $\mathrm{FASnI}_{3}$ perovskite solar cell was fabricated resulting in PCE of $4.8 \%$ and $98 \%$ of this efficiency was retained over 100 days with encapsulation. Liao et al. [45] reported low dimensional $\mathrm{FASnI}_{3}$ perovskite films exhibiting remarkably improved air stability as compared to their three dimensional $\mathrm{FASnI}_{3}$ counterparts, that showed PCE of $5.94 \%$ in solar cells. Further, no noticeable decay in the efficiency of the device was found when its performance was tracked for 100 hours.

Shao et al. [46] reported a planar p-i-n device involving FASnI $_{3}$ films which exhibited PCE as high as $9.0 \%$ for the first time. Highly crystalline $\mathrm{FASnI}_{3}$ films were obtained by mixing two dimensional Sn perovskite $(0.08 \mathrm{M})$ with three dimensional $\mathrm{FASnI}_{3}(0.92 \mathrm{M})$. These devices displayed low shunt losses, extremely low trap-aided recombination, and much proficient charge collection that resulted in negligible hysteresis. Moreover, background carrier density was also successfully reduced. Therefore, a 50\% enhancement in PCE was indicated by the experiment in comparison to the most excellent reference cell of $\mathrm{FASnI}_{3}$ film with reducing agent $\mathrm{SnF}_{2}$. Chen et al. [47] introduced a phenylethylammonium bromide (PEABr) layer on PEDOT: PSS film prior to the deposition of $\mathrm{FASnI}_{3}$ in an inverted solar cell. The purpose of PEABr was to partly/fully separate three dimensional perovskites into two dimensional nanolayers because of a steric effect that would form a low-dimensional perovskite (LDP) interlayer at the interface. The formation of LDP could favorably fascinate the growth of bulk perovskites in the vicinity of the interface, which in turn resulted in enhanced film morphology and even lowered the trap states. It was confirmed that passivation of traps successfully censored accumulation and recombination of carriers in the device. Consequently, the resulting solar cell device showed a PCE as high as $7.05 \%$.

To fabricate solar cell devices with PCE beyond the Shockley-Queisser limit, it's crucial to have an unpredictably long lifetime. In view of this, Fang et al. [48] described photoluminescence from hot-carriers that exhibited unexpectedly extended lifetime (of the order of few ns) in $\mathrm{FASnI}_{3}$. Since relaxation process of the hot-carriers was slow and moreover due to subsequent band filling, a remarkably large blue shift was demonstrated in the timeintegrated photoluminescence along with increased excitation power. These annotations play a vital role for the perceptive of perovskites and for an ultimate potential advancement of competent photovoltaics. According to Gu et al. [49], a PCE of $6.75 \%$ was accomplished when Sn powder was added into the precursor solution of $\mathrm{FASnI}_{3}$ that 
was prepared from $\mathrm{SnI}_{2}$ with $99 \%$. This was the first ever reported purification technique of $\mathrm{SnI}_{2}$ by Sn powder. Various parameters like reaction time, annealing temperature and the composition of $\mathrm{FASnI}_{3}$ film, were optimized in an inverted device resulting in improved efficiency. For enhancement of crystallinity in inverted devices based on planar FASnI $_{3}$ films, Jokar et al. [50] examined the outcome of doping bulky organic cation where butylammonium iodide (BAI) and ethylenediammonium diiodide $\left(\mathrm{EDAI}_{2}\right)$ were added for the passivation of surface defects. Fig. 5(a) demonstrates the current-voltage graphs for the prepared solar cells that were based on pristine $\mathrm{FASnI}_{3}$ film, $\mathrm{FASnI}_{3}-\mathrm{BAI} 15 \%$ and $\mathrm{FASnI}_{3}-\mathrm{EDAI}_{2} 1 \%$. The stabilized PCEs and photocurrent densities of the fabricated devices for $240 \mathrm{~s}$ are demonstrated in Fig. 5(b) while Fig. 5(c) demonstrates the efficiencies of solar cells during different storage period. On $\mathrm{FASnI}_{3}$ film surface, the existence of pinholes was unavoidable and the device incorporating pristine $\mathrm{FASnI}_{3}$ film demonstrated PCE of 4.0\%. However, the crystal growth orientation was drastically changed by using BAI as additive and the connectivity of the crystal grains was also found to get better, thus, resulting in superior device performance with PCE 5.5\%. On the other hand, with $\mathrm{EDAI}_{2}$ additive (1\%), $\mathrm{FASnI}_{3}$ based solar cell device achieved initial efficiency of 7.4\%. As demonstrated in Fig. 5(d), the devices during storage were however found to improve continuously reaching maximum PCE of $8.9 \%$ for the device where storage was done for over 1400 hours in glove box and there was merely minor deterioration when stored further than $2000 \mathrm{~h}$. Thus, EDAI addition solved various issues like this additive cured the pinhole problem, passivated the surface defect states, prevented $\mathrm{Sn}^{2+} / \mathrm{Sn}^{4+}$ oxidation and induced slow relaxation of the crystal structure. 

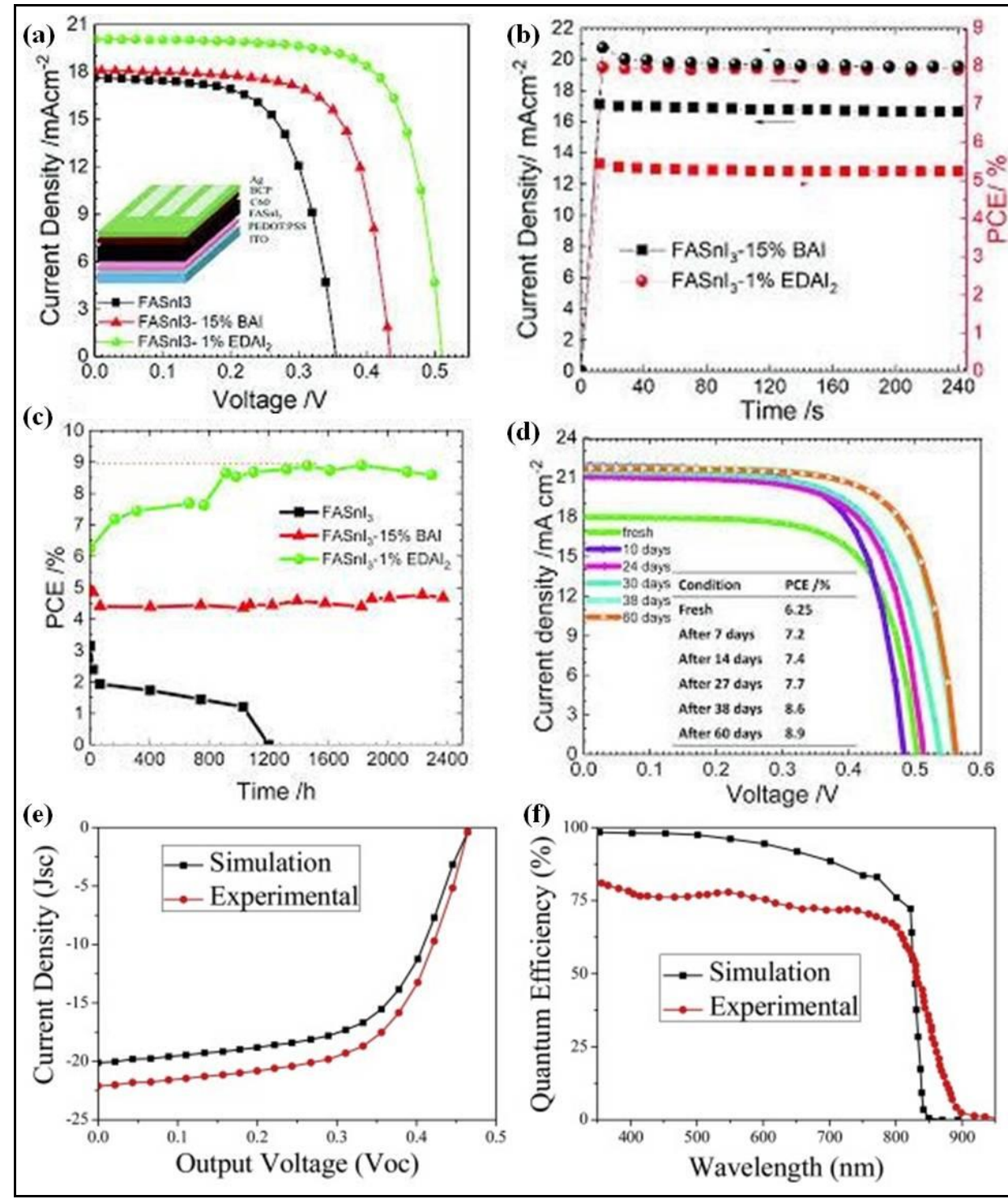

Fig. 5 (a) Current-voltage curves, (b) stabilized PCEs and photocurrent densities measured for 240 s, (c) Enduring stability of the fabricated devices, (d) J-V graph of a typical FASnI $3-\mathrm{EDAI}_{2} 1 \%$ device. Reproduced from [50] with permission. Copyright 2018, The Royal Society of Chemistry. (e) Current-voltage curves and (f) Quantum efficiency as a function of wavelength resulted from simulation as well as experimental data. Reproduced from [55] with permission. Copyright 2019, Urban and Fischer.

For the extensive implementation of Sn-based lead-free perovskite thin films in high-performance photovoltaics, their deprived oxidative stability is still a hindrance. To cope up this obstacle, Kim et al. [51] for the first time, demonstrated that thiocyanate-based compound is a promising additive to be incorporated in Sn-based lead-free perovskites, thereby exerting an incredible impact on the device performance and stability. They synthesized efficient quasi-2D Sn-based lead-free perovskite using FASCN (formamidinium thiocyanate) additive. The inclusion of the FASCN additive considerably barred quasi-2D perovskite from oxidation throughout the formation of film, by 
interacting strongly with $\mathrm{Sn}^{2+}$. Furthermore, a higher degree of crystallinity was observed because of the formation of coarse grains of the perovskite. These effects as a consequence led to remarkable enhancements in both optoelectronic performance as well as stability of devices and reached a maximum PCE of $8.17 \%$ and over $90 \%$ of this PCE was retained even after 1000 hours. This work demonstrated a flexible and effortless method that can also be useful for other lead-free perovskites enduring from deprived oxidative stability. An air stable $\mathrm{FASnI}_{3}$ based photovoltaic cell was described by Tai et al. [52] where hydroxybenzene sulfonic acid was utilized as an antioxidant that was introduced into precursor solution in addition to $\mathrm{SnCl}_{2}$. As a consequence of interaction of $\mathrm{Sn}^{2+}$ ion with sulfonate group, the oxidation stability of $\mathrm{FASnI}_{3}$ film improved significantly.

Based on multichannel interdiffusion two-step film fabrication procedure, Ran et al. [53] improved the PCE of $\mathrm{FASnI}_{3}$ solar cell by a bilateral interfacial engineering strategy. In this strategy, large cation PEAI and bifunctional $\mathrm{LiF}$ were evaporated at the bilateral interfaces of $\mathrm{FASnI}_{3}$ film, forming a 2D-3D bulk heterojunction arrangement. Thus, film coverage was improved, the work function of PEDOT:PSS lowered and the hole extraction at the ITO/PEDOT:PSS interface facilitated, resulting in an enhanced $\mathrm{V}_{\text {oc }}$. Hence, the fabricated devices using bilateral interfacial engineering strategy achieved PCE of 6.98\%. One of the successful ways to tackle the open issues related with Sn-based lead-free perovskites is to achieve a better crystallinity. Shao et al. [54] succeeded in doing this by enhancing the crystallinity of 3D grains with the incorporation of EAI (ethylammonium iodide) into a 2D/3D film, where 3D is $\mathrm{FASnI}_{3}$ and $2 \mathrm{D}$ is $\mathrm{PEA}_{2} \mathrm{FASn}_{2} \mathrm{I}_{7}$, (PEA= phenylethylammonium). The resulting $\mathrm{EA}_{\mathbf{x}} 2 \mathrm{D} / 3 \mathrm{D}$ samples showed uniform film morphology, higher crystallinity and stronger orientation leading to reduced background carrier density and traps in comparison to the 2D/3D films without EA cation. This induced a reduction in charge recombination losses. Maximum PCE of $8.4 \%$ was attained with $\mathrm{EA}_{0.08} 2 \mathrm{D} / 3 \mathrm{D}$ in comparison to the other devices with PCE of 7.7\% for mixed 2D/3D perovskites and 4.7\% for 3D perovskite. Dixit et al. [55] reported $\mathrm{FASnI}_{3}$ based inverted solar cell with ETL NiO and HTL (hole transport layer) $\mathrm{C}_{60}$ by means of device simulation tool. The J-V and Quantum efficiency-wavelength graphs were plotted for both simulation and experimental work as shown in Fig. 5(e,f) and were found to be nearly identical. Simulation results showed that champion PCE of 9.99\% was accomplished with fabricated solar cell.

For attaining better performance in photovoltaics, perovskite films with superior electronic quality and balanced charge transportation is another important criteria. But, the tin-based perovskite films with poorer band alignment and adjacent HTL results in poor hole transportation and collection. For enhancing the hole transportation and collection, Liu et al. [56] introduced poly[tetraphenylethene3,3'-(((2,2-diphenylethene-1,1-diyl)bis(4,1phenylene))bis(oxy) $)$ bis( $N, N$ dimethylpropan-1-amine)tetraphenylethene] i.e. PTN-Br that exhibits HOMO energy of $-5.41 \mathrm{eV}$, into the $\mathrm{FASnI}_{3}$ precursor solution. The complete mechanism of charge transportation in perovskites including and excluding PTN-Br is shown in Fig. 6(a). PTN-Br molecule can fill up into $\mathrm{FASnI}_{3}$ film grain boundaries and thus serves as hole-transport medium consequently forming a bulk heterojunction film. As a result, the uncoordinated tin atoms and dimethylamino of PTN-Br formed Lewis adducts between them. Thus, the passivation of trap states by $\pi$-conjugated polymer PTN-Br resulted in a champion efficiency of $7.94 \%$. J-V characteristic graphs of each fabricated device are demonstrated in Fig. 6(b) while the stabilized PCE as well as photocurrent density of champion solar cell is demonstrated in Fig. 6(c). Further, Fig. 6(d,e) reveals the J-V 
characteristic graphs for reference as well as PTN-Br integrated device under constant UV irradiation for 5 hours. It was observed that the solar cell with PTN-Br exhibited good UV stability. Xu et al. [57] reported a novel approach to form highly vertically oriented quasi-2D perovskites $\left.\mathrm{AVA}_{2} \mathrm{FA}_{n-1} \mathrm{Sn}_{n} \mathrm{I}_{3 \mathrm{n}+1}(<\mathrm{n}\rangle=5\right)$ where 5-ammoniumvaleric acid i.e. 5- $\mathrm{AVA}^{+}$was used as an organic spacer along with suitable amount of $\mathrm{NH}_{4} \mathrm{Cl}$ as additive. This approach sufficiently enhanced the charge collection efficiency between two electrodes. The resulting solar cell device with prepared quasi-2D perovskite as absorber delivered a maximum PCE of $8.71 \%$. Fig. 6(f) displays J-V characteristic graphs of the unencapsulated devices incorporating $\mathrm{AVA}_{2} \mathrm{FA}_{n-1} \mathrm{Sn}_{n} \mathrm{I}_{3 n+1}(\langle\mathrm{n}\rangle=5)$ perovskite film with $10 \% \mathrm{NH}_{4} \mathrm{Cl}$ and excluding $\mathrm{NH}_{4} \mathrm{Cl}$. Normalized PCE of the two devices stored in nitrogen-filled glove box for over $400 \mathrm{~h}$ is depicted in Fig. 6(g). This study provides a future opportunity to utilize highly vertically oriented quasi-2D tin-based lead-free perovskites for well proficient and stable photovoltaics.

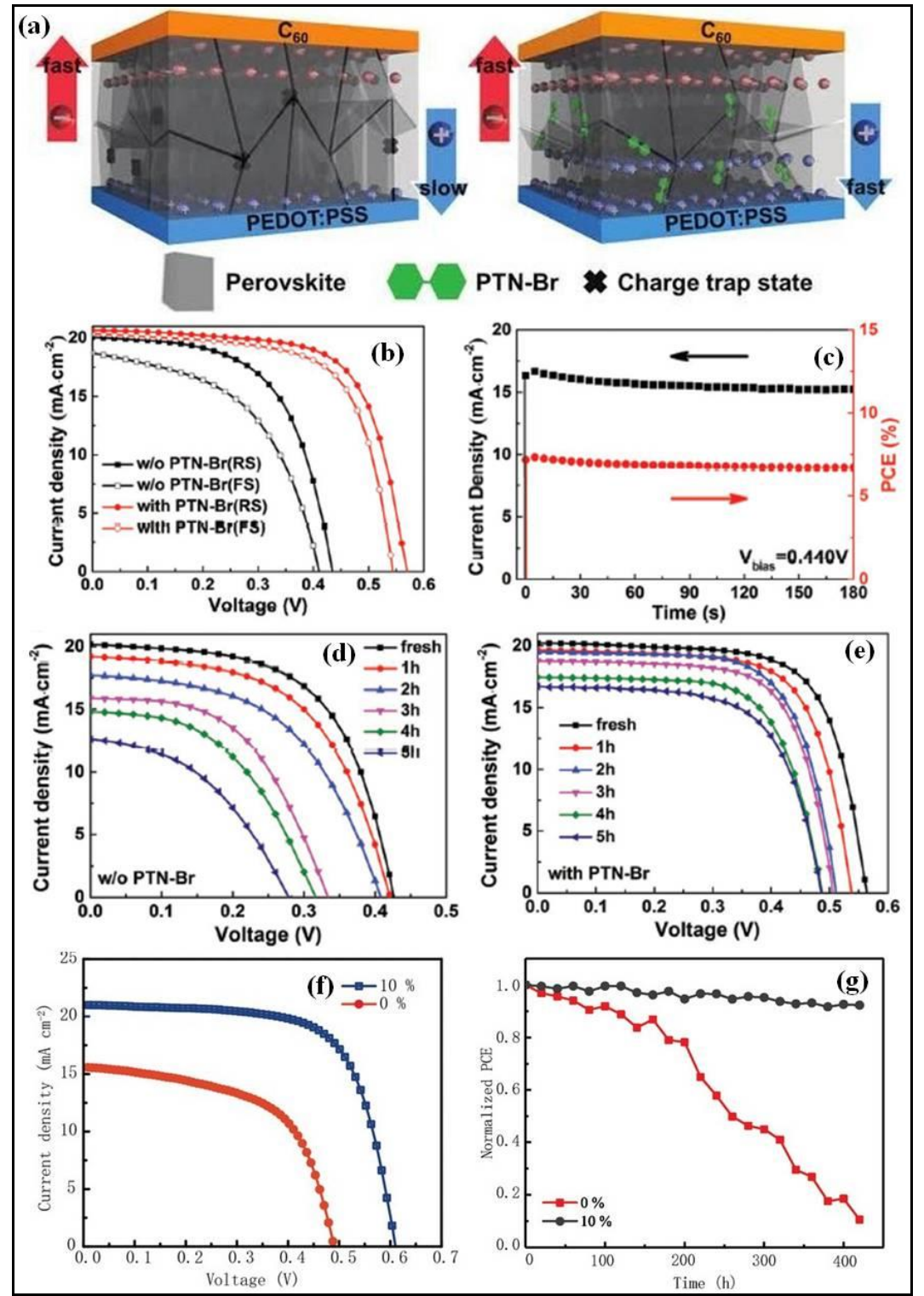


Fig. 6 (a) The mechanism of charge-transportation without and with PTN-Br in the perovskite layer, (b) J-V characteristic graphs of reference and PTN-Br integrated device, (c) Stabilized PCE and photocurrent density of champion PTN-Br integrated device, (d) J-V graphs of reference and (e) PTN-Br integrated device under constant UV irradiation for 5 hours. Reproduced from [56] with permission. Copyright 2019, WILEY-VCH. (f) J-V characteristic graphs of the unencapsulated devices incorporating $\left.\mathrm{AVA}_{2} \mathrm{FA}_{n-1} \mathrm{Sn}_{n} \mathrm{I}_{3 \mathrm{n}+1}(<\mathrm{n}\rangle=5\right)$ perovskite film with $10 \% \mathrm{NH}_{4} \mathrm{Cl}$ and excluding $\mathrm{NH}_{4} \mathrm{Cl}$, (g) Normalized PCE of the two devices stored in nitrogen-filled glove box for over 400 h. Reproduced from [57] with permission. Copyright 2019, WILEY-VCH.

Because of less redox potential of $\mathrm{Sn}^{2+}$ absorption layer, oxidation occurs while preparing precursor solution and fabricating perovskite film. Therefore, to reduce the oxidation process and to achieve excellent air stability, two approaches were demonstrated by $\mathrm{He}$ et al. [58] i.e. crystal-resolving and recrystallization technology. This new economical process enhanced the crystal growth of $\mathrm{FASnI}_{3}$ resulting in ultrapure crystals with reduced deep-level defects. By employing these strategies, PCEs of $8.9 \%$ and $5.5 \%$ respectively were obtained in spin-coated solar cells and large-scale printed solar cells. Abdelaziz et al. [59] utilized a device simulation technique for enhancing the performance of $\mathrm{FASnI}_{3}$ photovoltaic cells. Variation of various parameters of the absorber like thickness, defect density and doping concentration was done for investigating their impact on device performance. Moreover, the impact of variation of conduction band offset (CBO) and valence band offset (VBO), doping concentration and thickness of ETL and HTL was examined as well. Several candidates were employed as ETL and HTL like CuI, $\mathrm{Cu}_{2} \mathrm{O}, \mathrm{NiO}, \mathrm{ZnO}$ and $\mathrm{ZnSe}$. Based on experimental work, the initial PCE was demonstrated to be $1.75 \%$. However, the final device optimization using SCAPS resulted in a champion PCE of 14.03\%. Further, to restrain the oxidation of stannous absorption layer, Lin et al. [60] demonstrated a unique approach where they introduced bidentate ligand 8-hydroxyquinoline (8-HQ) into $\mathrm{FASnI}_{3}$ precursor. The introduction of 8-HQ formed a quite stable complex due to the interaction of the atoms of oxygen and nitrogen in the ligand with $\mathrm{Sn}^{2+}$ that improved the perovskite film quality. The non-radiative recombination induced by the defect states was also reduced and the resulting solar cell device exhibited an improved PCE of $7.15 \%$. Moreover, the device stability in nitrogen and air atmosphere was also significantly improved.

While spin coating $\mathrm{FASnI}_{3}$ precursor solution, Liu et al. [61] introduced poly(ethylene-co-vinyl acetate) i.e. EVA polymer into the anti-solvent. This strategy as described schematically in Fig. 7(a), effectively reduced the surface defects, optimized the orientation and improved the size of grains. The efficient control of the grain growth process decreases the likelihood of astonishing perovskite film defects and morphology that results in a remarkable efficiency of 7.72\%. Fig. 7(b) demonstrates the J-V plot of fabricated solar cells under both forward and reverse scans. Further the solar cell device based on $\mathrm{FASnI}_{3}$-EVA absorber showed good reproducibility and even eminent moisture and oxygen barrier property due to self-encapsulation effect. The device retained $62.4 \%$ of initial efficiency value even after 48 hours of ageing in air atmosphere having humidity of $60 \%$ (Fig. 7(c)). In place of traditionally used PCBM ETL, Jiang et al. [62] utilized indene- $\mathrm{C}_{60}$ bisadduct (ICBA) as ETL in formamidinium based lead-free perovskite. The perovskite film was prepared by a usual anti-solvent method using a one-step process. The concentration of PEA (PEA $=\mathrm{C}_{6} \mathrm{H}_{5} \mathrm{CH}_{2} \mathrm{CH}_{2} \mathrm{NH}_{3}{ }^{+}$) was tuned in the precursor solution yielding 
$\mathrm{PEA}_{\mathrm{x}} \mathrm{FA}_{1-\mathrm{x}} \mathrm{SnI}_{3}(\mathrm{x}=0,15)$. Further $\mathrm{NH}_{4} \mathrm{SCN}$ was used as additive to mutate the growth of perovskite film. ICBA exhibits a shallower energy level due to which it represses iodide remote doping. As a result, interface carriers recombination is also reduced and maximum attainable voltage is increased to $0.94 \mathrm{~V}$, in comparison to the voltage of 0.6 V for the device in which ETL was PCBM. J-V characteristic graphs of PEA15-SCN based solar cell devices incorporating ICBA and PCBM as ETL is demonstrated in Fig. 7(d) while Fig. 7(e) shows stability of encapsulated PEA15-SCN solar cell during storage in $\mathrm{N}_{2}$ atmosphere. ICBA incorporated solar cell exhibited a significantly soaring PCE of $12.4 \%$, and maintained $90 \%$ of original efficiency for about 3800 hours. This study paves the way to modify the efficiency of tin-based photovoltaic devices. Fig. 8 demonstrates the performance progress of FASnX 3 based photovoltaic cells until now.

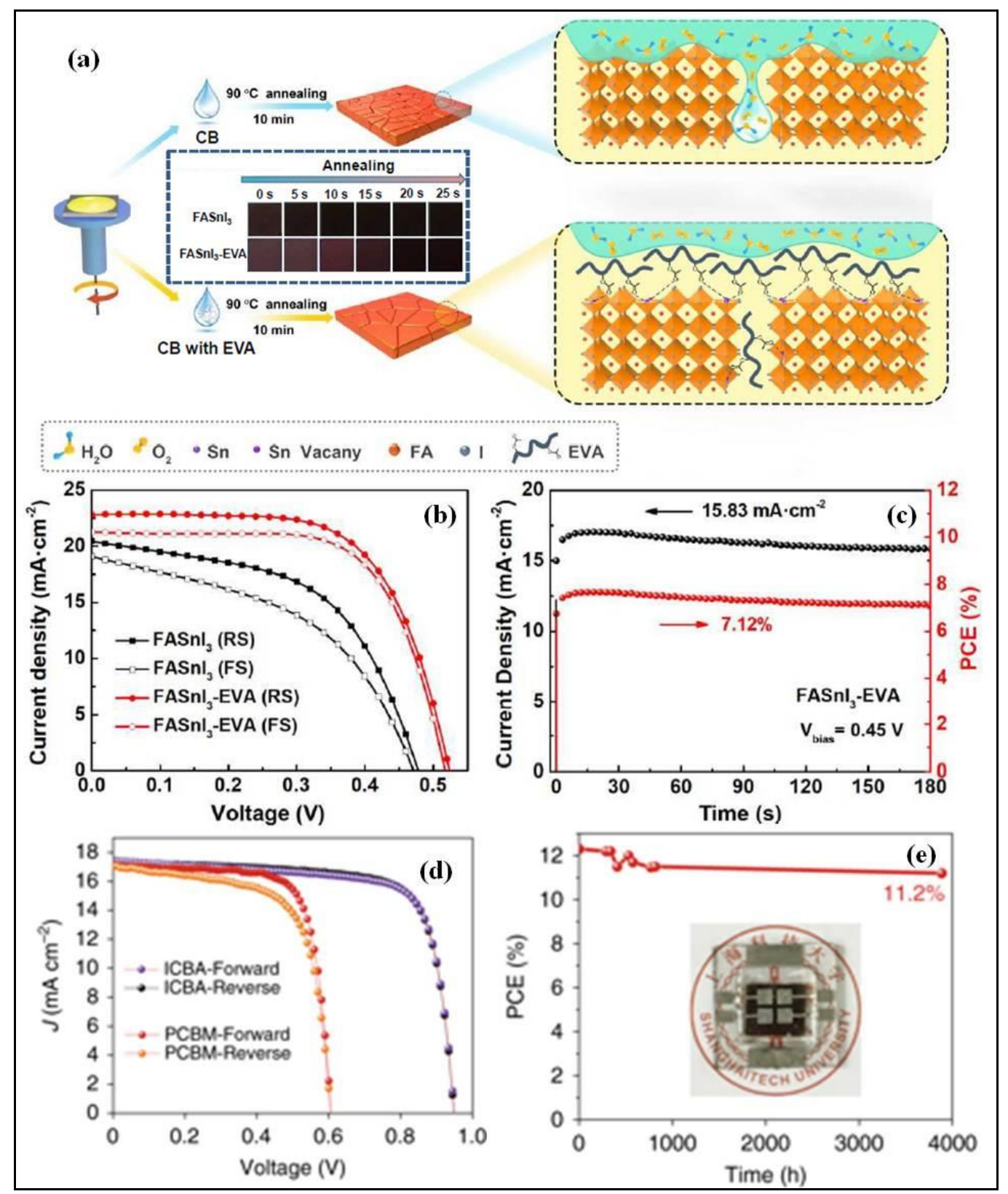


Fig. 7 (a) Schematic depiction of preparation processes, (b) J-V characteristics, (c) Steady-state efficiencies of champion device incorporating EVA treatment. Reproduced from [61] with permission. Copyright 2020, American Chemical Society. (d) Current density-voltage characteristic graphs of PEA15-SCN based devices incorporating ICBA and PCBM as ETL (e) stability of encapsulated PEA15-SCN solar cell during storage in $\mathrm{N}_{2}$ atmosphere. Reproduced from [62] with permission. Copyright 2020, Nature. 


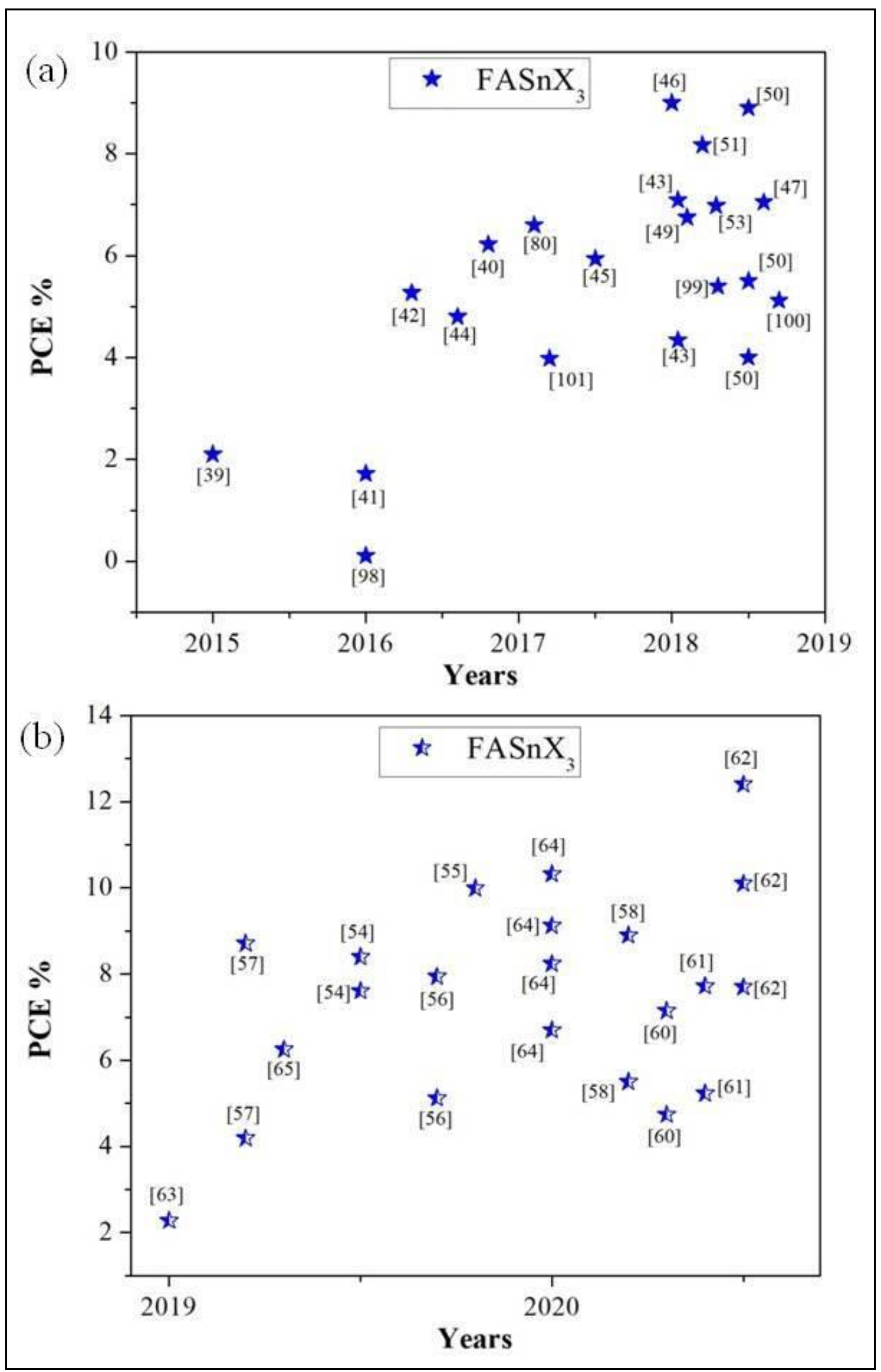

Fig. 8 Efficiency of FASnX 3 based solar cells during different years. 


\section{c. $\mathrm{CsSnX}_{3}$}

Kumar et al. [66] reported a low temperature solution process for preparing $\mathrm{CsSnI}_{3}$ precursor where $\mathrm{CsI}, \mathrm{SnI}_{2}$ and $\mathrm{SnF}_{2}$ were mixed in a stoichiometric ratio in appropriate solvents. By utilizing $\mathrm{CsSnI}_{3}$ as an absorber in solar cell, they opened up the potential of exploiting solution processed lead-free perovskites for highly efficient photovoltaics where high photocurrent densities $\left(>22 \mathrm{mAcm}^{-2}\right.$ ) were attained. However, the PCEs were bottlenecked due to low $\mathrm{V}_{\text {oc }}$. Therefore, to enhance $\mathrm{V}_{\text {oc }}$, Sabba et al. [67] chemically doped $\mathrm{Br}$ in $\mathrm{CsSnI}_{3}$ thus forming $\mathrm{CsSnI}_{3-\mathrm{x}} \mathrm{Br}_{\mathrm{x}}$ mixed halide perovskites where $0 \leq \mathrm{x} \leq 3$. With the increase in $\mathrm{Br}^{-}$doping, the optical properties changed and a blue shift was seen in absorption and IPCE onset. Further, the crystal structure also changed where $\mathrm{CsSnI}_{3}$ crystals had orthorhombic structure whereas $\mathrm{CsSnBr}_{3}$ crystals exhibited cubic structure. A lower charge carrier density and decreased charge recombination was obtained for $\mathrm{Br}$ rich $\mathrm{CsSnI}_{3-\mathrm{x}} \mathrm{Br}_{\mathrm{x}}$ perovskite that reflects a decrease in $\mathrm{Sn}$ vacancies consequently leading to improvement in open circuit voltages. Gupta et al. [68] utilized $\mathrm{CsSnBr}_{3}$ as a light harvester in solar cell and a best PCE of $2.1 \%$ in the devices with n-i-p configuration was obtained using spiroMeOTAD as HTL. Wang et al. [69] deposited $\mathrm{B}-\gamma-\mathrm{CsSnI}_{3}$ thin films as absorbing layer using a simple solution method. Instead of utilizing organic $\mathrm{HTL}$, they used $\mathrm{NiO}_{\mathrm{x}}$ with energetically favorable band alignments which resolved the problem of the incompatibility of organic HTL. Thus, the balanced control of the solar cell architecture resulted in PCE of $3.31 \%$.

Marshall et al. [25] demonstrated a PCE of 3.56\% for $\mathrm{CsSnI}_{3}$ based photovoltaic cell with no HSL and the resulting device exhibited better stability than the analogous $\mathrm{MAPbI}_{3}$ perovskite device. Chen et al. [29] demonstrated for the first time the fabrication of $\mathrm{CsSnX}_{3}$ quantum rods by simple solvothermal process. They revealed that it is possible to tune photoluminescence as well as optical characteristics of $\mathrm{CsSnX}_{3}$ by changing the halides. The results indicated a record PCE of $12.96 \%$ for $\mathrm{CsSnI}_{3}$ under AM 1.5 G. Fig. 9(a,b) displays the J-V graph and EQE of $\mathrm{CsSnX}_{3}$ perovskite devices. The champion $\mathrm{CsSnI}_{3}$ solar cell is also compared with the reference $\mathrm{MAPbI}_{3}$ and the graphs are shown in Fig. 9(c,d,e,f). 

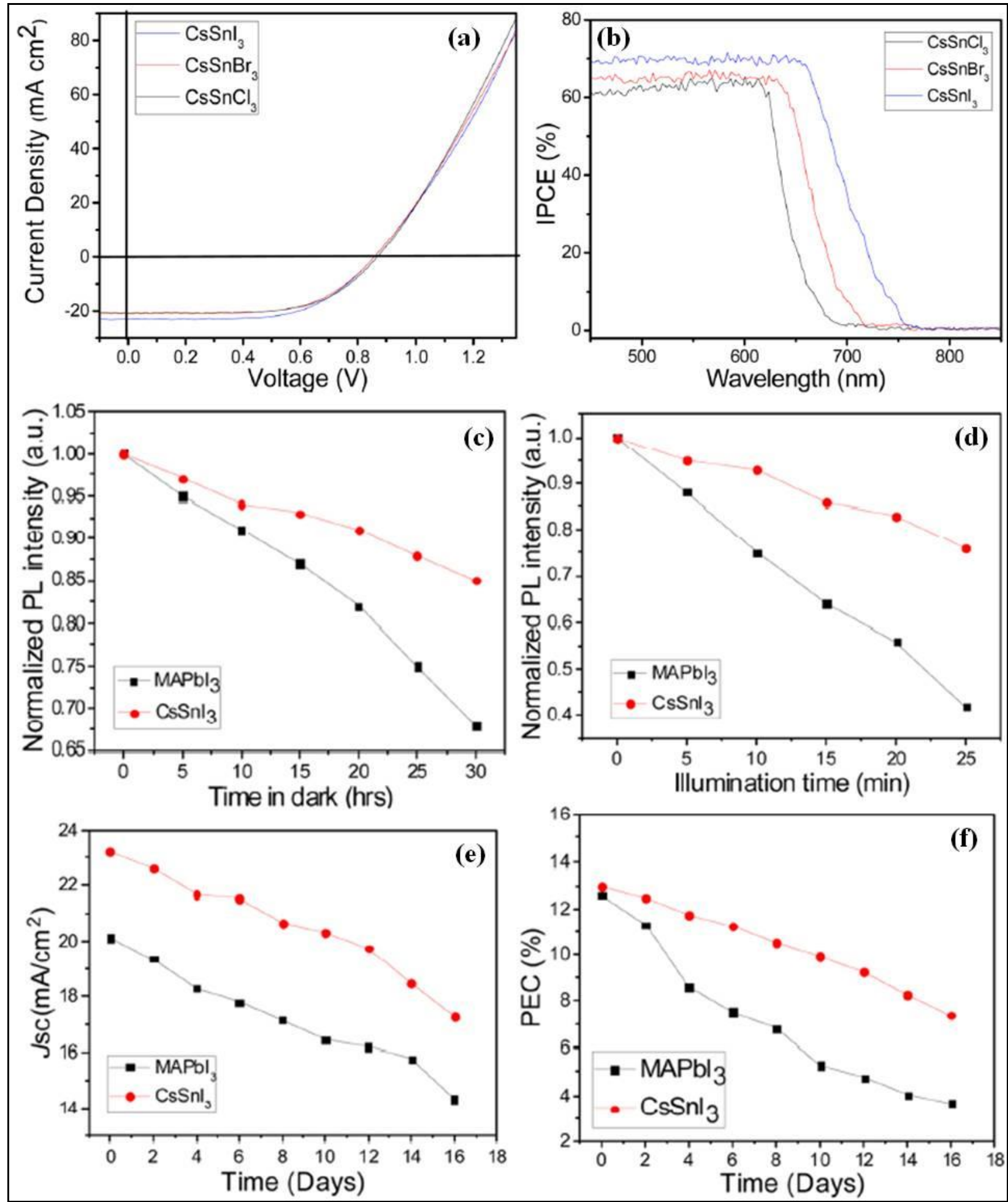

Fig. 9 (a) $\mathrm{J}-\mathrm{V}$ characteristics and (b) $\mathrm{EQE}$ of $\mathrm{CsSnX}_{3}$ perovskite solar cells, (c) Normalized fluorescence decay of reference $\left(\mathrm{MAPbI}_{3}\right)$ and $\mathrm{CsSnI}_{3}$ quantum rod based devices stored in the dark and (d) under illumination at certain time intervals, (e) Temporal evolution of $\mathrm{J}_{\mathrm{SC}}$ and (f) efficiency for both devices. Reproduced from [29] with permission. Copyright 2016, American Chemical Society. 
Qiu et al. [70] synthesized $\mathrm{Cs}_{2} \mathrm{SnI}_{6}$ by a modified solution process. The resulting perovskite exhibited a direct bandgap $(1.48 \mathrm{eV})$. Different nanostructured $\mathrm{ZnO}$ nanorodarrays were used as ETL and HTL that were grown by keeping a control during the seed layer formation. When $\mathrm{Cs}_{2} \mathrm{SnI}_{6}$ absorber was highly loaded, the pore size and length of $\mathrm{ZnO}$ nanorod were cautiously controlled, and the fabricated solar cell device achieved PCE $~ 1 \%$. Qiu et al. [71] for the first time utilized chronological deposition process involving two steps where superior quality films of $\mathrm{B}-\gamma-\mathrm{CsSnI}_{3}$ were grown. Moreover, phase change occurring within the atmosphere was also explored. It was observed that the formed unstable B- $\gamma$ - $\mathrm{CsSnI}_{3}$ thin film undergone spontaneous oxidative conversion in air to form air-stable $\mathrm{Cs}_{2} \mathrm{SnI}_{6}$ perovskite with high absorption coefficient and exhibiting energy gap of $1.48 \mathrm{eV}$. The fabricated device with $\mathrm{Cs}_{2} \mathrm{SnI}_{6}$ thin film as an absorbing layer showed PCE of $0.96 \%$ with $\mathrm{V}_{\mathrm{oc}} 0.51 \mathrm{~V}$ and $\mathrm{J}_{\mathrm{sc}} 5.41 \mathrm{~mA} / \mathrm{cm}^{2}$.

Through ultrafast optical spectroscopies, Wu et al. [72] revealed exceptional photophysical properties of melt synthesized $\mathrm{CsSnI}_{3}$ ingots which exhibited extremely low defect density, high minority charge carriers' diffusion length, and bulk carrier lifetimes in comparison to the polycrystalline counterparts. This was attributed to a reduction in grain boundaries as well as enhanced crystal quality. Further, an extremely low surface recombination velocity was obtained which contributed negligible to the photophysical dynamics. This indicated that for $\mathrm{CsSnI}_{3}$ to achieve most favorable performance, surface passivation is not required. Hence, the study suggested that the polycrystalline thin films can be replaced by melt-synthesized ingots for enhancing the device performance. The effects of $\mathrm{SnX}_{2}$ additive on the stabilization of Sn-based lead-free perovskite was described by Heo et al. [73] through density functional theory (DFT) as well as relative experiments. It was confirmed that the addition of $\mathrm{SnX}_{2}$ can perk up the stability of $\mathrm{CsSnI}_{3}$ photovoltaic devices. It is generally accepted that the additives eradicate defects, however in this study; it was observed that the additives efficiently do the job of surface passivation and perovskite phase stabilization that consequently promotes $\mathrm{CsSnI}_{3}$ stability. The overall results indicated that $\mathrm{SnBr}_{2}$ is the most promising candidate in terms of prolonged stability resulting in a high PCE of 4.3\%. Further to solve the problem of poor reproducibility, Song et al. [74] reported $\mathrm{CsSnI}_{3}$ thin film perovskite where excess of $\mathrm{SnI}_{2}$ was used that dispersed homogeneously inside the perovskite film. So, it worked both like a compensator and suppressor of $\mathrm{Sn}^{2+}$ vacancies. This efficiently helped in reducing p-type conductivity and enhanced the device performances of $\mathrm{CsSnI}_{3}$ on mesoporous $\mathrm{TiO}_{2}$. Various devices were fabricated using different molar ratios of $\mathrm{CsI} / \mathrm{SnI}_{2}$ and their $\mathrm{J}-\mathrm{V}$ characteristics are demonstrated in Fig. 10(a). Further the solar cell parameters were plotted against CsI/SnI $\mathrm{I}_{2}$ molar ratio and resulting graphs are shown in Fig. 10(b). The device with the molar ratio of 0.4 showed the best performance that resulted in maximum PCE of $4.81 \%$ (Fig. 10(c)). A representative EQE spectrum and integrated $\mathrm{J}_{\mathrm{SC}}$ of champion solar cell is shown in Fig. 10(d). Fig. 11 demonstrates the performance progress of $\mathrm{CsSnX}_{3}$ based photovoltaic cells until now. 

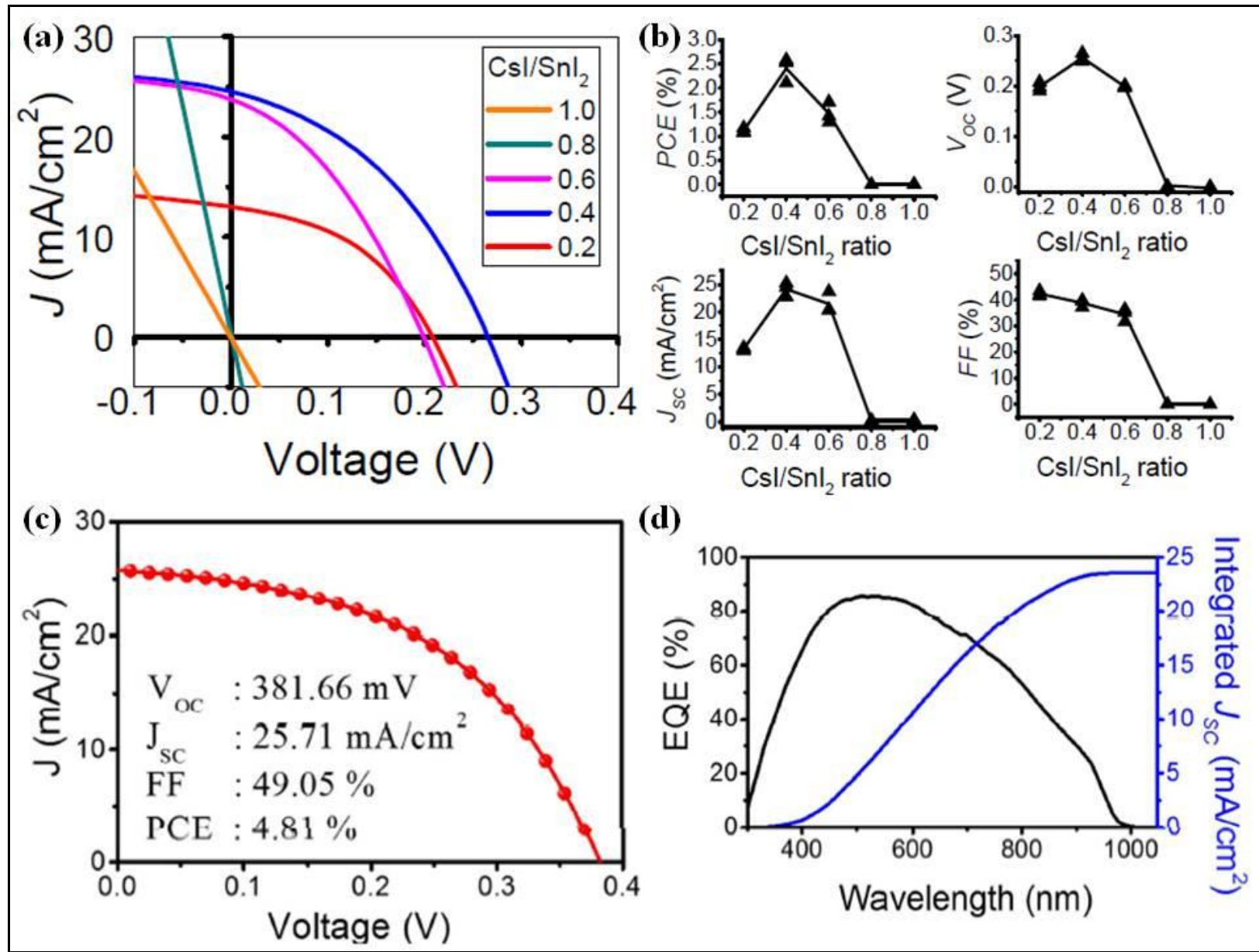

Fig. 10 (a) J-V characteristics of $\mathrm{CsSnI}_{3}$ incorporated devices for different CsI/SnI 2 molar ratio, (b) Plot of solar cell parameters against $\mathrm{CsI} / \mathrm{SnI}_{2}$ molar ratio, (c) Current density-voltage curve of champion device where $\mathrm{CsI} / \mathrm{SnI}_{2}=0.4$, (d) A representative EQE spectrum and integrated $\mathbf{J}_{\mathrm{SC}}$. Reproduced from [74] with permission. Copyright 2017, American Chemical Society. 


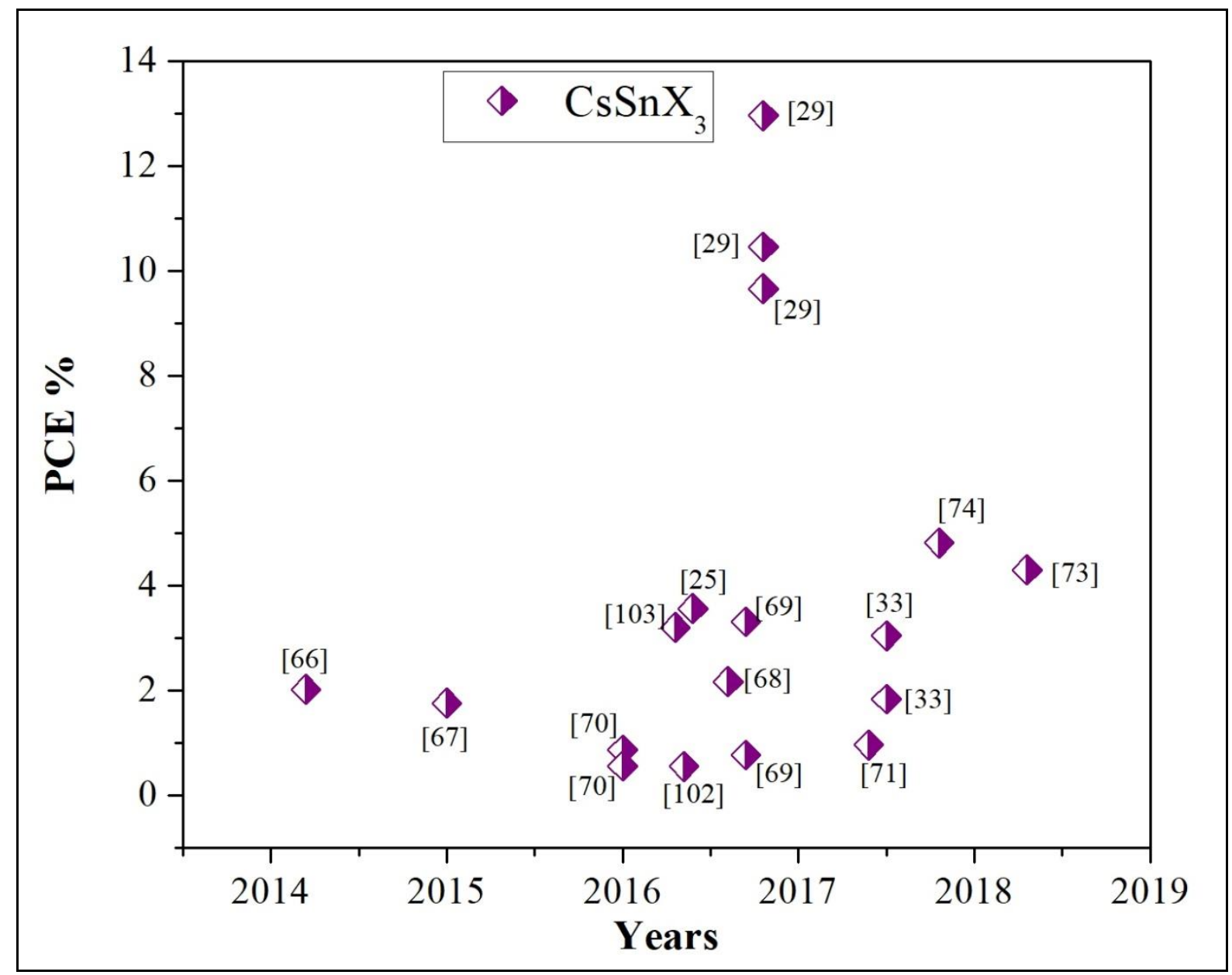

Fig. 11 Efficiency of $\mathrm{CsSnX}_{3}$ based photovoltaic devices during different years.

\section{d. Some mixed cation Sn-based perovskites}

A new tin-based perovskite absorber of the type $\left\{\right.$ en $\mathrm{FASnI}_{3}$ incorporating both ethylenediammonium (en) and formamidinium (FA), was reported by Ke et al. [75]. The incorporation of (en) introduced a new bandgap tuning mechanism caused by considerable Schottky style defects. Thus, introduction of (en) cation improved the photoelectric properties and air stability reaching PCE of $7.14 \%$ for the fabricated \{en\}FASnI 3 solar cell and retained nearly $96 \%$ of this efficiency for more than 1000 hours with encapsulation. Their group [76] further studied (en) based lead-free perovskite but this time instead of using formamidinium (FA), they used methylammonium (MA) to form \{en $\mathrm{MASnI}_{3}$ perovskite as absorbers. The introduction of (en) cation created a lot of $\mathrm{SnI}_{2}$ vacancies which resulted in a considerable increase in band gap, unit cell volume and carrier lifetime in comparison to $\mathrm{MASnI}_{3}$. The air stability was also improved and a maximum PCE of $6.63 \%$ is obtained with \{en\}MASnI ${ }_{3}$ solar cell. To achieve superior-performance photovoltaics, the dopant-free HTL plays a crucial role. Normally, HTLs involve hygroscopic dopants as well as additives for most favorable performance and this adds additional cost to fabrication and further restricts the long-term device stability. To solve this issue, Ke et al. [77] utilized a new superior dopant-free HTL tetrakistriphenylamine (TPE) in \{en\}FASnI 3 hollow perovskite based photovoltaic device 
that showed the maximum PCE of 7.23\%. The device performance was superior in comparison to the devices with doped PTAA and doped Spiro-based HTLs. Their work therefore describes the promising application of TPE as HTL in economical superior-performance Sn-based lead-free perovskite solar cells. Later on, Vegiraju et al. [78] also fabricated $\left\{\right.$ en $\mathrm{FASnI}_{3}$ based solar cells using a series of interfacial benzodithiophene (BDT) as hole transporting materials (HTMs). BDT related small organic molecules having tetra-triphenyl amine donor (BDT-4D) and di-triphenyl amine donor (BDT-2D) synthesized through a simple synthetic route were found to be promising candidate to serve as HTMs than the traditional expensive PTAA or spiro-OMeTAD. The UV-vis spectra, DPV curves and DFT-derived HOMOs and LUMOs of BDT-2D and BDT-4D based devices are demonstrated in Fig. 12(a,b,c). Current density-voltage characteristic graphs of $\{$ en $\} \mathrm{FASnI}_{3}$ solar cells with doped PTAA, BDT-2D, and BDT-4D HTLs are demonstrated in Fig. 12(d) and it was observed that the solar cell delivered a champion PCE of 7.59\% using BDT-4D as HTM. Further, Fig. 12(e) shows the EQE, and integrated $\mathrm{J}_{\mathrm{sc}}$ plots of the devices. This study provides a new opportunity to employ this new class of organic HTMs for increasing the efficiency of tin-based photovoltaic devices. 


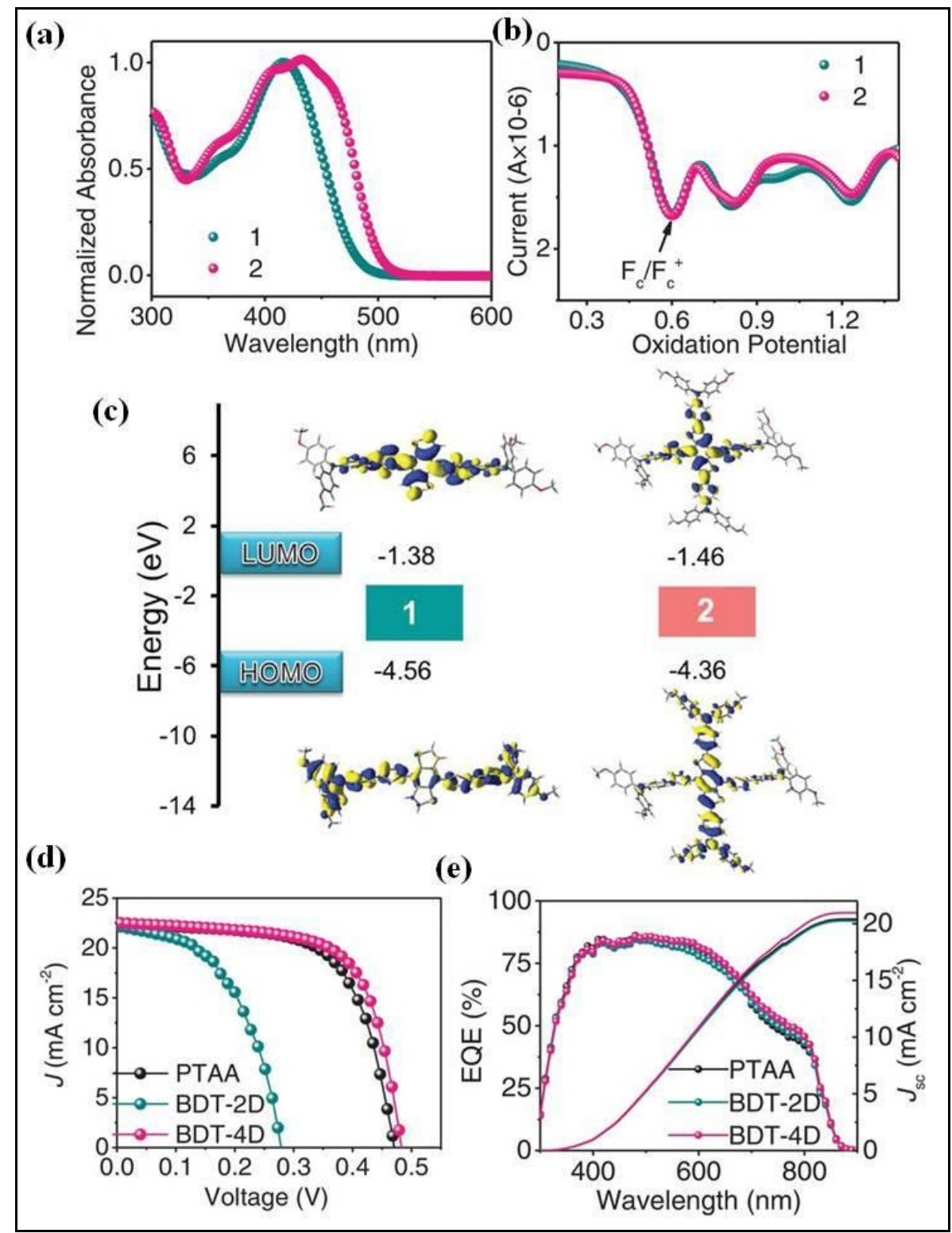

Fig. 12 (a) UV-vis spectra of 1 (BDT-2D) and 2 (BDT-4D) in solution, (b) DPV curves of 1 and

2, (c) DFT-derived HOMOs and LUMOs of BDT 1 and 2 derivatives, (d) Current density-voltage, (e) EQE, and integrated $\mathrm{J}_{\mathrm{sc}}$ plots of $\{$ en $\} \mathrm{FASnI}_{3}$ solar cells with doped PTAA, BDT-2D, and BDT-4D HTLs. Reproduced from [78] with permission. Copyright 2019, WILEY-VCH.

Liu et al. [79] described two feasible methods to enhance the synthesized $\mathrm{FA}_{0.75} \mathrm{MA}_{0.25} \mathrm{SnI}_{3}$ perovskite film structure. To prevent the electrical shunting in the solar cell, firstly, a hot antisolvent treatment (HAT) was introduced that enhanced the film coverage. Moreover, the average crystallite size was also observed to increase by the second method where annealing was done in an environment of DMSO vapor under low partial pressure. Thus, both treatments together led to the substantive improvement of the electrical as well as topographical qualities of the $\mathrm{FA}_{0.75} \mathrm{MA}_{0.25} \mathrm{SnI}_{3}$ films, resulting in PCE over 7\%. Similarly, Zhao et al. [80] reported (FA) $)_{x}(\mathrm{MA})_{1-x} \mathrm{SnI}_{3}$ mixed 
organic cation lead-free perovskite thin films that were utilized as an absorber in inverted solar cells. FA and MA ratio was optimized and $\mathrm{J}-\mathrm{V}$ graphs of fabricated solar cells are demonstrated in Fig. 13(a). Out of all fabricated devices, the device incorporating (FA) ${ }_{0.75}(\mathrm{MA})_{0.25} \mathrm{SnI}_{3}$ exhibited champion performance resulting in a very high PCE (8.12\%). Fig. 13(b,c) shows the J-V characteristics and normalized PCE of best solar cell that was kept for storage $(400 \mathrm{~h})$ in glovebox. Sn-based lead-free perovskite thin film synthesized by mixing the precursors FAI, MAI and $\mathrm{SnI}_{2}$ in a solution of DMF, DMSO and $\mathrm{SnF}_{2}$ forming $\mathrm{FA}_{0.75} \mathrm{MA}_{0.25} \mathrm{SnI}_{3}$, was further utilized as a light absorbing layer by Liu et al. [81] where the effects of various antisolvent like diethyl ether (DE), toluene (TL) and chlorobenzene (CB) on the morphology of the film and charge recombination was studied. It was observed that CB led to a homogeneous and dense perovskite film and the resulting devices showed good reproducibility. The fabricated solar cell achieved champion PCE of $9.06 \%$ under forward scan and $9.02 \%$ under reverse scan and its $\mathrm{J}-\mathrm{V}$ graph is demonstrated in Fig. 13(d). Furthermore, the device retained 75\% of the initial efficiency for 30 days of storage for the encapsulated cells and thus depicting a long-term stability.
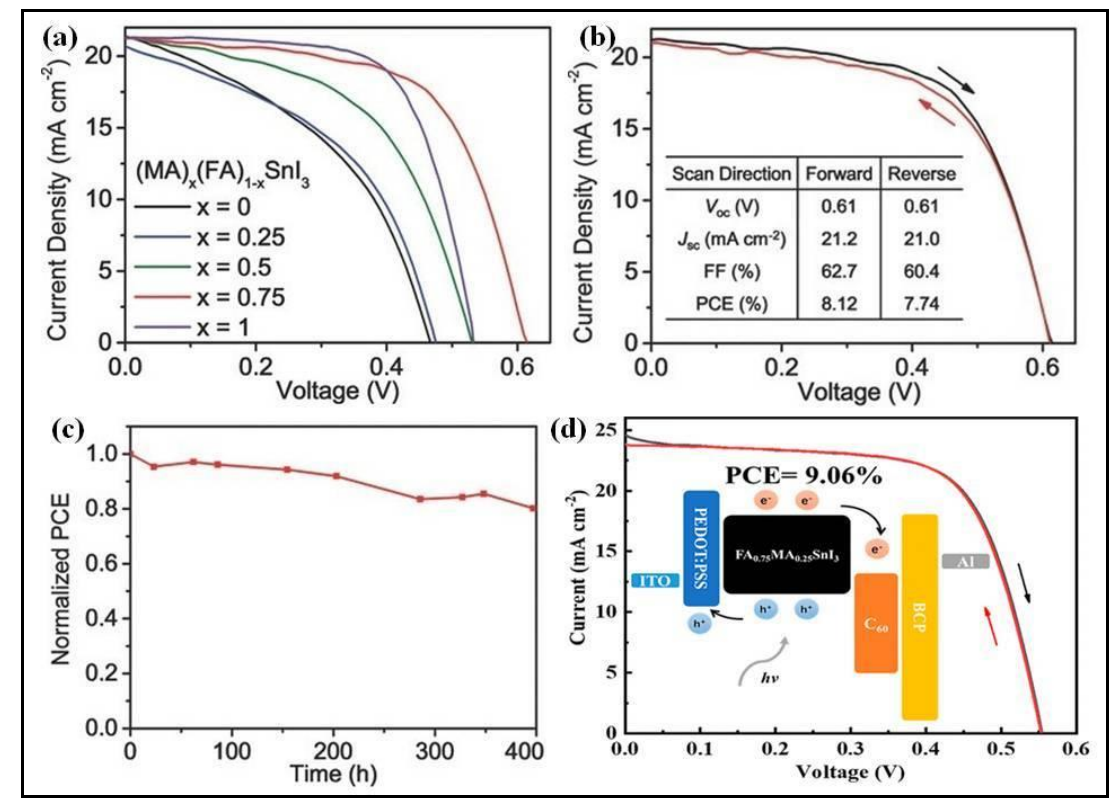

Fig. 13 (a) J-V characteristics of solar cells incorporating (FA) $x(\mathrm{MA})_{1-x} \mathrm{SnI}_{3}$ measured under forward scan mode, (b) $\mathrm{J}-\mathrm{V}$ characteristics of the device with $\mathrm{x}=0.75$, (c) Normalized PCE of best solar cell that was kept for storage (400 h) in glovebox. Reproduced from [80] with permission. Copyright 2017, WILEY-VCH. (d) J-V characteristics of champion solar cell incorporating $\mathrm{FA}_{0.75} \mathrm{MA}_{0.25} \mathrm{SnI}_{3}$ calculated in forward (black), reverse (red) scan and inset shows band alignment diagram. Reproduced from [81] with permission. Copyright 2018, American Chemical Society.

By means of relativistic hybrid DFT calculations, Wang et al. [82] examined optical, electronic and geometrical characteristics of 2D Sn-based lead-free perovskite (BA) $2(M A)_{n-1} \operatorname{Sn}_{n} I_{3 n+1} \quad(n=1,2,3)$. It was found that with the increase in value of $\mathrm{n}$ (i.e thickness of the perovskite layer), the bandgap decreased from $1.85 \mathrm{eV}$ to $1.38 \mathrm{eV}$. Both the electrons and holes exhibited small effective masses in the laminar plane. Further, strong as well as expansive absorption was observed for entire series. For the perovskite composition $n=3$, maximum efficiency of $24.6 \%$ was 
displayed. The observed intrinsic properties indicated that this series of two dimensional Sn-based perovskites are suitable for efficient and stable photovoltaics. By substituting cations and anions in $\mathrm{CsSnI}_{3}$ perovskite, Jiang et al. [83] reported perovskites of mixed cation and mixed halide forming $\mathrm{Rb}_{y} \mathrm{Cs}_{1-\mathrm{y}} \mathrm{Sn}\left(\mathrm{Br}_{\mathrm{x}} \mathrm{I}_{1-\mathrm{x}}\right)_{3}$ where $\mathrm{x} \geq 1 / 3$, which can be used for application in photovoltaics. The thermal as well as structural stabilities were found to improve by the gradual substitution procedure. Moreover, the redundant yellow phase was censored by the substitution of $\mathrm{Br}$ in place of $\mathrm{I}$ in $\mathrm{CsSn}\left(\mathrm{Br}_{\mathrm{x}} \mathrm{I}_{1-\mathrm{x}}\right)_{3}$. It was also envisaged that substituting $\mathrm{Rb}$ for Cs resulted in an extremely uniform solid solution that enhanced the film quality and utilization in photovoltaics.

Jokar et al. [84] for the first time included a nonpolar guanidinium $\left(\mathrm{GA}^{+}\right)$cation in various proportions, along with $1 \% \mathrm{EDAI}_{2}$ as an additive in $\mathrm{FASnI}_{3}$ structure. By optimizing the GAI:FAI ratio to 20:80, PCE of 8.5\% was achieved with the freshly prepared precursor solution. The J-V characteristics of fabricated solar cells are demonstrated in Fig. 14(a). The PCE increased regularly after storing for $2000 \mathrm{~h}$ in glove-box, reaching maximum efficiency of 9.6\%. The device passed all harsh standard tests as revealed in Fig. 14(b,c,d) indicating its extraordinary performance in photovoltaics. Kamarudin et al. [85] demonstrated highly efficient $\mathrm{FA}_{0.98} \mathrm{EDA}_{0.01} \mathrm{SnI}_{3}$ lead-free perovskite via Lewis bases post-treatment. Edamine was used in fine concentrations that aided the conversion of unreacted $\mathrm{SnI}_{2}$ to cubic phase perovskite. This led to an enhanced surface morphology and moreover, a smooth film was formed with large-sized grains. The XRD graphs of the obtained perovskites having different edamine concentrations are displayed in Fig. 14(e) whereas the schematic band diagram is demonstrated in Fig. 14(f). Further, the devices were stored for 7 days in a glovebox and the $\mathrm{J}-\mathrm{V}$ characteristics of champion solar cells for fresh samples as well as for stored samples are shown in Fig. 14(g,h). It was confirmed that the passivation of edamine helped in preventing the perovskite surface from oxidation. Further, the undercoordinated Sn was stabilized because of amine group that was present in edamine molecules by donation of free electron pairs. In this case, there was a nonstoichiometric ratio of $\mathrm{Sn} / \mathrm{I}$ leading to iodide deficiency that was the core cause for charge recombination rather than the oxidation of tin. As a consequence, all these enhancements led to an improvement in the electronic properties like carrier density, Hall Effect mobility and increased $\mathrm{V}_{\mathrm{oc}}$ leading to a champion PCE of $10.18 \%$. Hence, a facile surface passivation technique plays a significant role for competent Sn-based lead-free perovskite solar cells. Fig. 15 shows the performance progress of some mixed cation tin-based solar cells until now. 


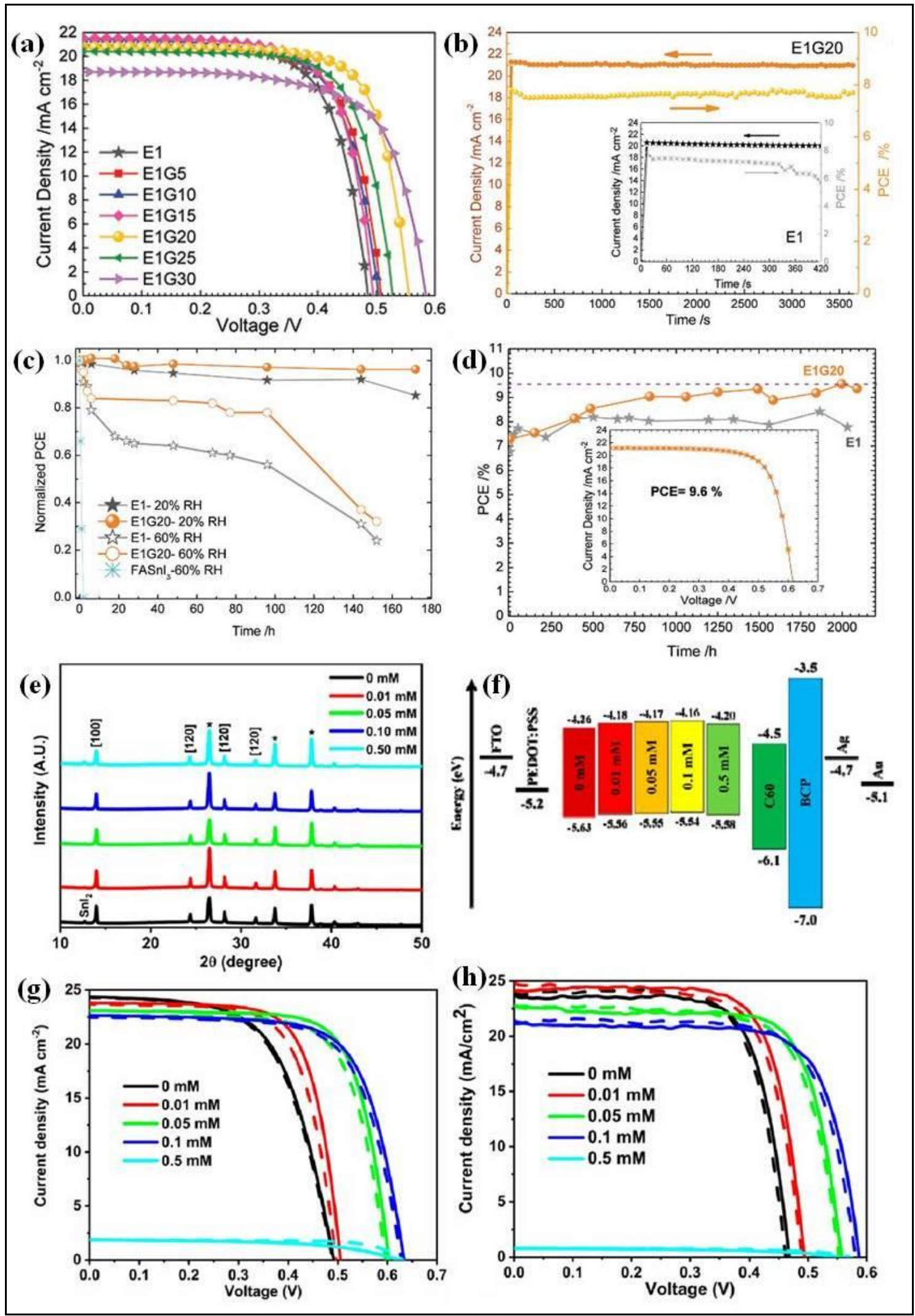

Fig. 14 (a) Current-voltage curves of the fabricated devices, (b) Stabilized efficiency of power conversion and photocurrent density of the E1G20 and E1 (shown in the inset) devices taken at the position of maximum power for 
1 sun irradiation with AM1.5G solar simulator for $3600 \mathrm{~s}$, (c) enduring stability showing PCE of E1 and E1G20 devices when stored in ambient air for $\mathrm{RH}=20 \%, 60 \%$ without encapsulation, and (d) in $\mathrm{N}_{2}$-filled glove box. Reproduced from [84] with permission. Copyright 2018, WILEY-VCH. (e) The XRD graphs of the obtained $\mathrm{FA}_{0.98} \mathrm{EDA}_{0.01} \mathrm{SnI}_{3}$ perovskites having different edamine concentrations, (f) Schematic band energy diagram, (g) $\mathrm{J}-\mathrm{V}$ characteristics of champion solar cells for fresh samples, and (h) stored samples. Reproduced from [85] with permission. Copyright 2019, American Chemical Society.

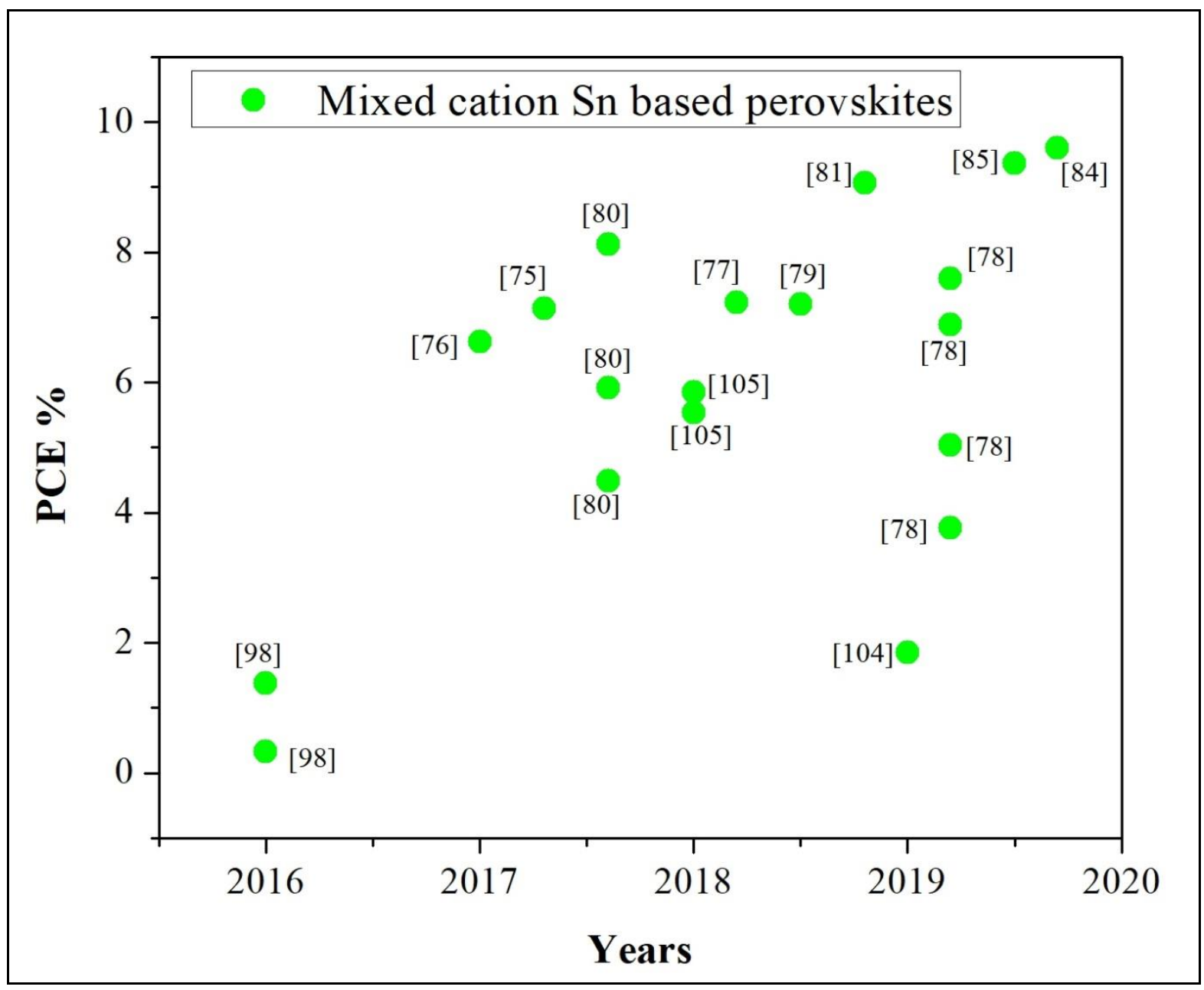

Fig. 15 Efficiency of some mixed cation tin-based solar cells during different years.

Table 1: Various Sn-based lead-free perovskites as absorbers in solar cells along with their photovoltaic parameters.

\begin{tabular}{|l|l|l|l|l|l|l|}
\hline Absorbers & Device architecture & $\begin{array}{l}\mathbf{V}_{\text {oc }} \\
(\mathbf{V})\end{array}$ & $\begin{array}{l}\mathbf{J}_{\text {sc }} \\
\left(\mathbf{m A} / \mathbf{c m}^{2}\right)\end{array}$ & $\begin{array}{l}\mathbf{F F} \\
(\boldsymbol{\%})\end{array}$ & $\begin{array}{l}\text { PCE } \\
(\boldsymbol{\%})\end{array}$ & \begin{tabular}{l} 
Ref. \\
\hline $\mathrm{MASnI}_{3}$
\end{tabular} \\
\hline $\begin{array}{l}\text { FTO/c-TiO } \\
\text { OMeTAD-TiO } / \mathrm{Au} / \text { absorber/Spiro- }\end{array}$ & 0.88 & 16.8 & 42 & 6.4 & {$[30]$} \\
\hline
\end{tabular}




\begin{tabular}{|c|c|c|c|c|c|c|}
\hline $\mathrm{MASnI}_{3}$ & ITO/PEDOT/TPD/absorber/C $60 / \mathrm{BCP} / \mathrm{Ag}$ & 0.377 & 12.1 & 36.6 & 1.7 & [31] \\
\hline $\begin{array}{l}\mathrm{MASnI}_{3}+20 \% \\
\mathrm{SnF}_{2} / \text { Hydrazine }\end{array}$ & $\mathrm{FTO} / \mathrm{c}-\mathrm{TiO}_{2} / \mathrm{m}-\mathrm{TiO}_{2} /$ absorber/PTAA/Au & 0.378 & 19.92 & 51.73 & 3.89 & [33] \\
\hline $\begin{array}{l}\mathrm{MASnI}_{3}+20 \% \\
\mathrm{SnF}_{2}\end{array}$ & $\mathrm{FTO} / \mathrm{c}-\mathrm{TiO}_{2} / \mathrm{m}-\mathrm{TiO}_{2} /$ absorber/PTAA$/ \mathrm{Au}$ & 0.25 & 26.1 & 30 & 1.94 & {$[34]$} \\
\hline $\begin{array}{l}\mathrm{MASnIBr}_{2}+30 \% \\
\mathrm{SnF}_{2}\end{array}$ & $\begin{array}{l}\mathrm{FTO} / \mathrm{c}-\mathrm{TiO}_{2} / \mathrm{m}-\mathrm{TiO}_{2} / \text { absorber/Spiro- } \\
\mathrm{OMeTAD} / \mathrm{Au}\end{array}$ & 0.45 & 13.77 & 59.58 & 3.7 & {$[35]$} \\
\hline $\operatorname{MASn}\left(\mathrm{I}_{0.33} \mathrm{Br}_{0.67}\right)_{3}$ & $\begin{array}{l}\mathrm{FTO} / \mathrm{c}-\mathrm{TiO}_{2} / \mathrm{m}-\mathrm{TiO}_{2} / \text { absorber/Spiro- } \\
\mathrm{OMeTAD} / \mathrm{Au}\end{array}$ & 0.58 & 11.09 & 49.50 & 3.20 & {$[36]$} \\
\hline $\mathrm{MASnI}_{3}$ & $\mathrm{FTO} / \mathrm{c}-\mathrm{TiO}_{2} / \mathrm{m}-\mathrm{TiO}_{2} /$ absorber/PTAA$/ \mathrm{Au}$ & 0.486 & 22.91 & 64 & 7.13 & [37] \\
\hline $\mathrm{MASnI}_{3}$ & ITO/PEDOT:PSS/absorber/PC ${ }_{60} \mathrm{BM} / \mathrm{Ag}$ & 0.57 & 20.68 & 66 & 7.78 & {$[38]$} \\
\hline $\begin{array}{l}\mathrm{MASnI}_{3}+10 \% \\
\mathrm{SnF}_{2}\end{array}$ & ITO/PEDOT:PSS/absorber/C $60 / \mathrm{BCP} / \mathrm{Ag}$ & 0.46 & 21.4 & 42.7 & 4.29 & {$[80]$} \\
\hline $\mathrm{MASnI}_{3}$ & $\mathrm{FTO} / \mathrm{c}-\mathrm{TiO}_{2} / \mathrm{m}-\mathrm{TiO}_{2} /$ absorber/PTAA$/ \mathrm{Au}$ & 0.273 & 17.36 & 39.1 & 1.86 & {$[86]$} \\
\hline $\mathrm{MASnBr}_{3}$ & FTO/c-TiO $/$ /absorber/P3HT/Au & 0.498 & 4.27 & 49.1 & 1.12 & {$[87]$} \\
\hline $\mathrm{MASnI}_{3}$ & $\begin{array}{l}\mathrm{FTO} / \mathrm{c}-\mathrm{TiO}_{2} / \mathrm{m}-\mathrm{TiO}_{2} / \text { absorber/Spiro- } \\
\mathrm{OMeTAD} / \mathrm{Au}\end{array}$ & 0.68 & 16.30 & 48 & 5.23 & {$[88]$} \\
\hline $\mathrm{MASnI}_{2} \mathrm{Br}$ & $\begin{array}{l}\mathrm{FTO} / \mathrm{c}-\mathrm{TiO}_{2} / \mathrm{m}-\mathrm{TiO}_{2} / \text { absorber/Spiro- } \\
\mathrm{OMeTAD} / \mathrm{Au}\end{array}$ & 0.77 & 14.38 & 50 & 5.48 & {$[88]$} \\
\hline $\mathrm{MASnIBr}_{2}$ & $\begin{array}{l}\text { FTO/c- } \mathrm{TiO}_{2} / \mathrm{m}-\mathrm{TiO}_{2} / \text { absorber/Spiro- } \\
\text { OMeTAD/Au }\end{array}$ & 0.82 & 12.30 & 57 & 5.73 & {$[88]$} \\
\hline $\mathrm{MASnBr}_{3}$ & $\begin{array}{l}\mathrm{FTO} / \mathrm{c}-\mathrm{TiO}_{2} / \mathrm{m}-\mathrm{TiO}_{2} / \text { absorber/Spiro- } \\
\mathrm{OMeTAD} / \mathrm{Au}\end{array}$ & 0.88 & 8.26 & 59 & 4.27 & {$[88]$} \\
\hline $\mathrm{MASnI}_{3}$ & $\begin{array}{l}\mathrm{FTO} / \mathrm{c}-\mathrm{TiO}_{2} / \mathrm{m}-\mathrm{TiO}_{2} / \text { absorber/Spiro- } \\
\mathrm{OMeTAD} / \mathrm{Au}\end{array}$ & 0.716 & 15.18 & 50.07 & 5.44 & [89] \\
\hline $\begin{array}{l}\mathrm{MASnI}_{3}+20 \% \\
\mathrm{SnF}_{2}\end{array}$ & 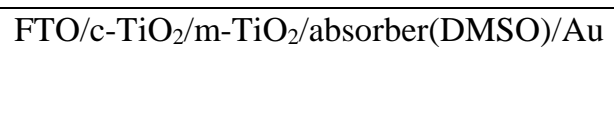 & 0.32 & 21.4 & 46 & 3.15 & {$[90]$} \\
\hline $\begin{array}{l}\text { MASnI }_{3}+20 \% \\
\mathrm{SnF}_{2}\end{array}$ & FTO/c-TiO $2 / \mathrm{m}^{-\mathrm{TiO}_{2} / \text { absorber/PTAA} / \mathrm{Au}}$ & 0.232 & 26.0 & 38.6 & 2.33 & {$[91]$} \\
\hline $\mathrm{MASnI}_{3-\mathrm{x}} \mathrm{Br}_{\mathrm{x}}$ & 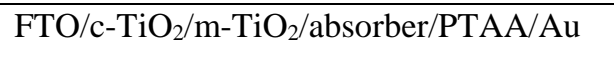 & 0.452 & 5.02 & 48.3 & 1.10 & {$[92]$} \\
\hline $\mathrm{MASnBr}_{3}$ & ITO/c- $\mathrm{TiO}_{2} / \mathrm{m}-\mathrm{TiO}_{2} /$ absorber/PTAA/Au & 0.307 & 1.22 & 36.8 & 0.14 & {$[92]$} \\
\hline $\begin{array}{l}\mathrm{MASnIBr}_{1.8} \mathrm{Cl}_{0.2}+ \\
20 \% \mathrm{SnF}_{2}\end{array}$ & $\mathrm{FTO} / \mathrm{c}-\mathrm{TiO}_{2} / \mathrm{m}-\mathrm{TiO}_{2} / \mathrm{m}-\mathrm{Al}_{2} \mathrm{O}_{3} /$ absorber/C & 0.38 & 13.99 & 57.3 & 3.11 & {$[93]$} \\
\hline $\mathrm{MASnI}_{3}$ & $\begin{array}{l}\text { ITO/PEDOT:PSS/NiO/absorber/PC }{ }_{61} \mathrm{BM} / \\
\mathrm{Al}\end{array}$ & 0.595 & 17.8 & 29.8 & 3.2 & [94] \\
\hline $\mathrm{MASnI}_{3}+20 \%$ & ITO/PEDOT:PSS/absorber/C $60 / \mathrm{BCP} / \mathrm{Ag}$ & 0.45 & 11.82 & 40 & 2.14 & {$[95]$} \\
\hline
\end{tabular}




\begin{tabular}{|c|c|c|c|c|c|c|}
\hline $\mathrm{SnF}_{2}$ & & & & & & \\
\hline $\begin{array}{l}\mathrm{BA}_{2} \mathrm{MA}_{3} \mathrm{Sn}_{4} \mathrm{I}_{13}+ \\
100 \% \mathrm{SnF}_{2}\end{array}$ & $\mathrm{FTO} / \mathrm{c}-\mathrm{TiO}_{2} / \mathrm{m}-\mathrm{TiO}_{2} /$ absorber/PTAA$/ \mathrm{Au}$ & 0.229 & 24.1 & 45.7 & 2.53 & {$[96]$} \\
\hline $\mathrm{MASnCl}_{3}$ & $\mathrm{FTO} / \mathrm{c}-\mathrm{TiO}_{2} /$ absorber/CuSCN/Ag & 0.576 & 12.89 & 55 & 3.41 & {$[97]$} \\
\hline $\begin{array}{l}\mathrm{FASnI}_{3}+20 \% \\
\mathrm{SnF}_{2}\end{array}$ & $\begin{array}{l}\mathrm{FTO} / \mathrm{c}-\mathrm{TiO}_{2} / \mathrm{m}-\mathrm{TiO}_{2} / \text { absorber/Spiro- } \\
\text { OMeTAD/Au }\end{array}$ & 0.238 & 24.45 & 36 & 2.10 & [39] \\
\hline $\begin{array}{l}\mathrm{FASnI}_{3}+10 \% \\
\mathrm{SnF}_{2}\end{array}$ & ITO/PEDOT:PSS/absorber/C ${ }_{60} / \mathrm{BCP} / \mathrm{Ag}$ & 0.465 & 22.07 & 60.67 & 6.22 & {$[40]$} \\
\hline $\mathrm{FASnI}_{2} \mathrm{Br}$ & ITO/PEDOT:PSS/absorber/C ${ }_{60} / \mathrm{Ca} / \mathrm{Al}$ & 0.467 & 6.82 & 54 & 1.72 & {$[41]$} \\
\hline $\begin{array}{l}\mathrm{FASnI}_{3}+20 \% \\
\mathrm{SnF}_{2}\end{array}$ & $\begin{array}{l}\mathrm{FTO} / \mathrm{c}-\mathrm{TiO}_{2} / \mathrm{m}_{-}\left(\mathrm{TiO}_{2}-\mathrm{ZnS}\right) / \text { absorber/ } \\
\text { PTAA/Au }\end{array}$ & 0.38 & 23.09 & 60.01 & 5.27 & {$[42]$} \\
\hline $\begin{array}{l}\mathrm{FASnI}_{3}+10 \% \\
\mathrm{SnF}_{2}+\mathrm{TMA}\end{array}$ & $\begin{array}{l}\text { ITO/SnO }{ }_{2} / \mathrm{C}_{60} / \text { absorber/Spiro- } \\
\text { OMeTAD/Ag }\end{array}$ & 0.31 & 21.65 & 64.7 & 4.34 & {$[43]$} \\
\hline $\begin{array}{l}\mathrm{FASnI}_{3}+10 \% \\
\mathrm{SnF}_{2}+\mathrm{TMA}^{2}\end{array}$ & ITO/PEDOT:PSS/absorber/C $\mathrm{C}_{60} / \mathrm{bis} \mathrm{C}_{60} / \mathrm{Ag}$ & 0.47 & 22.45 & 67.8 & 7.09 & {$[43]$} \\
\hline $\begin{array}{l}\mathrm{FASnI}_{3}+10 \% \\
\mathrm{SnF}_{2}+\text { pyrazine }\end{array}$ & $\begin{array}{l}\mathrm{FTO} / \mathrm{c}-\mathrm{TiO}_{2} / \mathrm{m}-\mathrm{TiO}_{2} / \text { absorber/Spiro- } \\
\text { OMeTAD/Au }\end{array}$ & 0.32 & 23.7 & 63 & 4.8 & {$[44]$} \\
\hline $\begin{array}{l}\mathrm{FASnI}_{3}+10 \% \\
\mathrm{SnF}_{2}+20 \% \text { PEA }\end{array}$ & ITO/NiO/absorber/PCBM/Al & 0.59 & 14.44 & 69 & 5.94 & {$[45]$} \\
\hline $\begin{array}{l}0.92 \mathrm{FASnI}_{3}+ \\
0.08 \mathrm{PEA}+10 \% \\
\mathrm{SnF}_{2}\end{array}$ & ITO/PEDOT:PSS/absorber/C ${ }_{60} / \mathrm{BCP} / \mathrm{Al}$ & 0.525 & 24.1 & 71 & 9 & {$[46]$} \\
\hline $\mathrm{FASnI}_{3}+\mathrm{PEABr}$ & ITO/PEDOT:PSS/absorber/C ${ }_{60} / \mathrm{BCP} / \mathrm{Cu}$ & 0.45 & 24.87 & 63 & 7.05 & {$[47]$} \\
\hline $\mathrm{FASnI}_{3}$ & ITO/PEDOT:PSS/absorber/C $60 / \mathrm{BCP} / \mathrm{Ag}$ & 0.58 & 17.5 & 66.3 & 6.75 & {$[49]$} \\
\hline $\mathrm{FASnI}_{3}$ & ITO/PEDOT:PSS/absorber/C ${ }_{60} / \mathrm{BCP} / \mathrm{Ag}$ & 0.36 & 17.6 & 62.7 & 4 & {$[50]$} \\
\hline $\begin{array}{l}\mathrm{FASnI}_{3}+15 \% \\
\mathrm{BAI}\end{array}$ & ITO/PEDOT:PSS/absorber/C ${ }_{60} / \mathrm{BCP} / \mathrm{Ag}$ & 0.44 & 18 & 69.4 & 5.5 & {$[50]$} \\
\hline $\begin{array}{l}\mathrm{FASnI}_{3}+1 \% \\
\mathrm{EDAI}_{2}\end{array}$ & ITO/PEDOT:PSS/absorber/C $60 / \mathrm{BCP} / \mathrm{Ag}$ & 0.583 & 21.3 & 71.8 & 8.9 & {$[50]$} \\
\hline $\begin{array}{l}\mathrm{FASnI}_{3}+5 \% \\
\text { FASCN }\end{array}$ & ITO/PEDOT:PSS/absorber/PC ${ }_{60} \mathrm{BM} / \mathrm{Al}$ & 0.53 & 22.5 & 68.3 & 8.17 & {$[51]$} \\
\hline$(\mathrm{PEA}, \mathrm{FA}) \mathrm{SnI}_{3}$ & LiF/PEDOT:PSS/absorber/C ${ }_{60} / \mathrm{BCP} / \mathrm{Ag}$ & 0.47 & 20.07 & 74 & 6.98 & {$[53]$} \\
\hline $\begin{array}{l}\left(\mathrm{PEA}_{2} \mathrm{FASn}_{2} \mathrm{I}_{7}\right) / \\
\mathrm{FASnI}_{3}\end{array}$ & ITO/PEDOT:PSS/absorber/C ${ }_{60} / \mathrm{BCP} / \mathrm{Al}$ & 0.48 & 23.25 & 68 & 7.61 & {$[54]$} \\
\hline $\begin{array}{l}\mathrm{EA}_{0.08}\left(\mathrm{PEA}_{2} \mathrm{FASn}\right. \\
\left.{ }_{2} \mathrm{I}_{7}\right) / \mathrm{FASnI}_{3}\end{array}$ & ITO/PEDOT:PSS/absorber/C ${ }_{60} / \mathrm{BCP} / \mathrm{Al}$ & 0.51 & 23.75 & 70 & 8.4 & {$[54]$} \\
\hline
\end{tabular}




\begin{tabular}{|c|c|c|c|c|c|c|}
\hline $\mathrm{FASnI}_{3}$ & FTO/NiO/absorber/C $60 / \mathrm{Au}$ & 0.97 & 25.95 & 80.85 & 9.99 & {$[55]$} \\
\hline $\mathrm{FASnI}_{3}$ & ITO/PEDOT:PSS/absorber/C ${ }_{60} / \mathrm{BCP} / \mathrm{Ag}$ & 0.435 & 20.04 & 58.83 & 5.12 & {$[56]$} \\
\hline $\mathrm{FASnI}_{3}+\mathrm{PTN}-\mathrm{Br}$ & ITO/PEDOT:PSS/absorber/C ${ }_{60} / \mathrm{BCP} / \mathrm{Ag}$ & 0.57 & 20.66 & 67.40 & 7.94 & {$[56]$} \\
\hline $\begin{array}{l}\mathrm{AVA}_{2} \mathrm{FA}_{\mathrm{n}-1} \mathrm{Sn}_{\mathrm{n}} \mathrm{I}_{3 \mathrm{n}} \\
+1(<\mathrm{n}>=5)\end{array}$ & $\begin{array}{l}\text { ITO/PEDOT:PSS/absorber/PCBM/BCP/ } \\
\mathrm{Ag}\end{array}$ & 0.47 & 15.6 & 57.2 & 4.19 & [57] \\
\hline $\begin{array}{l}\mathrm{AVA}_{2} \mathrm{FA}_{\mathrm{n}-1} \mathrm{Sn}_{\mathrm{n}} \mathrm{I}_{3 \mathrm{n}} \\
+1(<\mathrm{n}>=5)+ \\
10 \% \mathrm{NH}_{4} \mathrm{Cl}\end{array}$ & $\begin{array}{l}\text { ITO/PEDOT:PSS/absorber/PCBM/BCP/ } \\
\mathrm{Ag}\end{array}$ & 0.61 & 21 & 68 & 8.71 & {$[57]$} \\
\hline $\mathrm{FASnI}_{3}$ & $\begin{array}{l}\text { ITO/SnO } / \text { /absorber/Spiro-OMeTAD/ } \\
\mathrm{MoO}_{3} / \mathrm{Au}\end{array}$ & 0.55 & 19.61 & 51 & 5.50 & {$[58]$} \\
\hline $\mathrm{FASnI}_{3}$ & ITO/PEDOT:PSS/absorber/PC ${ }_{71} \mathrm{BM} / \mathrm{Ag}$ & 0.55 & 22.72 & 71.2 & 8.9 & {$[58]$} \\
\hline $\mathrm{FASnI}_{3}$ & $\begin{array}{l}\text { ITO/PEDOT:PSS/absorber/PCBM/BCP/ } \\
\mathrm{Ag}\end{array}$ & 0.408 & 19.95 & 58.22 & 4.74 & {$[60]$} \\
\hline $\mathrm{FASnI}_{3}+8-\mathrm{HQ}$ & $\begin{array}{l}\text { ITO/PEDOT:PSS/absorber/PCBM/BCP/ } \\
\mathrm{Ag}\end{array}$ & 0.493 & 22.24 & 65.19 & 7.15 & {$[60]$} \\
\hline $\mathrm{FASnI}_{3}$ & $\begin{array}{l}\text { ITO/PEDOT:PSS/absorber/PC }{ }_{61} \mathrm{BM} / \mathrm{BCP} / \\
\mathrm{Ag}\end{array}$ & 0.478 & 20.43 & 53.47 & 5.23 & [61] \\
\hline $\mathrm{FASnI}_{3}+\mathrm{EVA}$ & $\begin{array}{l}\text { ITO/PEDOT:PSS/absorber/PC }{ }_{61} \mathrm{BM} / \mathrm{BCP} / \\
\mathrm{Ag}\end{array}$ & 0.523 & 22.80 & 64.69 & 7.72 & [61] \\
\hline $\mathrm{PEA}_{\mathrm{x}} \mathrm{FA}_{1-\mathrm{x}} \mathrm{SnI}_{3}$ & ITO/PEDOT:PSS/absorber/ICBA/BCP/Ag & 0.78 & 17.8 & 72 & 10.1 & {$[62]$} \\
\hline $\begin{array}{l}\mathrm{PEA}_{\mathrm{x}} \mathrm{FA}_{1-\mathrm{x}} \mathrm{SnI}_{3}+ \\
\mathrm{NH}_{4} \mathrm{SCN}\end{array}$ & $\begin{array}{l}\text { ITO/PEDOT:PSS/absorber/PCBM/BCP/ } \\
\mathrm{Ag}\end{array}$ & 0.60 & 17.1 & 74 & 7.7 & {$[62]$} \\
\hline $\begin{array}{l}\mathrm{PEA}_{\mathrm{x}} \mathrm{FA}_{1-\mathrm{x}} \mathrm{SnI}_{3}+ \\
\mathrm{NH}_{4} \mathrm{SCN}\end{array}$ & ITO/PEDOT:PSS/absorber/ICBA/BCP/Ag & 0.94 & 17.4 & 75 & 12.4 & {$[62]$} \\
\hline $\mathrm{FASnI}_{3}$ & $\begin{array}{l}\text { ITO/PEDOT:PSS/absorber/PCBM/BCP/ } \\
\mathrm{Ag}\end{array}$ & 0.268 & 12.73 & 39.43 & 1.35 & [63] \\
\hline $\begin{array}{l}\text { FASnI }{ }_{3}+\text { PAMS } \\
(0.3 \mathrm{mg} / \mathrm{mL})\end{array}$ & $\begin{array}{l}\text { ITO/PEDOT:PSS/absorber/PCBM/BCP/ } \\
\mathrm{Ag}\end{array}$ & 0.225 & 15.70 & 39.29 & 1.39 & {$[63]$} \\
\hline $\begin{array}{l}\text { FASnI }_{3}+\text { PAMS } \\
(0.5 \mathrm{mg} / \mathrm{mL})\end{array}$ & $\begin{array}{l}\text { ITO/PEDOT:PSS/absorber/PCBM/BCP/ } \\
\mathrm{Ag}\end{array}$ & 0.314 & 17.64 & 41.09 & 2.28 & {$[63]$} \\
\hline $\begin{array}{l}\text { FASnI }_{3}+\text { PAMS } \\
(1 \mathrm{mg} / \mathrm{mL})\end{array}$ & $\begin{array}{l}\text { ITO/PEDOT:PSS/absorber/PCBM/BCP/ } \\
\mathrm{Ag}\end{array}$ & 0.259 & 16.46 & 45.02 & 1.92 & [63] \\
\hline $\begin{array}{l}\mathrm{FASnI}_{3}+\text { PAMS } \\
(2 \mathrm{mg} / \mathrm{mL})\end{array}$ & $\begin{array}{l}\text { ITO/PEDOT:PSS/absorber/PCBM/BCP/ } \\
\mathrm{Ag}\end{array}$ & 0.228 & 13.50 & 44.26 & 1.36 & [63] \\
\hline $\begin{array}{l}\text { FASnI }_{3}+\text { PAMS } \\
(3 \mathrm{mg} / \mathrm{mL})\end{array}$ & $\begin{array}{l}\text { ITO/PEDOT:PSS/absorber/PCBM/BCP/ } \\
\mathrm{Ag}\end{array}$ & 0.230 & 13.99 & 41.49 & 1.33 & [63] \\
\hline
\end{tabular}




\begin{tabular}{|c|c|c|c|c|c|c|}
\hline $\mathrm{FASnI}_{3}$ & ITO/PEDOT:PSS/absorber/C $60 / \mathrm{BCP} / \mathrm{Ag}$ & 0.52 & 19.92 & 64.6 & 6.70 & {$[64]$} \\
\hline $\mathrm{FASnI}_{3}+\mathrm{CTA}-\mathrm{F}$ & ITO/PEDOT:PSS/absorber/C ${ }_{60} / \mathrm{BCP} / \mathrm{Ag}$ & 0.60 & 20.69 & 66.4 & 8.24 & [64] \\
\hline $\begin{array}{l}\mathrm{FASnI}_{3}+\mathrm{CTA}- \\
\mathrm{OMe}\end{array}$ & ITO/PEDOT:PSS/absorber/C $60 / \mathrm{BCP} / \mathrm{Ag}$ & 0.61 & 20.95 & 71.4 & 9.12 & [64] \\
\hline $\mathrm{FASnI}_{3}+\mathrm{CDTA}$ & ITO/PEDOT:PSS/absorber/C $60 / \mathrm{BCP} / \mathrm{Ag}$ & 0.64 & 21.83 & 73.9 & 10.32 & {$[64]$} \\
\hline $\mathrm{FASnI}_{3}$ & ITO/CuSCN/absorber/PCBM/Ag & 0.25 & 17.72 & 51.11 & 2.34 & {$[65]$} \\
\hline $\mathrm{FASnI}_{3}+3 \% \mathrm{AHP}$ & ITO/CuSCN/absorber/PCBM/Ag & 0.35 & 18.54 & 59.89 & 3.93 & [65] \\
\hline $\mathrm{FASnI}_{3}+5 \% \mathrm{AHP}$ & ITO/CuSCN/absorber/PCBM/Ag & 0.50 & 19.55 & 63.71 & 6.25 & {$[65]$} \\
\hline $\mathrm{FASnI}_{3}+7 \% \mathrm{AHP}$ & ITO/CuSCN/absorber/PCBM/Ag & 0.33 & 19.18 & 57.91 & 3.71 & {$[65]$} \\
\hline $\begin{array}{l}\mathrm{FASnI}_{3}+10 \% \\
\mathrm{SnF}_{2}\end{array}$ & ITO/PEDOT:PSS/absorber/C $60 / \mathrm{BCP} / \mathrm{Ag}$ & 0.48 & 21.3 & 64.6 & 6.60 & {$[80]$} \\
\hline $\mathrm{FASnI}_{3}$ & $\begin{array}{l}\text { ITO/PEDOT:PSS/absorber/PCBM/bis- } \\
\mathrm{C}_{60} / \mathrm{Ag}\end{array}$ & 0.04 & 11.73 & 23.4 & 0.11 & {$[98]$} \\
\hline $\begin{array}{l}\mathrm{FASnI}_{3}+2.5 \% \\
\mathrm{~N}_{2} \mathrm{H}_{5} \mathrm{Cl}+10 \% \\
\mathrm{SnF}_{2}\end{array}$ & $\begin{array}{l}\text { ITO/PEDOT:PSS/absorber/PCBM/BCP/ } \\
\mathrm{Ag}\end{array}$ & 0.455 & 17.64 & 67.3 & 5.40 & [99] \\
\hline $\begin{array}{l}\mathrm{FASnI}_{3}+12 \% \\
\mathrm{SnF}_{2}\end{array}$ & $\begin{array}{l}\text { FTO/PEDOT:PSS(PEG)/Absorber/PCBM/ } \\
\text { BCP/Ag }\end{array}$ & 0.37 & 22.06 & 62.7 & 5.12 & $\begin{array}{l}{[100} \\
]\end{array}$ \\
\hline $\mathrm{FASnI}_{3}$ & $\begin{array}{l}\text { PEN-ITO/PEDOT:PSS/absorber/C } 60 / \mathrm{BCP} / \\
\mathrm{Ag}\end{array}$ & 0.31 & 16.07 & 62.6 & 3.12 & $\begin{array}{l}{[101} \\
]\end{array}$ \\
\hline $\mathrm{FASnI}_{3}$ & ITO/PEDOT:PSS/absorber/C ${ }_{60} / \mathrm{BCP} / \mathrm{Ag}$ & 0.33 & 17.78 & 67.9 & 3.98 & $\begin{array}{l}{[101} \\
]\end{array}$ \\
\hline $\begin{array}{l}\mathrm{CsSnI}_{3}+20 \% \\
\mathrm{SnF}_{2}\end{array}$ & $\begin{array}{l}\mathrm{FTO} / \mathrm{c}-\mathrm{TiO}_{2} / \mathrm{m}-\mathrm{TiO}_{2} / \text { absorber } / \mathrm{m}- \\
\text { MTDATA } / \mathrm{Au}\end{array}$ & 0.24 & 22.70 & 37 & 2.02 & {$[66]$} \\
\hline $\begin{array}{l}\mathrm{CsSnI}_{3}+20 \% \\
\mathrm{SnF}_{2}\end{array}$ & $\begin{array}{l}\mathrm{FTO} / \mathrm{c}-\mathrm{TiO}_{2} / \mathrm{m}-\mathrm{TiO}_{2} / \text { absorber} / \text { Spiro- } \\
\mathrm{OMeTAD} / \mathrm{Au}\end{array}$ & 0.201 & 27.67 & 29 & 1.66 & [67] \\
\hline $\begin{array}{l}\mathrm{CsSnI}_{2} \mathrm{Br}+20 \% \\
\mathrm{SnF}_{2}\end{array}$ & $\begin{array}{l}\mathrm{FTO} / \mathrm{c}-\mathrm{TiO}_{2} / \mathrm{m}-\mathrm{TiO}_{2} / \text { absorber/Spiro- } \\
\text { OMeTAD/Au }\end{array}$ & 0.289 & 15.06 & 38 & 1.67 & [67] \\
\hline $\begin{array}{l}\mathrm{CsSnIBr}_{2}+20 \% \\
\mathrm{SnF}_{2}\end{array}$ & $\begin{array}{l}\mathrm{FTO} / \mathrm{c}-\mathrm{TiO}_{2} / \mathrm{m}-\mathrm{TiO}_{2} / \text { absorber/Spiro- } \\
\text { OMeTAD/Au }\end{array}$ & 0.311 & 11.57 & 43 & 1.56 & [67] \\
\hline $\begin{array}{l}\mathrm{CsSnI}_{2.9} \mathrm{Br}_{0.1} \quad+ \\
20 \% \mathrm{SnF}_{2}\end{array}$ & $\begin{array}{l}\mathrm{FTO} / \mathrm{c}-\mathrm{TiO}_{2} / \mathrm{m}-\mathrm{TiO}_{2} / \text { absorber/Spiro- } \\
\text { OMeTAD/Au }\end{array}$ & 0.222 & 24.16 & 33 & 1.76 & {$[67]$} \\
\hline $\begin{array}{l}\mathrm{CsSnBr}_{3}+20 \% \\
\mathrm{SnF}_{2}\end{array}$ & $\begin{array}{l}\mathrm{FTO} / \mathrm{c}-\mathrm{TiO}_{2} / \mathrm{m}-\mathrm{TiO}_{2} / \text { absorber/Spiro- } \\
\mathrm{OMeTAD} / \mathrm{Au}\end{array}$ & 0.42 & 9.1 & 57 & 2.17 & {$[68]$} \\
\hline $\mathrm{CsSnI}_{3}$ & ITO/c-TiO $2 /$ absorber/Spiro-OMeTAD/Au & 0.48 & 8.11 & 19.8 & 0.77 & [69] \\
\hline $\mathrm{CsSnI}_{3}$ & ITO/NiO/absorber/PCBM/Al & 0.52 & 10.21 & 62.5 & 3.31 & [69] \\
\hline
\end{tabular}




\begin{tabular}{|c|c|c|c|c|c|c|}
\hline $\begin{array}{l}\mathrm{CsSnI}_{3}+10 \% \\
\mathrm{SnCl}_{2}\end{array}$ & ITO/Absorber/PC ${ }_{61} \mathrm{BM} / \mathrm{BCP} / \mathrm{Al}$ & 0.50 & 9.89 & 68 & 3.56 & {$[25]$} \\
\hline $\mathrm{CsSnI}_{3}$ & $\mathrm{ITO} / \mathrm{c}-\mathrm{TiO}_{2} /$ absorber/Spiro-OMeTAD/Au & 0.86 & 23.2 & 65 & 12.96 & {$[29]$} \\
\hline $\mathrm{CsSnBr}_{3}$ & ITO/c-TiO $2 /$ absorber/Spiro-OMeTAD/Au & 0.85 & 21.23 & 58 & 10.46 & [29] \\
\hline $\mathrm{CsSnCl}_{3}$ & ITO/c-TiO $2 /$ absorber/Spiro-OMeTAD/Au & 0.87 & 19.82 & 56 & 9.66 & [29] \\
\hline $\mathrm{Cs}_{2} \mathrm{SnI}_{6}$ & $\begin{array}{l}\text { FTO/PLD-ZnO seed layer }(20 \mathrm{mM}) / \mathrm{ZnO} \\
\text { nanorods/absorber/P3HT/Ag }\end{array}$ & 0.47 & 2.56 & 43.25 & 0.54 & {$[70]$} \\
\hline $\mathrm{Cs}_{2} \mathrm{SnI}_{6}$ & $\begin{array}{l}\text { FTO/PLD-ZnO seed layer }(30 \mathrm{mM}) / \mathrm{ZnO} \\
\text { nanorods/absorber/P3HT/Ag }\end{array}$ & 0.52 & 3.20 & 51.50 & 0.86 & {$[70]$} \\
\hline $\mathrm{Cs}_{2} \mathrm{SnI}_{6}$ & $\begin{array}{l}\text { FTO/PLD-ZnO seed layer }(40 \mathrm{mM}) / \mathrm{ZnO} \\
\text { nanorods/absorber/P3HT/Ag }\end{array}$ & 0.48 & 1.11 & 37.97 & 0.21 & {$[70]$} \\
\hline $\mathrm{Cs}_{2} \mathrm{SnII}_{6}$ & $\begin{array}{l}\text { FTO/spin coated-ZnO seed layer }(30 \\
\mathrm{mM}) / \mathrm{ZnO} \text { nanorods/absorber/P3HT/Ag }\end{array}$ & 0.42 & 3.08 & 43.06 & 0.56 & {$[70]$} \\
\hline $\mathrm{Cs}_{2} \mathrm{SnI}_{6}$ & FTO/TiO $/$ /absorber/P3HT/Ag & 0.51 & 5.41 & 35 & 0.96 & [71] \\
\hline $\begin{array}{l}\mathrm{CsSnI}_{3}+10 \% \\
\mathrm{SnF}_{2}\end{array}$ & FTO/c-TiO $2 /$ absorber/PTAA/Au & 0.41 & 18 & 46.3 & 3.4 & {$[73]$} \\
\hline $\begin{array}{l}\mathrm{CsSnI}_{3}+10 \% \\
\mathrm{SnCl}_{2}\end{array}$ & FTO/c-TiO $2 /$ absorber/PTAA/Au & 0.43 & 17.4 & 52.3 & 3.9 & {$[73]$} \\
\hline $\begin{array}{l}\mathrm{CsSnI}_{3}+10 \% \\
\mathrm{SnBr}_{2}\end{array}$ & FTO/c-TiO $2 /$ absorber/PTAA/Au & 0.44 & 18.5 & 52.9 & 4.3 & [73] \\
\hline $\begin{array}{l}\mathrm{CsSnI}_{3} \quad+ \\
\text { Hydrazine }\end{array}$ & $\begin{array}{l}\mathrm{FTO} / \mathrm{c}-\mathrm{TiO}_{2} / \mathrm{m}-\mathrm{TiO}_{2} / \text { absorber/ } \\
\text { PTAA:TPFB/Au }\end{array}$ & 0.381 & 25.71 & 49.05 & 4.81 & [74] \\
\hline $\begin{array}{l}\mathrm{CsSnI}_{3}+20 \% \\
\mathrm{SnF}_{2} / \text { Hydrazine }\end{array}$ & $\mathrm{FTO} / \mathrm{c}-\mathrm{TiO}_{2} / \mathrm{m}-\mathrm{TiO}_{2} /$ absorber/PTAA$/ \mathrm{Au}$ & 0.170 & 30.75 & 34.88 & 1.83 & {$[33]$} \\
\hline $\begin{array}{l}\mathrm{CsSnBr}_{3}+20 \% \\
\mathrm{SnF}_{2}\end{array}$ & $\mathrm{FTO} / \mathrm{c}-\mathrm{TiO}_{2} / \mathrm{m}-\mathrm{TiO}_{2} /$ absorber/PTAA$/ \mathrm{Au}$ & 0.367 & 13.96 & 59.36 & 3.04 & {$[33]$} \\
\hline $\begin{array}{l}\mathrm{CsSnBr}_{3}+2.5 \% \\
\mathrm{SnF}_{2}\end{array}$ & ITO/MoO $/$ /absorber $/ \mathrm{C}_{60} / \mathrm{BCP} / \mathrm{Ag}$ & 0.40 & 2.4 & 55 & 0.55 & $\begin{array}{l}{[102} \\
]\end{array}$ \\
\hline $\begin{array}{l}\mathrm{CsSnIBr}_{2}+60 \% \\
\mathrm{SnF}_{2}+\mathrm{H}_{3} \mathrm{PO}_{2}\end{array}$ & $\mathrm{FTO} / \mathrm{c}-\mathrm{TiO}_{2} / \mathrm{m}-\mathrm{TiO}_{2} / \mathrm{m}-\mathrm{Al}_{2} \mathrm{O}_{3} /$ absorber/C & 0.31 & 17.4 & 56 & 3.2 & $\begin{array}{l}{[103} \\
]\end{array}$ \\
\hline $\begin{array}{l}\{\text { en }\} \mathrm{FASnI}_{3}+ \\
15 \% \mathrm{SnF}_{2}\end{array}$ & FTO/c-TiO $/ 2 / \mathrm{m}^{-\mathrm{TiO}_{2} / \text { absorber/PTAA} / \mathrm{Au}}$ & 0.48 & 22.54 & 65.96 & 7.14 & {$[75]$} \\
\hline $\begin{array}{l}\{\text { en }\} \mathrm{MASnI}_{3}+ \\
15 \% \mathrm{SnF}_{2}\end{array}$ & $\mathrm{FTO} / \mathrm{c}-\mathrm{TiO}_{2} / \mathrm{m}-\mathrm{TiO}_{2} /$ absorber/PTAA$/ \mathrm{Au}$ & 0.428 & 24.28 & 63.72 & 6.63 & [76] \\
\hline $\begin{array}{l}\{\text { en }\} \mathrm{FASnI}_{3}+ \\
15 \% \mathrm{SnF}_{2}\end{array}$ & $\mathrm{FTO} / \mathrm{c}-\mathrm{TiO}_{2} / \mathrm{m} \mathrm{TiO}_{2} /$ absorber/TPE$/ \mathrm{Au}$ & 0.459 & 22.54 & 69.74 & 7.23 & [77] \\
\hline
\end{tabular}




\begin{tabular}{|c|c|c|c|c|c|c|}
\hline$\{$ en $\} \mathrm{FASnI}_{3}$ & $\mathrm{FTO} / \mathrm{c}-\mathrm{TiO}_{2} / \mathrm{m}-\mathrm{TiO}_{2} /$ absorber/PTAA$/ \mathrm{Au}$ & 0.47 & 22.36 & 65.49 & 6.89 & [78] \\
\hline$\{$ en $\} \mathrm{FASnI}_{3}$ & $\begin{array}{l}\mathrm{FTO} / \mathrm{c}-\mathrm{TiO}_{2} / \mathrm{m}-\mathrm{TiO}_{2} / \text { absorber/Spiro- } \\
\text { OMeTAD/Au }\end{array}$ & 0.36 & 19.11 & 54.44 & 3.76 & [78] \\
\hline$\{$ en $\} \mathrm{FASnI}_{3}$ & FTO/c- $-\mathrm{TiO}_{2} / \mathrm{m}_{-} \mathrm{TiO}_{2} /$ absorber/BDT-2D/Au & 0.42 & 22.19 & 53.80 & 5.04 & [78] \\
\hline$\{$ en $\} \mathrm{FASnI}_{3}$ & FTO/c- $\mathrm{TiO}_{2} / \mathrm{m}_{-}-\mathrm{TiO}_{2} /$ absorber/BDT-4D/Au & 0.497 & 22.41 & 68.21 & 7.59 & [78] \\
\hline $\mathrm{FA}_{0.75} \mathrm{MA}_{0.25} \mathrm{SnI}_{3}$ & ITO/PEDOT:PSS/absorber/C ${ }_{60} / \mathrm{BCP} / \mathrm{Ag}$ & 0.55 & 19.4 & 67 & 7.2 & [79] \\
\hline $\begin{array}{l}(\mathrm{FA})_{0.75}(\mathrm{MA})_{0.25} \mathrm{~S} \\
\mathrm{nI}_{3}+10 \% \mathrm{SnF}_{2}\end{array}$ & ITO/PEDOT:PSS/absorber/C ${ }_{60} / \mathrm{BCP} / \mathrm{Ag}$ & 0.61 & 21.2 & 62.7 & 8.12 & [80] \\
\hline $\begin{array}{l}(\mathrm{FA})_{0.5}(\mathrm{MA})_{0.5} \mathrm{SnI} \\
3+10 \% \mathrm{SnF}_{2}\end{array}$ & ITO/PEDOT:PSS/absorber/C ${ }_{60} / \mathrm{BCP} / \mathrm{Ag}$ & 0.53 & 21.3 & 52.4 & 5.92 & [80] \\
\hline $\begin{array}{l}(\mathrm{FA})_{0.25}(\mathrm{MA})_{0.75} \mathrm{~S} \\
\mathrm{nI}_{3}+10 \% \mathrm{SnF}_{2}\end{array}$ & ITO/PEDOT:PSS/absorber/C ${ }_{60} / \mathrm{BCP} / \mathrm{Ag}$ & 0.48 & 20.7 & 45.2 & 4.49 & [80] \\
\hline $\mathrm{FA}_{0.75} \mathrm{MA}_{0.25} \mathrm{SnI}_{3}$ & ITO/PEDOT:PSS/absorber/C $60 / \mathrm{BCP} / \mathrm{Al}$ & 0.55 & 24.3 & 67.3 & 9.06 & [81] \\
\hline $\begin{array}{l}\mathrm{GA}_{\mathrm{x}} \mathrm{FA}_{1-\mathrm{x}-2 \mathrm{y}} \mathrm{SnI}_{3}- \\
\mathrm{yEDAI}_{2}\end{array}$ & ITO/PEDOT:PSS/absorber/C ${ }_{60} / \mathrm{BCP} / \mathrm{Ag}$ & 0.619 & 21.2 & 72.9 & 9.6 & {$[84]$} \\
\hline $\begin{array}{l}\mathrm{FA}_{0.98} \mathrm{EDA}_{0.01} \mathrm{SnI}_{3} \\
+\quad 0.05 \mathrm{mM} \\
\text { edamine }\end{array}$ & ITO/PEDOT:PSS/absorber/C ${ }_{60} / \mathrm{BCP} / \mathrm{Ag}$ & 0.56 & 22.80 & 74 & 9.37 & [85] \\
\hline $\mathrm{FA}_{0.75} \mathrm{MA}_{0.25} \mathrm{SnI}_{3}$ & FTO/c-TiO $2 /$ absorber/PTAA/Au & 0.26 & 17.4 & 42 & 1.85 & $\begin{array}{l}{[104} \\
]\end{array}$ \\
\hline $\mathrm{MA}_{0.9} \mathrm{Cs}_{0.1} \mathrm{SnI}_{3}$ & $\begin{array}{l}\text { ITO/PEDOT:PSS/absorber/PCBM/bis- } \\
\mathrm{C}_{60} / \mathrm{Ag}\end{array}$ & 0.20 & 4.53 & 36.4 & 0.33 & [98] \\
\hline $\mathrm{FA}_{0.8} \mathrm{Cs}_{0.2} \mathrm{SnI}_{3}$ & $\begin{array}{l}\text { ITO/PEDOT:PSS/absorber/PCBM/bis- } \\
\mathrm{C}_{60} / \mathrm{Ag}\end{array}$ & 0.24 & 16.05 & 35.8 & 1.38 & [98] \\
\hline $\begin{array}{l}\{\mathrm{TN}\} \mathrm{FASnI}_{3}+ \\
15 \% \mathrm{SnF}_{2}\end{array}$ & $\mathrm{FTO} / \mathrm{c}-\mathrm{TiO}_{2} / \mathrm{m}-\mathrm{TiO}_{2} /$ absorber/PTAA$/ \mathrm{Au}$ & 0.40 & 22.72 & 61.04 & 5.53 & $\begin{array}{l}{[105} \\
]\end{array}$ \\
\hline $\begin{array}{l}\{\mathrm{PN}\} \mathrm{FASnI}_{3}+ \\
15 \% \mathrm{SnF}_{2}\end{array}$ & $\mathrm{FTO} / \mathrm{c}-\mathrm{TiO}_{2} / \mathrm{m}-\mathrm{TiO}_{2} /$ absorber/PTAA$/ \mathrm{Au}$ & 0.44 & 22.15 & 60.67 & 5.85 & $\begin{array}{l}{[105} \\
]\end{array}$ \\
\hline
\end{tabular}

\section{Fabrication challenges of tin-based lead-free perovskite thin films}

It was observed that in the perovskite lattice, tin can be fruitfully substituted in place of lead. This approach however, has not resulted in a similar performance of tin-based lead-free perovskite solar cells with those of lead counterparts till date. This 'not up to the mark' performance might have emanated due to several factors like substandard electronic properties, poor film quality, and most significantly the poor stability originating from the natural oxidative conversion of $\mathrm{Sn}^{2+}$ to $\mathrm{Sn}^{4+}$. The solar cells containing tin-based lead-free perovskite thin films as absorbers are generally fabricated in an inert environment that heaves the apprehension about the real-life feasibility 
of the approach. Further, the fabrication of such devices in an ambient atmosphere is not viable. For the enhancement of the film quality, a variety of strategies like hybrid deposition, gas pumping treatment, use of additives [103-106], etc. is offered by various researchers. But these strategies resulted in unsatisfactory PCEs that disclose the incompetence of such efforts. The poor film quality and the chemical composition together result in substandard electronic properties of tin-based lead-free perovskites as compared to lead analogs. The tin perovskite films are commonly inundated with large number of extremely small crystallite domains and large grain boundaries [107] acting as trap states that in turn result in improved recombination and reduced charge separation and transport [48]. Although the tin-based lead-free perovskites have narrower bandgap as compared to lead analogs, the interband transfer of charges is restricted by effectual masses anisotropy of electrons and holes emanated due to the orbitals making up the electronic bands [108]. Furthermore, the easy oxidation of $\mathrm{Sn}^{2+}$ to $\mathrm{Sn}^{4+}$ creates superfluous tin vacancies and p-doping in the perovskite film that makes it difficult to effectively control the conductivity of the material that results in poor stability of tin-based lead-free perovskite solar cells in ambient conditions [30, 109]. Frequent efforts were made to restrain $\mathrm{Sn}^{2+}$ to $\mathrm{Sn}^{4+}$ oxidation like using $\mathrm{SnF}_{2}$ or other additives and synthesizing mixed tin and lead perovskites [110-112], but the resultant thin films and solar cell devices were still found to be low-grade than lead analogs.

\section{a. Challenges in Solution Processing}

A variety of methods have been used until now for the fabrication of perovskite films that includes spin coating, dip coating, doctor blading, inkjet printing and vapour deposition [113]. Amongst these, the technique that is frequently employed for fabricating perovskite films is spin coating where a glove box is utilized. The glove box is filled with $\mathrm{N}_{2}$ gas for creating a shield environment that prevents moisture as well as oxygen so that they cannot penetrate into Sn-based perovskite thin film. But this technique however causes a considerable waste of materials that in turn increases the cost of the process. So, the large-scale fabrication of perovskite films cannot employ spin coating as it will become unsuitable. In addition, the conventional fabrication methods of lead-based perovskite films are not compatible in case of tin-based perovskite thin films due to the rapid crystallization of $\mathrm{MASnI}_{3}$ [114]. An intermediate-phase $\mathrm{SnI}_{2} \cdot 3 \mathrm{DMSO}$ was found to adequately resolve this trouble by employing DMSO and NMP as solvents. It was investigated that the easy conversion of $\mathrm{Sn}^{2+}$ to $\mathrm{Sn}^{4+}$ in ambient air can annihilate the perovskite structure $[115,116]$ and this has restricted their studies. $\mathrm{Cs}_{2} \mathrm{SnI}_{6}$ is however an exception to this because of $\mathrm{Sn}^{4+}$ oxidation state that makes it remarkably stable in ambient air atmosphere [117, 118]. But it is still not appropriate as an absorber in solar cell and exhibits much less PCE due to the n-type nature of pristine $\mathrm{Cs}_{2} \mathrm{SnI}_{6}$.

\section{b. Challenges in Vacuum Thermal Evaporation Processing}

Investigations revealed that it is effortless to deposit MAI, FAI, MABr, $\mathrm{SnBr}_{2}$ and $\mathrm{SnI}_{2}$ on a substrate via vapour deposition [113]. But the deposition of high-quality films of tin-based lead-free perovskites is quite a challenging task. Xi et al. [101] reported a water-related multichannel interdiffusion protocol for $\mathrm{FASnI}_{3}$-based $\mathrm{PHJ}$ (planar heterojunction) solar cell devices that demonstrated a best PCE of 3.98\%. This environmental friendly protocol drastically promoted uniform film coverage and crystallinity by individually manipulating FAI/PEDOT: PSS and

$\mathrm{SnI}_{2}$ layers. Moreover, the device accumulated on polyethylene naphthalate (PEN)-ITO flexible substrate demonstrated PCE of $3.12 \%$. Moghe et al. [102] demonstrated an alternate procedure for fabricating planar $\mathrm{CsSnBr}_{3}$ 
incorporated photovoltaic cells with excellent stability in air. The results illustrated that the synthesized films can be doped by thermal vapor deposition that would consequently enhance the quantum efficiency and the overall performance of the device. Best results were obtained with $2.5 \mathrm{~mol} \%$ of the fluoride dopant where films retained the same absorption value over 24 hours and the fabricated devices retained $80 \%$ of their performance over 50 minutes. Accordingly, Jung et al. [87] reported the preparation of $\mathrm{MASnBr}_{3}$ films using two procedures. It was observed that the films synthesized by the first method i.e. co-evaporation resulted in much less PCEs $(0.03-0.35 \%)$ caused by comparatively higher resistances as well as due to rapidly formed oxide of $\mathrm{Sn}-\mathrm{Br}$ over the top layer because of air exposure. However, solar cells fabricated using the other method i.e. sequential evaporation exhibited enhanced performance resulting in PCE of $1.12 \%$. The better performance was due to the top MABr layer that prevented the air-induced oxidation resulting in higher efficiencies.

\section{c. Other Preparation Processes}

In order to effectively manage the growth of $\mathrm{MASnI}_{3}$ films, Yokoyama et al. [86] utilized a low-temperature vapourassisted solution process (LT-VASP). It was confirmed that the film morphology and reproducibility of the solar cell devices can show a drastic improvement by modifying the conventional vapour-assisted solution process (VASP) resulting in $1.86 \%$ PCE. Weiss et al. [119] fabricated $\mathrm{MASnI}_{3}$ perovskite films by utilizing a two-step method. The first step employs vapour deposition for preparing $\mathrm{SnI}_{2}$ film which was then transformed to $\mathrm{MASnI}_{3}$ films in the second step by reacting with MAI via spin coating process. Investigation revealed that it is possible to control the morphology of $\mathrm{MASnI}_{3}$ by adjusting MAI concentration. Fig. 16 demonstrates various fabrication processes described above.

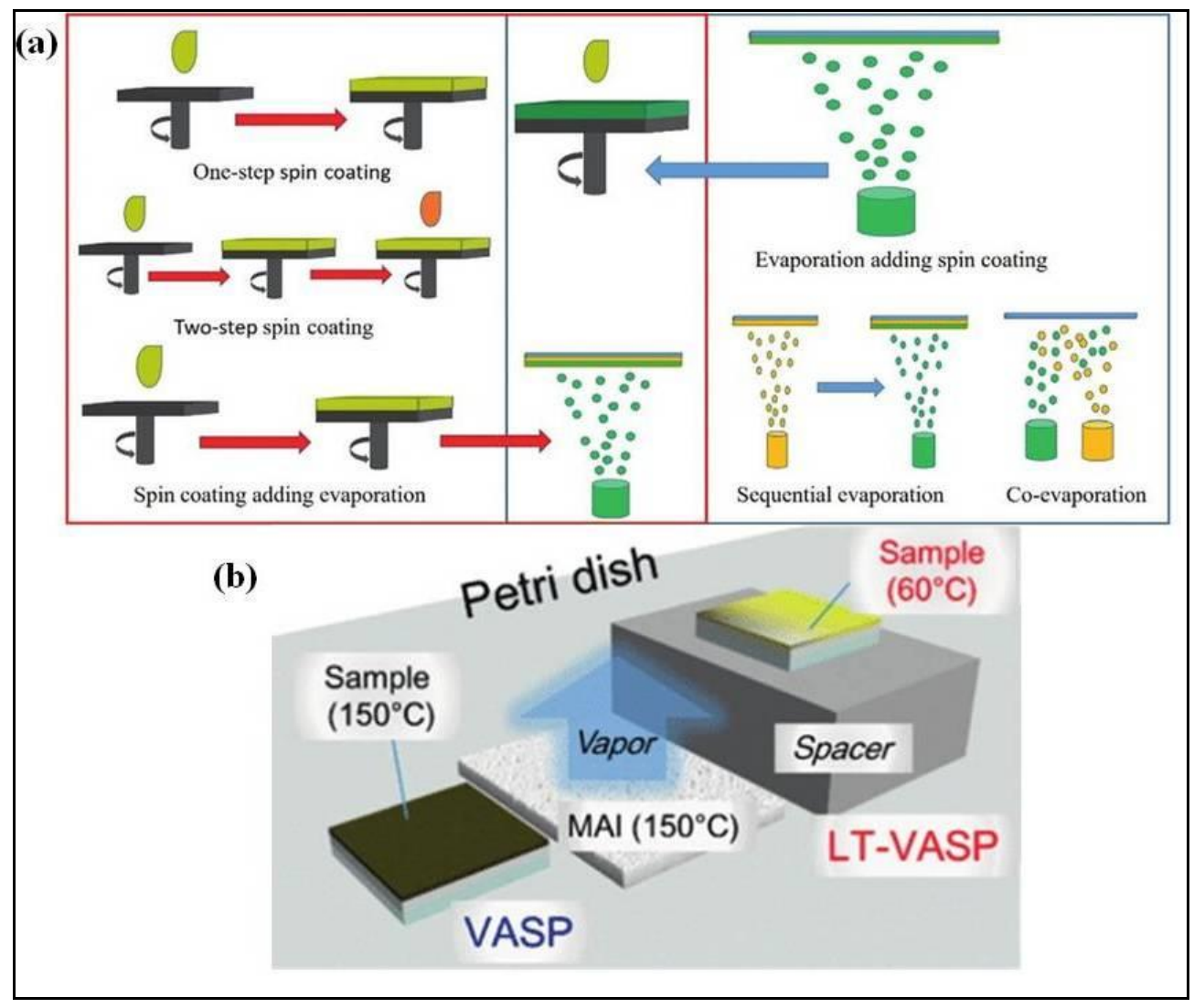


Fig. 16 Schematic representation of (a) Spin-coating and evaporation process, (b) Vapour-assisted solution process (VASP) and low-temperature VASP (LT-VASP) fabrication techniques. Reproduced from [113] with permission. Copyright 2019, Cell Press.

\section{Material stability}

Sn-based lead-free perovskite solar cells have emerged to be a hopeful candidate for achieving high performance. However, in comparison to lead-based perovskite solar cells, these materials have significantly worse stability. Neverthless, a variety of approaches were utilized in the recent years to boost the stability and enhance the PCE of tin-based perovskite solar cells simultaneously. The $\mathrm{MASnI}_{3}$ based solar cell prepared with $20 \% \mathrm{SnF}_{2}$, demonstrated a PCE of $1.94 \%$ and showed almost no drop in the conversion efficiency during 146 days [34]. Through tin-fluorideassisted heterogeneous nucleation, $\mathrm{MASnIBr}_{2}$ based solar cell with $30 \mathrm{~mol}^{2} \mathrm{SnF}_{2}$ exhibited a PCE of $3.7 \%$ and good stability. The solar cell maintained over $80 \%$ of its initial efficiency after storing in nitrogen-filled glove box for 60 days [35]. The stability of $\mathrm{MASnI}_{3}$ based solar cell can also be improved through ion exchange/insertion reactions. The process resulted in high PCE of $7.78 \%$ along with high reproducibility and good stability [38]. Other techniques that have been utilized in the recent years to improve the stability of methylammonium tin halide perovskites include low-temperature vapor-assisted solution process [92] and co-crystallization of three halides [93]. A good stability for over 100 days under ambient condition was observed for encapsulated $\mathrm{FASnI}_{3}$ cells that were fabricated using solvent-engineering and non-solvent dripping process [44]. $10 \% \mathrm{SnF}_{2}$ and pyrazine were also used and the process resulted in PCE of $4.8 \%$. Slow surface passivation process where $1 \% \mathrm{EDAI}_{2}$ was employed in $\mathrm{FASnI}_{3}$ solar cell resulted in a high PCE of 8.9\% [50]. The device maintained this efficiency even for $2000 \mathrm{~h}$ of storage. This excellent stability was due to the presence of $\mathrm{EDAI}_{2}$ that slowly relaxed the crystal strain of the perovskite. Most recently, a usual anti-solvent method resulted in excellent shelf stability of $\mathrm{PEA}_{\mathrm{x}} \mathrm{FA}_{1-\mathrm{x}} \mathrm{SnI}_{3}$ based solar cell where $\mathrm{NH}_{4} \mathrm{SCN}$ was used as additive and ICBA was utilized as ETL in place of traditionally used PCBM ETL. Moreover, high PCE of $12.4 \%$ was obtained in the process and the device maintained $90 \%$ of the initial efficiency for over 3800 hours [62]. In another study, where $\pi$-conjugated Lewis base strategy was employed using CDTA for the fabrication of $\mathrm{FASnI}_{3}$ based solar cell, the device showed a PCE of $10.32 \%$ and maintained over $90 \%$ of its initial PCE [64]. Other techniques that have been observed to be successful to improve the stability of formamidinium tin halide perovskites include tin source purification [49], bilateral interfacial engineering strategy [53], orientation regulation process [57], anti-solvent-free spin-coating and inkjet printing [58], bidentate coordination strategy [60], intercalation of PEG into PEDOT:PSS layer [100], etc. $\mathrm{CsSnI}_{3}$ based solar cell with 10\% $\mathrm{SnCl}_{2}$ which was fabricated without any HTL demonstrated good stability and efficiency of 3.56\% [25]. Using 10\% $\mathrm{SnBr}_{2}, \mathrm{CsSnI}_{3}$ based solar cell achieved $4.3 \%$ efficiency and excellent stability [73]. Further, reducing vapor atmosphere method [33] and vapor deposition method [102] were also found to be helpful to improve the stability of $\mathrm{CsSnBr}_{3}$ based devices using $\mathrm{SnF}_{2}$ as additive, but the obtained efficiencies were however less in both of these techniques. In addition to the MA, FA and Cs cation, the mixed cation based solar cells were also studied and demonstrated effectual stability and efficiency. The $\{$ en $\}$ cation when utilized along with FA and MA cations in the perovskite solar cells demonstrated excellent air stabilities [75, 76]. Moreover, a mixture of FA and MA cations can 
also be utilized to enhance the stability as well as efficiency of tin-based lead-free perovskite solar cells. An antisolvent dripping method was employed for the fabrication of $\mathrm{FA}_{0.75} \mathrm{MA}_{0.25} \mathrm{SnI}_{3}$ based solar cell [81]. The resulting device showed high PCE of $9.06 \%$ and retained $75 \%$ of the initial efficiency for 30 days of storage for the encapsulated cells and thus depicting a long-term stability. A non-polar guanidinium $\left(\mathrm{GA}^{+}\right)$cation was incorporated in various proportions, along with $1 \% \mathrm{EDAI}_{2}$ as an additive in $\mathrm{FASnI}_{3}$ structure [84]. By optimizing the GAI:FAI ratio to $20: 80$, PCE of $8.5 \%$ was achieved with the freshly prepared precursor solution and it increased regularly after storing for $2000 \mathrm{~h}$ in glove-box, reaching maximum efficiency of $9.6 \%$. The device passed all harsh standard tests indicating its extraordinary performance in photovoltaics. Similarly, like \{en $\}$ and GA cations, other cations can also be utilized to form mixed cation tin-based lead-free perovskites to improve the stability of solar cells. The progress in the stability of various reported Sn-based solar cells during different years from 2014 till now, have been summarized in Table 2.

Table 2: Stability test results of reported Sn-based lead-free perovskite solar cells.

\begin{tabular}{|c|c|c|c|c|c|}
\hline Absorbers & Device architecture & Technique used & Stability & Year & Ref. \\
\hline $\begin{array}{l}\mathrm{MASnI}_{3}+20 \% \\
\mathrm{SnF}_{2} / \text { Hydrazine }\end{array}$ & 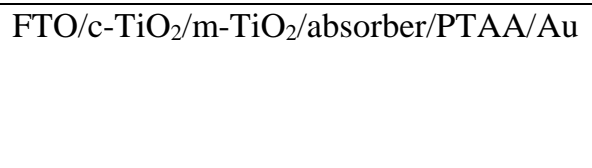 & $\begin{array}{l}\text { Reducing vapor } \\
\text { atmosphere } \\
\text { method }\end{array}$ & $\begin{array}{l}\text { Unstable in } \\
\text { air }\end{array}$ & 2017 & {$[33]$} \\
\hline $\begin{array}{l}\mathrm{MASnI}_{3}+20 \% \\
\mathrm{SnF}_{2}\end{array}$ & $\mathrm{FTO} / \mathrm{c}-\mathrm{TiO}_{2} / \mathrm{m}-\mathrm{TiO}_{2} /$ absorber/PTAA$/ \mathrm{Au}$ & - & $\begin{array}{l}\text { Good long- } \\
\text { term } \\
\text { stability }\end{array}$ & 2017 & [34] \\
\hline $\begin{array}{l}\mathrm{MASnIBr}_{2}+30 \% \\
\mathrm{SnF}_{2}\end{array}$ & $\begin{array}{l}\mathrm{FTO} / \mathrm{c}-\mathrm{TiO}_{2} / \mathrm{m}-\mathrm{TiO}_{2} / \text { absorber/Spiro- } \\
\mathrm{OMeTAD} / \mathrm{Au}\end{array}$ & $\begin{array}{l}\text { Tin-fluoride } \\
\text { assisted } \\
\text { heterogeneous } \\
\text { nucleation }\end{array}$ & $\begin{array}{l}\text { Good } \\
\text { stability }\end{array}$ & 2018 & {$[35]$} \\
\hline $\operatorname{MASn}\left(\mathrm{I}_{0.33} \mathrm{Br}_{0.67}\right)_{3}$ & $\begin{array}{l}\mathrm{FTO} / \mathrm{c}-\mathrm{TiO}_{2} / \mathrm{m}_{-} \mathrm{TiO}_{2} / \text { absorber/Spiro- } \\
\text { OMeTAD/Au }\end{array}$ & $\begin{array}{l}\text { Solvent } \\
\text { optimization }\end{array}$ & $\begin{array}{l}\text { Poor } \\
\text { stability }\end{array}$ & 2019 & {$[36]$} \\
\hline $\mathrm{MASnI}_{3}$ & ITO/PEDOT:PSS/absorber/PC ${ }_{60} \mathrm{BM} / \mathrm{Ag}$ & $\begin{array}{l}\text { Ion } \\
\text { exchange/inserti } \\
\text { on reactions }\end{array}$ & $\begin{array}{l}\text { Good } \\
\text { stability }\end{array}$ & 2020 & {$[38]$} \\
\hline $\mathrm{MASnI}_{3}$ & 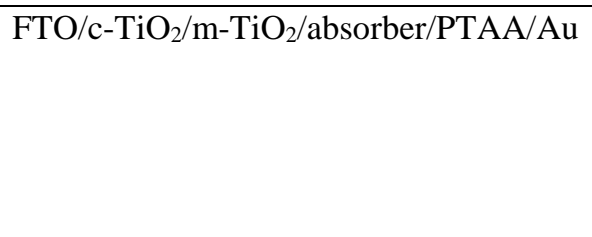 & $\begin{array}{l}\text { Low- } \\
\text { temperature } \\
\text { vapor-assisted } \\
\text { solution process }\end{array}$ & $\begin{array}{l}\text { Better } \\
\text { stability }\end{array}$ & 2016 & {$[86]$} \\
\hline $\mathrm{MASnI}_{3}$ & $\begin{array}{l}\mathrm{FTO} / \mathrm{c}-\mathrm{TiO}_{2} / \mathrm{m}-\mathrm{TiO}_{2} / \text { absorber/Spiro- } \\
\text { OMeTAD/Au }\end{array}$ & $\begin{array}{l}\text { Atomic layer } \\
\text { deposition }\end{array}$ & $\begin{array}{l}\text { Poor } \\
\text { stability }\end{array}$ & 2014 & {$[88]$} \\
\hline $\mathrm{MASnBr}_{3}$ & ITO/c- $-\mathrm{TiO}_{2} / \mathrm{m}-\mathrm{TiO}_{2} /$ absorber/PTAA/Au & Low- & Better air & 2017 & [92] \\
\hline
\end{tabular}




\begin{tabular}{|c|c|c|c|c|c|}
\hline & & $\begin{array}{l}\text { temperature } \\
\text { vapor-assisted } \\
\text { solution process }\end{array}$ & stability & & \\
\hline $\begin{array}{l}\mathrm{MASnIBr}_{1.8} \mathrm{Cl}_{0.2}+ \\
20 \% \mathrm{SnF}_{2}\end{array}$ & $\begin{array}{l}\mathrm{FTO} / \mathrm{c}-\mathrm{TiO}_{2} / \mathrm{m}-\mathrm{TiO}_{2} / \mathrm{m}- \\
\mathrm{Al}_{2} \mathrm{O}_{3} / \text { absorber/C }\end{array}$ & $\begin{array}{l}\text { Co- } \\
\text { crystallization } \\
\text { of three halides }\end{array}$ & $\begin{array}{l}\text { Good long- } \\
\text { term } \\
\text { stability }\end{array}$ & 2017 & {$[93]$} \\
\hline $\begin{array}{l}\mathrm{FASnI}_{3}+10 \% \\
\mathrm{SnF}_{2}\end{array}$ & ITO/PEDOT:PSS/absorber/C $60 / \mathrm{BCP} / \mathrm{Ag}$ & $\begin{array}{l}\text { Anti-solvent } \\
\text { dripping } \\
\text { technique }\end{array}$ & $\begin{array}{l}\text { Good long- } \\
\text { term } \\
\text { illuminatio } \\
\text { n stability }\end{array}$ & 2016 & {$[40]$} \\
\hline $\mathrm{FASnI}_{2} \mathrm{Br}$ & ITO/PEDOT:PSS/absorber/C60/Ca/Al & $\begin{array}{l}\text { Low- } \\
\text { temperature } \\
\text { processing } \\
\text { method }\end{array}$ & $\begin{array}{l}\text { Poor } \\
\text { stability }\end{array}$ & 2016 & {$[41]$} \\
\hline $\begin{array}{l}\mathrm{FASnI}_{3}+10 \% \\
\mathrm{SnF}_{2}+\mathrm{TMA}\end{array}$ & $\begin{array}{l}\text { ITO/PEDOT:PSS/absorber/C }{ }_{60} / \text { bis- } \\
\mathrm{C}_{60} / \mathrm{Ag}\end{array}$ & $\begin{array}{l}\text { Sequential two } \\
\text { step deposition } \\
\text { route }\end{array}$ & $\begin{array}{l}\text { Unsatisfact } \\
\text { ory } \\
\text { stability in } \\
\text { ambient } \\
\text { environme } \\
\text { nt }\end{array}$ & 2018 & {$[43]$} \\
\hline $\begin{array}{l}\mathrm{FASnI}_{3}+10 \% \\
\mathrm{SnF}_{2}+\text { pyrazine }\end{array}$ & $\begin{array}{l}\mathrm{FTO} / \mathrm{c}-\mathrm{TiO}_{2} / \mathrm{m}-\mathrm{TiO}_{2} / \text { absorber/Spiro- } \\
\text { OMeTAD/Au }\end{array}$ & $\begin{array}{l}\text { Solvent- } \\
\text { engineering and } \\
\text { non-solvent } \\
\text { dripping process }\end{array}$ & $\begin{array}{l}\text { Excellent } \\
\text { long-term } \\
\text { stability }\end{array}$ & 2016 & {$[44]$} \\
\hline $\begin{array}{l}\mathrm{FASnI}_{3}+10 \% \\
\mathrm{SnF}_{2}+20 \% \text { PEA }\end{array}$ & ITO/NiO/absorber/PCBM/Al & - & $\begin{array}{l}\text { Good } \\
\text { stability }\end{array}$ & 2017 & {$[45]$} \\
\hline $\begin{array}{l}0.92 \mathrm{FASnI}_{3}+ \\
0.08 \mathrm{PEA}+10 \% \\
\mathrm{SnF}_{2}\end{array}$ & ITO/PEDOT:PSS/absorber/C $60 / \mathrm{BCP} / \mathrm{Al}$ & $\begin{array}{l}\text { Mixing of } 2 \mathrm{D} \\
\text { perovskite with } \\
\text { 3D perovskite }\end{array}$ & $\begin{array}{l}\text { Better } \\
\text { stability }\end{array}$ & 2018 & {$[46]$} \\
\hline $\mathrm{FASnI}_{3}$ & ITO/PEDOT:PSS/absorber/C ${ }_{60} / \mathrm{BCP} / \mathrm{Ag}$ & $\begin{array}{l}\text { Tin source } \\
\text { purification }\end{array}$ & $\begin{array}{l}\text { Good } \\
\text { stability }\end{array}$ & 2018 & {$[49]$} \\
\hline $\begin{array}{l}\mathrm{FASnI}_{3}+1 \% \\
\mathrm{EDAI}_{2}\end{array}$ & ITO/PEDOT:PSS/absorber/C $60 / \mathrm{BCP} / \mathrm{Ag}$ & $\begin{array}{l}\text { Slow surface } \\
\text { passivation }\end{array}$ & $\begin{array}{l}\text { Excellent } \\
\text { stability }\end{array}$ & 2018 & {$[50]$} \\
\hline $\begin{array}{l}\mathrm{FASnI}_{3}+5 \% \\
\text { FASCN }\end{array}$ & ITO/PEDOT:PSS/absorber/PC ${ }_{60} \mathrm{BM} / \mathrm{Al}$ & - & $\begin{array}{l}\text { Good } \\
\text { stability }\end{array}$ & 2018 & {$[51]$} \\
\hline$(\mathrm{PEA}, \mathrm{FA}) \mathrm{SnI}_{3}$ & LiF/PEDOT:PSS/absorber/C $60 / \mathrm{BCP} / \mathrm{Ag}$ & $\begin{array}{l}\text { Bilateral } \\
\text { interfacial }\end{array}$ & $\begin{array}{l}\text { Good } \\
\text { stability }\end{array}$ & 2018 & {$[53]$} \\
\hline
\end{tabular}




\begin{tabular}{|c|c|c|c|c|c|}
\hline & & $\begin{array}{l}\text { engineering } \\
\text { strategy }\end{array}$ & & & \\
\hline $\mathrm{FASnI}_{3}+\mathrm{PTN}-\mathrm{Br}$ & ITO/PEDOT:PSS/absorber/C60/BCP/Ag & - & $\begin{array}{l}\text { Moderate } \\
\text { UV } \\
\text { stability }\end{array}$ & 2019 & {$[56]$} \\
\hline $\begin{array}{l}\mathrm{AVA}_{2} \mathrm{FA}_{\mathrm{n}-1} \mathrm{Sn}_{\mathrm{n}} \mathrm{I}_{3 \mathrm{n}} \\
+1(<\mathrm{n}>=5)+ \\
10 \% \mathrm{NH}_{4} \mathrm{Cl}\end{array}$ & $\begin{array}{l}\text { ITO/PEDOT:PSS/absorber/PCBM/BCP/ } \\
\mathrm{Ag}\end{array}$ & $\begin{array}{l}\text { Orientation } \\
\text { regulation } \\
\text { process }\end{array}$ & $\begin{array}{l}\text { Excellent } \\
\text { long-term } \\
\text { stability }\end{array}$ & 2019 & {$[57]$} \\
\hline $\mathrm{FASnI}_{3}$ & ITO/PEDOT:PSS/absorber/PC ${ }_{71} \mathrm{BM} / \mathrm{Ag}$ & $\begin{array}{l}\text { Anti-solvent- } \\
\text { free spin- } \\
\text { coating and } \\
\text { inkjet printing }\end{array}$ & $\begin{array}{l}\text { Good } \\
\text { stability }\end{array}$ & 2020 & {$[58]$} \\
\hline $\mathrm{FASnI}_{3}+8-\mathrm{HQ}$ & $\begin{array}{l}\text { ITO/PEDOT:PSS/absorber/PCBM/BCP/ } \\
\mathrm{Ag}\end{array}$ & $\begin{array}{l}\text { Bidentate } \\
\text { Coordination } \\
\text { strategy }\end{array}$ & $\begin{array}{l}\text { Excellent } \\
\text { stability }\end{array}$ & 2020 & {$[60]$} \\
\hline $\mathrm{FASnI}_{3}+\mathrm{EVA}$ & $\begin{array}{l}\text { ITO/PEDOT:PSS/absorber/PC }{ }_{61} \mathrm{BM} / \mathrm{BC} \\
\mathrm{P} / \\
\mathrm{Ag}\end{array}$ & $\begin{array}{l}\text { Regulated } \\
\text { crystallization } \\
\text { via self-sealing } \\
\text { polymer }\end{array}$ & $\begin{array}{l}\text { Moderate } \\
\text { stability }\end{array}$ & 2020 & {$[61]$} \\
\hline $\begin{array}{l}\mathrm{PEA}_{\mathrm{x}} \mathrm{FA}_{1-\mathrm{x}} \mathrm{SnI}_{3}+ \\
\mathrm{NH}_{4} \mathrm{SCN}\end{array}$ & $\begin{array}{l}\text { ITO/PEDOT:PSS/absorber/ICBA/BCP/ } \\
\mathrm{Ag}\end{array}$ & $\begin{array}{l}\text { Usual anti- } \\
\text { solvent method }\end{array}$ & $\begin{array}{l}\text { Excellent } \\
\text { shelf } \\
\text { stability }\end{array}$ & 2020 & {$[62]$} \\
\hline $\mathrm{FASnI}_{3}+\mathrm{CDTA}$ & ITO/PEDOT:PSS/absorber/C60/BCP/Ag & $\begin{array}{l}\pi \text {-conjugated } \\
\text { Lewis base } \\
\text { strategy }\end{array}$ & $\begin{array}{l}\text { Excellent } \\
\text { stability }\end{array}$ & 2020 & [64] \\
\hline $\mathrm{FASnI}_{3}+5 \% \mathrm{AHP}$ & ITO/CuSCN/absorber/PCBM/Ag & - & $\begin{array}{l}\text { Good long- } \\
\text { term } \\
\text { stability }\end{array}$ & 2019 & {$[65]$} \\
\hline $\begin{array}{l}\mathrm{FASnI}_{3}+2.5 \% \\
\mathrm{~N}_{2} \mathrm{H}_{5} \mathrm{Cl}+10 \% \\
\mathrm{SnF}_{2}\end{array}$ & $\begin{array}{l}\text { ITO/PEDOT:PSS/absorber/PCBM/BCP/ } \\
\mathrm{Ag}\end{array}$ & $\begin{array}{l}\text { Co-additive } \\
\text { engineering } \\
\text { process }\end{array}$ & $\begin{array}{l}\text { Better } \\
\text { stability }\end{array}$ & 2018 & [99] \\
\hline $\begin{array}{l}\mathrm{FASnI}_{3}+12 \% \\
\mathrm{SnF}_{2}\end{array}$ & $\begin{array}{l}\text { FTO/PEDOT:PSS(PEG)/Absorber/PCB } \\
\text { M/BCP/Ag }\end{array}$ & $\begin{array}{l}\text { Intercalation of } \\
\text { PEG into } \\
\text { PEDOT:PSS }\end{array}$ & $\begin{array}{l}\text { Good } \\
\text { stability }\end{array}$ & 2018 & $\begin{array}{l}{[10} \\
0]\end{array}$ \\
\hline $\mathrm{FASnI}_{3}$ & ITO/PEDOT:PSS/absorber/C60/BCP/Ag & $\begin{array}{l}\text { Multichannel } \\
\text { interdiffusion } \\
\text { protocol }\end{array}$ & $\begin{array}{l}\text { Poor } \\
\text { stability }\end{array}$ & 2017 & $\begin{array}{l}{[10} \\
1]\end{array}$ \\
\hline
\end{tabular}




\begin{tabular}{|c|c|c|c|c|c|}
\hline $\begin{array}{l}\mathrm{CsSnBr}_{3}+20 \% \\
\mathrm{SnF}_{2}\end{array}$ & $\begin{array}{l}\mathrm{FTO} / \mathrm{c}-\mathrm{TiO}_{2} / \mathrm{m}-\mathrm{TiO}_{2} / \text { absorber/Spiro- } \\
\text { OMeTAD/Au }\end{array}$ & - & $\begin{array}{l}\text { Instable } \\
\text { under } \\
\text { ambient air }\end{array}$ & 2016 & [68] \\
\hline $\begin{array}{l}\mathrm{CsSnI}_{3}+10 \% \\
\mathrm{SnCl}_{2}\end{array}$ & ITO/Absorber/PC ${ }_{61} \mathrm{BM} / \mathrm{BCP} / \mathrm{Al}$ & $\begin{array}{l}\text { HTL-free } \\
\text { protocol }\end{array}$ & $\begin{array}{l}\text { Excellent } \\
\text { stability }\end{array}$ & 2016 & [25] \\
\hline $\begin{array}{l}\mathrm{CsSnI}_{3}+10 \% \\
\mathrm{SnCl}_{2}\end{array}$ & ITO/Absorber/PC ${ }_{61} \mathrm{BM} / \mathrm{BCP} / \mathrm{Al}$ & $\begin{array}{l}\text { Solvothermal } \\
\text { synthesis of } \\
\text { quantum rods }\end{array}$ & $\begin{array}{l}\text { Moderate } \\
\text { stability }\end{array}$ & 2016 & [29] \\
\hline $\begin{array}{l}\mathrm{CsSnI}_{3}+10 \% \\
\mathrm{SnF}_{2}\end{array}$ & FTO/c- $\mathrm{TiO}_{2} /$ absorber/PTAA/Au & - & $\begin{array}{l}\text { Stability } \\
\text { degraded } \\
\text { quickly } \\
\text { over time }\end{array}$ & 2018 & [73] \\
\hline $\begin{array}{l}\mathrm{CsSnI}_{3}+10 \% \\
\mathrm{SnCl}_{2}\end{array}$ & FTO/c- $\mathrm{TiO}_{2} /$ absorber/PTAA/Au & - & $\begin{array}{l}\text { Stability } \\
\text { degraded } \\
\text { quickly } \\
\text { over time }\end{array}$ & 2018 & [73] \\
\hline $\begin{array}{l}\mathrm{CsSnI}_{3}+10 \% \\
\mathrm{SnBr}_{2}\end{array}$ & FTO/c-TiO $2 /$ absorber/PTAA/Au & - & $\begin{array}{l}\text { Excellent } \\
\text { stability }\end{array}$ & 2018 & [73] \\
\hline $\begin{array}{l}\mathrm{CsSnI}_{3}+20 \% \\
\mathrm{SnF}_{2} / \text { Hydrazine }\end{array}$ & $\mathrm{FTO} / \mathrm{c}-\mathrm{TiO}_{2} / \mathrm{m} \mathrm{TiO}_{2} /$ absorber/PTAA/Au & $\begin{array}{l}\text { Reducing vapor } \\
\text { atmosphere } \\
\text { method }\end{array}$ & $\begin{array}{l}\text { Unstable in } \\
\text { air }\end{array}$ & 2017 & [33] \\
\hline $\begin{array}{l}\mathrm{CsSnBr}_{3}+20 \% \\
\mathrm{SnF}_{2}\end{array}$ & FTO/c- $\mathrm{TiO}_{2} / \mathrm{m}-\mathrm{TiO}_{2} /$ absorber/PTAA/Au & $\begin{array}{l}\text { Reducing vapor } \\
\text { atmosphere } \\
\text { method }\end{array}$ & $\begin{array}{l}\text { Good } \\
\text { stability } \\
\text { without } \\
\text { encapsulati } \\
\text { on in air }\end{array}$ & 2017 & [33] \\
\hline $\begin{array}{l}\mathrm{CsSnBr}_{3}+2.5 \% \\
\mathrm{SnF}_{2}\end{array}$ & ITO/MoO $/$ /absorber/C $60 / \mathrm{BCP} / \mathrm{Ag}$ & $\begin{array}{l}\text { Vapor } \\
\text { deposition } \\
\text { method }\end{array}$ & $\begin{array}{l}\text { Good } \\
\text { stability }\end{array}$ & 2016 & $\begin{array}{l}{[10} \\
2]\end{array}$ \\
\hline $\begin{array}{l}\{\text { en }\} \mathrm{FASnI}_{3} \quad+ \\
15 \% \mathrm{SnF}_{2}\end{array}$ & $\mathrm{FTO} / \mathrm{c}-\mathrm{TiO}_{2} / \mathrm{m}-\mathrm{TiO}_{2} /$ absorber/PTAA/Au & - & Very stable & 2017 & [75] \\
\hline $\begin{array}{l}\{\text { en }\} \mathrm{MASnI}_{3}+ \\
15 \% \mathrm{SnF}_{2}\end{array}$ & $\mathrm{FTO} / \mathrm{c}-\mathrm{TiO}_{2} / \mathrm{m} \mathrm{TiO}_{2} /$ absorber/PTAA/Au & $\begin{array}{l}\text { One-step } \\
\text { solution method }\end{array}$ & $\begin{array}{l}\text { Better air } \\
\text { stability }\end{array}$ & 2017 & [76] \\
\hline $\mathrm{FA}_{0.75} \mathrm{MA}_{0.25} \mathrm{SnI}_{3}$ & ITO/PEDOT:PSS/absorber/C ${ }_{60} / \mathrm{BCP} / \mathrm{Ag}$ & $\begin{array}{l}\text { Hot anti-solvent } \\
\text { treatment }\end{array}$ & $\begin{array}{l}\text { Poor } \\
\text { stability }\end{array}$ & 2018 & [79] \\
\hline $\mathrm{FA}_{0.75} \mathrm{MA}_{0.25} \mathrm{SnI}_{3}$ & ITO/PEDOT:PSS/absorber/C ${ }_{60} / \mathrm{BCP} / \mathrm{Al}$ & $\begin{array}{l}\text { Anti-solvent } \\
\text { dripping method }\end{array}$ & $\begin{array}{l}\text { Good long- } \\
\text { term }\end{array}$ & 2018 & [81] \\
\hline
\end{tabular}




\begin{tabular}{|l|l|l|l|l|l|}
\hline & & & stability & & \\
\hline $\mathrm{GA}_{\mathrm{x}} \mathrm{FA}_{1-\mathrm{x}-2 \mathrm{y}} \mathrm{SnI}_{3-}-$ & ITO/PEDOT:PSS/absorber/C60/BCP/Ag & $\begin{array}{l}\text { Incorporation of } \\
\text { a non-polar } \\
\text { organic cation }\end{array}$ & $\begin{array}{l}\text { Outstandin } \\
\text { g stability }\end{array}$ & 2019 & {$[84]$} \\
\hline
\end{tabular}

\section{Summary}

Typical tin-based lead-free perovskite solar cells that have been reviewed include $\mathrm{MASnI}_{3}, \mathrm{FASnI}_{3}, \mathrm{CsSnI}_{3}$ and mixed cation tin-based perovskites. The mixed cation tin-based perovskite solar cells have the potential to show the combined advantage of different incorporated cations and have reached a maximum PCE of 9.6\% [84]. This efficiency was achieved by the incorporation of a non-polar organic guanidinium $\left(\mathrm{GA}^{+}\right)$cation along with formamidinium cation and the fabricated solar cell demonstrated an outstanding stability. The MASnI 3 based perovskite solar cells achieved maximum PCE of 7.78\% [38] with high reproducibility and good stability. This strategy that involved ion exchange/insertion reactions resulted in highly consistent pinhole-free $\mathrm{MASnI}_{3}$ films by a reaction between $\mathrm{SnF}_{2}$ and MAI. Because of the presence of hefty amount of left $\mathrm{SnF}_{2}$, the unfavourable oxidation was successfully suppressed in the obtained film. This strategy presented an innovative approach for fabricating inexpensive as well as stable tin-based lead-free perovskite solar cells. Further, $\mathrm{FASnI}_{3}$ based perovskite solar cells achieved maximum soaring PCE of $12.4 \%$ [62] using ICBA in place of traditionally used PCBM ETL. The perovskite film was prepared by a usual anti-solvent method using a one-step process. Here, $\mathrm{NH}_{4} \mathrm{SCN}$ was used as additive to mutate the growth of perovskite film and PEA was also utilized. ICBA exhibits a shallower energy level due to which it repressed the iodide remote doping. As a result, interface carriers recombination was also reduced and maximum attainable voltage of $0.94 \mathrm{~V}$ was achieved. ICBA incorporated solar cell maintained $90 \%$ of original efficiency for about 3800 hours. In $\mathrm{MASnI}_{3}$ and $\mathrm{FASnI}_{3}$ perovskite solar cells, appreciable PCE is achieved recently with remarkable stability but these perovskites are prone to facile volatilization due to the presence of the organic cation. In this context, the all-inorganic lead-free $\mathrm{CsSnX}_{3}$ perovskite becomes a more attractive candidate. The maximum efficiency achieved with $\mathrm{CsSnX}_{3}$ perovskite solar cells is $12.96 \%$ [29] for $\mathrm{CsSnI}_{3}$. Here, a simple and fast solvothermal synthesis for lead-free high-quality perovskite-type $\mathrm{CsSnX}_{3}$ with a uniform quantum rod-shaped structure was utilized for enhancing photovoltaic efficiency. However, the facile oxidation of $\mathrm{Sn}^{2+}$ to $\mathrm{Sn}^{4+}$, and attendant phase instability in the $\mathrm{CsSnI}_{3}$ perovskite, results in the rapid degradation of its properties. The most effective strategy that has been proposed for mitigating this issue is to incorporate $\mathrm{Sn}^{2+}$-halide additive $\left(\mathrm{SnF}_{2}, \mathrm{SnCl}_{2}\right.$, and $\mathrm{SnI}_{2}$ ), and the resulting operational stability was still not good. Thus, new stabilization approaches are required that can boost the stability and PCE of tin-based perovskite solar cells simultaneously. Tin-based lead-free perovskite solar cells are promising for achieving high performance in the near future. However, these materials have significantly worse stability than the lead-based perovskite solar cells even with encapsulation. The tin and lead-based perovskites can borrow technologies from each other to further address the stability issues. We cannot yet judge, however, if they are viable candidates before the stability concern is addressed. Nevertheless, PCEs of $13 \%$ or higher are likely on the horizon. Once the $\mathrm{Sn}^{4+}$ oxidation issue is fully addressed and photocarrier 
recombination rates are suppressed to the levels of the lead halide perovskites, $\mathrm{V}_{\text {oc }}$ of more than $1.00 \mathrm{~V}$ should be achievable, which in turn will open the path to PCE beyond 15\% and dramatically improve their future prospects to a viable lead-free contender.

\section{Conclusions}

Over the decades, an incredible progress has been observed in the field of photovoltaics as a whole, and in particular, perovskites. Several researchers are still trying their best to further enhance the efficiencies in addition to modulating each factor essential for taking photovoltaic cells up to the mark on a broad range. Early development in this field suggested that lead needs an 'equal-ifnot- better' alternate because of some constraints and so majority of the researchers sidetracked their focus in the direction of finding a suitable replacement for lead in perovskite. From the reported studies on lead-free perovskites, tin-based perovskite is found to be the competent and potential candidate to that of lead-based perovskite. A PCE of 12.96\% was reported based on $\mathrm{CsSnI}_{3}$ which is the highest achieved PCE till date in tin-based solar cells. This substitution has several favourable effects on the resultant perovskites and devices, for instance bandgap narrowing but the above discussion clearly evidences that various issues still need to be tackled for tin-based lead-free perovskite solar cells to compete with the already reputed photovoltaic technologies. More efforts are required to deal with the stability of tin-based perovskite than that of lead analogs due to the conversion of $\mathrm{Sn}$ from its +2 to +4 oxidation state in ambient atmosphere. Even though $\mathrm{SnX} \mathrm{X}_{2}$ additive has been extensively used to avoid or hold up this process, there is still a need to explore some other additives and measures that could effectively protect $\mathrm{Sn}$ in its +2 state and avoid the conversion to the +4 state. Thus, to show better performance and stability for exhibiting real life feasibility, effective strategies in addition to those summarized here, need to be utilized. These strategies would include film quality improvement processes, employing appropriate fabrication techniques, and using more efficient additives that could afford an absolute isolation from oxygen as well as moisture.

\section{Conflict of Interest}

The authors declare that there is no conflict of interest.

\section{Data Availability}

The raw/processed data required to reproduce these findings cannot be shared at this time due to technical limitations.

\section{References}

[1] Poglitsch A, Weber D. Dynamic disorder in methylammoniumtrihalogenoplumbates (II) observed by millimeter-wave spectroscopy, J. Chem. Phys. 1987, 87(11), 6373-8.

[2] Nanda BR, Satpathy S. Effects of strain on orbital ordering and magnetism at perovskite oxide interfaces, $\mathrm{LaMnO}_{3} / \mathrm{SrMnO}_{3}$, Phys. Rev. B 2008, 78(5), 054427. 
[3] Mitzi DB. Templating and structural engineering in organic-inorganic perovskites. Journal of the Chemical Society, Dalton Trans. 2001, (1), 1-2.

[4] Bousquet E, Dawber M, Stucki N, Lichtensteiger C, Hermet P, Gariglio S, Triscone JM, Ghosez P. Improper ferroelectricity in perovskite oxide artificial superlattices, Nature, 2008, 452(7188), 732-6.

[5] Grinberg I, West DV, Torres M, Gou G, Stein DM, Wu L, Chen G, Gallo EM, Akbashev AR, Davies PK, Spanier JE. Perovskite oxides for visible-light-absorbing ferroelectric and photovoltaic materials, Nature, 2013, 503(7477), 509-12.

[6] Oka K, Yamada I, Azuma M, Takeshita S, Satoh KH, Koda A, Kadono R, Takano M, Shimakawa Y. Magnetic ground-state of perovskite $\mathrm{PbVO}_{3}$ with large tetragonal distortion, Inorg. Chem. 2008, 47(16), 7355-9.

[7] Li M, Pietrowski MJ, De Souza RA, Zhang H, Reaney IM, Cook SN, Kilner JA, Sinclair DC. A family of oxide ion conductors based on the ferroelectric perovskite $\mathrm{Na}_{0.5} \mathrm{Bi}_{0.5} \mathrm{TiO}_{3}$, Nat. Mater. 2014, 13(1), 31-5.

[8] Onoda-Yamamuro N, Matsuo T, Suga H. Calorimetric and IR spectroscopic studies of phase transitions in methylammonium trihalogenoplumbates (II), J. Phys. Chem. Solids, 1990, 51(12), 1383-95.

[9] Im JH, Jang IH, Pellet N, Grätzel M, Park NG. Growth of CH 3 NH 3 PbI 3 cuboids with controlled size for high-efficiency perovskite solar cells, Nat. Nanotechnol. 2014, 9(11), 927-32.

[10] Best Research-Cell Efficiency Chart, Photovoltaic Research, NREL https://www.nrel.gov/pv/cellefficiency.html (accessed March 9, 2020).

[11] Kour R, Arya S, Verma S, Gupta J, Bandhoria P, Bharti V, Datt R, Gupta V. Potential substitutes for replacement of lead in perovskite solar cells: a review, Global Challenges, 2019, 3(11), 1900050.

[12] Mei A, Li X, Liu L, Ku Z, Liu T, Rong Y, Xu M, Hu M, Chen J, Yang Y, Grätzel M. A hole-conductorfree, fully printable mesoscopic perovskite solar cell with high stability, Science, 2014, 345(6194), 295-8.

[13] Arya S, Mahajan P, Gupta R, Srivastava R, Tailor NK, Satapathi S, Radhakrishnan S, Datt R, Gupta V. A comprehensive review on synthesis and applications of single crystal perovskite Halides, Prog. Solid State Chem. 2020, 100286.

[14] Grätzel M. The light and shade of perovskite solar cells. Nat. Mater. 2014, 13(9), 838.

[15] Boix PP, Agarwala S, Koh TM, Mathews N, Mhaisalkar SG. Perovskite solar cells: beyond methylammonium lead iodide, J. Phys. Chem. Lett. 2015, 6(5), 898-907.

[16] Ahmad K, Ansari SN, Natarajan K, Mobin SM. Design and synthesis of 1D-polymeric chain based $\left[\left(\mathrm{CH}_{3} \mathrm{NH}_{3}\right) 3 \mathrm{Bi}_{2} \mathrm{Cl}_{9}\right] \mathrm{n}$ perovskite: A new light absorber material for lead free perovskite solar cells, ACS Appl. Energy Mater. 2018, 1(6), 2405-9.

[17] Krishnamoorthy T, Ding H, Yan C, Leong WL, Baikie T, Zhang Z, Sherburne M, Li S, Asta M, Mathews $\mathrm{N}$, Mhaisalkar SG. Lead-free germanium iodide perovskite materials for photovoltaic applications, $J$. Mater. Chem. A. 2015, 3(47), 23829-32.

[18] Cui XP, Jiang KJ, Huang JH, Zhang QQ, Su MJ, Yang LM, Song YL, Zhou XQ. Cupric bromide hybrid perovskite heterojunction solar cells, Synth. Met. 2015, 209, 247-50. 
[19] Cortecchia D, Dewi HA, Yin J, Bruno A, Chen S, Baikie T, Boix PP, Grätzel M, Mhaisalkar S, Soci C, Mathews N. Lead-free $\mathrm{MA}_{2} \mathrm{CuCl}_{\mathrm{x}} \mathrm{Br}_{4-\mathrm{x}}$ hybrid perovskites, Inorg. Chem. 2016, 55(3), 1044-52.

[20] Jacobsson TJ, Pazoki M, Hagfeldt A, Edvinsson T. Goldschmidt's rules and strontium replacement in lead halogen perovskite solar cells: theory and preliminary experiments on $\mathrm{CH}_{3} \mathrm{NH}_{3} \mathrm{SrI}_{3}, J$. Phys. Chem. C. 2015, 119(46), 25673-83.

[21] Uribe JI, Ramirez D, Osorio-Guillén JM, Osorio J, Jaramillo F. $\mathrm{CH}_{3} \mathrm{NH}_{3} \mathrm{CaI}_{3}$ perovskite: synthesis, characterization, and first-principles studies, J. Phys. Chem. C. 2016, 120(30), 16393-8.

[22] Ahmad K, Mobin SM. Lead-Free Perovskite Solar Cells: Fundamentals, Fabrication, and Future Prospective, Handbook of Nanomaterials and Nanocomposites for Energy and Environmental Applications. 2020, 1-26.

[23] Shockley W, Queisser HJ. Detailed balance limit of efficiency of p-n junction solar cells, J. Appl. Phys. 1961, 32(3), 510-9.

[24] Toshniwal A, Kheraj V. Development of organic-inorganic tin halide perovskites: A review, Sol. Energy, 2017, 149, 54-9.

[25] Marshall KP, Walker M, Walton RI, Hatton RA. Enhanced stability and efficiency in hole-transport-layerfree $\mathrm{CsSnI}_{3}$ perovskite photovoltaics, Nat. Energy, 2016, 1(12), 1-9.

[26] Herz LM. Charge-carrier mobilities in metal halide perovskites: fundamental mechanisms and limits, ACS Energy Lett. 2017, 2(7), 1539-48.

[27] Hussain I, Tran HP, Jaksik J, Moore J, Islam N, Uddin MJ. Functional materials, device architecture, and flexibility of perovskite solar cell, Emergent Mater. 2018, 1(3-4), 133-54.

[28] Ke W, Kanatzidis MG. Prospects for low-toxicity lead-free perovskite solar cells, Nat. Commun. 2019, $10(1), 965$.

[29] Chen LJ, Lee CR, Chuang YJ, Wu ZH, Chen C. Synthesis and optical properties of lead-free cesium tin halide perovskite quantum rods with high-performance solar cell application, J. Phys. Chem. Lett. 2016, $7(24), 5028-35$.

[30] Noel NK, Stranks SD, Abate A, Wehrenfennig C, Guarnera S, Haghighirad AA, Sadhanala A, Eperon GE, Pathak SK, Johnston MB, Petrozza AM, Herz LM, Snaith HJ. Lead-free organic-inorganic tin halide perovskites for photovoltaic applications, Energy Environ. Sci. 2014, 7(9), 3061-8.

[31] Yu Y, Zhao D, Grice CR, Meng W, Wang C, Liao W, Cimaroli AJ, Zhang H, Zhu K, Yan Y. Thermally evaporated methylammonium tin triiodide thin films for lead-free perovskite solar cell fabrication, $R S C$ Adv. 2016, 6(93), 90248-54.

[32] Hsu HY, Ji L, Du M, Zhao J, Edward TY, Bard AJ. Optimization of lead-free organic-inorganic tin (II) halide perovskite semiconductors by scanning electrochemical microscopy, Electrochim. Acta, 2016, 220, 205-10.

[33] Song TB, Yokoyama T, Stoumpos CC, Logsdon J, Cao DH, Wasielewski MR, Aramaki S, Kanatzidis MG. Importance of reducing vapor atmosphere in the fabrication of tin-based perovskite solar cells, J. Am. Chem. Soc. 2017, 139(2), 836-42. 
[34] Handa T, Yamada T, Kubota H, Ise S, Miyamoto Y, Kanemitsu Y. Photocarrier recombination and injection dynamics in long-term stable lead-free $\mathrm{CH}_{3} \mathrm{NH}_{3} \mathrm{SnI}_{3}$ perovskite thin films and solar cells, J. Phys. Chem. C. 2017, 121(30), 16158-65.

[35] Xiao M, Gu S, Zhu P, Tang M, Zhu W, Lin R, Chen C, Xu W, Yu T, Zhu J. Tin-Based Perovskite with Improved Coverage and Crystallinity through Tin-Fluoride-Assisted Heterogeneous Nucleation, $A d v$. Optical Mater. 2018, 6(1), 1700615.

[36] Nguyen BP, Shin D, Jung HR, Kim J, Nguyen TT, Yoon S, Yi Y, Jo W. Phase formation and local charge transport of lead-free $\mathrm{CH}_{3} \mathrm{NH}_{3} \mathrm{Sn}\left(\mathrm{I}_{1-}{ }_{\mathrm{x}} \mathrm{Br}_{\mathrm{x}}\right)_{3}(0 \leq \mathrm{x} \leq 1)$ perovskite solar cells fabricated by solvent optimization, Sol. Energy, 2019, 186, 136-44.

[37] Li F, Zhang C, Huang JH, Fan H, Wang H, Wang P, Zhan C, Liu CM, Li X, Yang LM, Song Y, Jiang KJ. A Cation-Exchange Approach for the Fabrication of Efficient Methylammonium Tin Iodide Perovskite Solar Cells, Angew. Chem. Int. Ed. 2019, 58(20), 6688-92.

[38] Wang P, Li F, Jiang KJ, Zhang Y, Fan H, Zhang Y, Miao Y, Huang JH, Gao C, Zhou X, Wang F, Yang LM, Zhan C, Song YL. Ion Exchange/Insertion Reactions for Fabrication of Efficient Methylammonium Tin Iodide Perovskite Solar Cells, Adv. Sci. 2020, 1903047.

[39] Koh TM, Krishnamoorthy T, Yantara N, Shi C, Leong WL, Boix PP, Grimsdale AC, Mhaisalkar SG, Mathews N. Formamidinium tin-based perovskite with low $\mathrm{E}_{\mathrm{g}}$ for photovoltaic applications, J. Mater. Chem. A. 2015, 3(29), 14996-5000.

[40] Liao W, Zhao D, Yu Y, Grice CR, Wang C, Cimaroli AJ, Schulz P, Meng W, Zhu K, Xiong RG, Yan Y. Lead-free inverted planar formamidinium tin triiodide perovskite solar cells achieving power conversion efficiencies up to $6.22 \%$, Adv. Mater. 2016, 28(42), 9333-40.

[41] Zhang M, Lyu M, Yun JH, Noori M, Zhou X, Cooling NA, Wang Q, Yu H, Dastoor PC, Wang L. Lowtemperature processed solar cells with formamidinium tin halide perovskite/fullerene heterojunctions, Nano Res. 2016, 9(6), 1570-7.

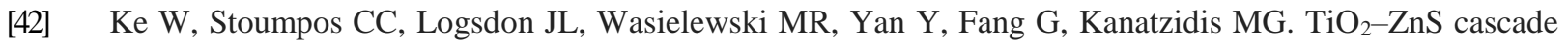
electron transport layer for efficient formamidinium tin iodide perovskite solar cells, J. Am. Chem. Soc. 2016, 138(45), 14998-5003.

[43] Zhu Z, Chueh CC, Li N, Mao C, Jen AK. Realizing Efficient Lead-Free Formamidinium Tin Triiodide Perovskite Solar Cells via a Sequential Deposition Route, Adv. Mater. 2018, 30(6), 1703800.

[44] Lee SJ, Shin SS, Kim YC, Kim D, Ahn TK, Noh JH, Seo J, Seok SI. Fabrication of efficient formamidinium tin iodide perovskite solar cells through $\mathrm{SnF}_{2}-$ pyrazine complex, J. Am. Chem. Soc. 2016, 138(12), 3974-7.

[45] Liao Y, Liu H, Zhou W, Yang D, Shang Y, Shi Z, Li B, Jiang X, Zhang L, Quan LN, Quintero-Bermudez R. Highly oriented low-dimensional tin halide perovskites with enhanced stability and photovoltaic performance, J. Am. Chem. Soc. 2017, 139(19), 6693-9.

[46] Shao S, Liu J, Portale G, Fang HH, Blake GR, ten Brink GH, Koster LJ, Loi MA. Highly reproducible Sn-based hybrid perovskite solar cells with 9\% efficiency, Adv. Energy Mater. 2018, 8(4), 1702019. 
[47] Chen K, Wu P, Yang W, Su R, Luo D, Yang X, Tu Y, Zhu R, Gong Q. Low-dimensional perovskite interlayer for highly efficient lead-free formamidinium tin iodide perovskite solar cells, Nano Energy, 2018, 49, 411-8.

[48] Fang HH, Adjokatse S, Shao S, Even J, Loi MA. Long-lived hot-carrier light emission and large blue shift in formamidinium tin triiodide perovskites, Nat. Commun. 2018, 9(1), 1-8.

[49] Gu F, Ye S, Zhao Z, Rao H, Liu Z, Bian Z, Huang C. Improving Performance of Lead-Free Formamidinium Tin Triiodide Perovskite Solar Cells by Tin Source Purification, Sol. RRL, 2018, 2(10), 1800136.

[50] Jokar E, Chien CH, Fathi A, Rameez M, Chang YH, Diau EW. Slow surface passivation and crystal relaxation with additives to improve device performance and durability for tin-based perovskite solar cells, Energy Environ. Sci. 2018, 11(9), 2353-62.

[51] Kim H, Lee YH, Lyu T, Yoo JH, Park T, Oh JH. Boosting the performance and stability of quasi-twodimensional tin-based perovskite solar cells using the formamidinium thiocyanate additive, J. Mater. Chem. A. 2018, 6(37), 18173-82.

[52] Tai Q, Guo X, Tang G, You P, Ng TW, Shen D, Cao J, Liu CK, Wang N, Zhu Y, Lee CS. Antioxidant Grain Passivation for Air-Stable Tin-Based Perovskite Solar Cells, Angew. Chem. Int. Ed. 2019, 58(3), 806-10.

[53] Ran C, Xi J, Gao W, Yuan F, Lei T, Jiao B, Hou X, Wu Z. Bilateral interface engineering toward efficient 2D-3D bulk heterojunction tin halide lead-free perovskite solar cells, ACS Energy Lett. 2018, 3(3), 713-21.

[54] Shao S, Dong J, Duim H, Gert H, Blake GR, Portale G, Loi MA. Enhancing the crystallinity and perfecting the orientation of formamidinium tin iodide for highly efficient Sn-based perovskite solar cells, Nano Energy. 2019, 60, 810-6.

[55] Dixit H, Punetha D, Pandey SK. Improvement in performance of lead free inverted perovskite solar cell by optimization of solar parameters, Optik, 2019, 179, 969-76.

[56] Liu C, Tu J, Hu X, Huang Z, Meng X, Yang J, Duan X, Tan L, Li Z, Chen Y. Enhanced Hole Transportation for Inverted Tin-Based Perovskite Solar Cells with High Performance and Stability, Adv. Funct. Mater. 2019, 29(18), 1808059.

[57] Xu H, Jiang Y, He T, Li S, Wang H, Chen Y, Yuan M, Chen J. Orientation Regulation of Tin-Based Reduced-Dimensional Perovskites for Highly Efficient and Stable Photovoltaics, Adv. Funct. Mater. 2019, 29(47), 1807696.

[58] He L, Gu H, Liu X, Li P, Dang Y, Liang C, Ono LK, Qi Y, Tao X. Efficient Anti-solvent-free Spin-Coated and Printed Sn-Perovskite Solar Cells with Crystal-Based Precursor Solutions, Matter, 2020, 2(1), 167-80.

[59] Abdelaziz S, Zekry A, Shaker A, Abouelatta M. Investigating the performance of formamidinium tin-based perovskite solar cell by SCAPS device simulation, Opt. Mater. 2020, 101, 109738.

[60] Lin Z, Liu C, Liu G, Yang J, Duan X, Tan L, Chen Y. Efficient Inverted Tin-based Perovskite Solar Cells via Bidentate Coordination Effect of 8-Hydroxyquinoline, Chem. Commun. 2020. 
[61] Liu G, Liu C, Lin Z, Yang J, Huang Z, Tan L, Chen Y. Regulated Crystallization of Efficient and Stable Tin-based Perovskite Solar Cells via Self-sealing Polymer, ACS Appl. Mater. Interfaces, 2020, 12(12), 14049-14056.

[62] Jiang X, Wang F, Wei Q, Li H, Shang Y, Zhou W, Wang C, Cheng P, Chen Q, Chen L, Ning Z. Ultra-high open-circuit voltage of tin perovskite solar cells via an electron transporting layer design, Nat. Commun. 2020, 11(1), 1-7.

[63] Zeng W, Cui D, Li Z, Tang Y, Yu X, Li Y, Deng Y, Ye R, Niu Q, Xia R, Min Y. Surface optimization by poly ( $\alpha$-methylstyrene) as additive in the antisolution to enhance lead-free Sn-based perovskite solar cells, Sol. Energy, 2019, 194, 272-8.

[64] Wu T, Liu X, He X, Wang Y, Meng X, Noda T, Yang X, Han L. Efficient and stable tin-based perovskite solar cells by introducing $\pi$-conjugated Lewis base, Sci. China Chem. 2020, 63(1), 107-15.

[65] Cao J, Tai Q, You P, Tang G, Wang T, Wang N, Yan F. Enhanced performance of tin-based perovskite solar cells induced by an ammonium hypophosphite additive, J. Mater. Chem. A. 2019, 7(46), 26580-5.

[66] Kumar MH, Dharani S, Leong WL, Boix PP, Prabhakar RR, Baikie T, Shi C, Ding H, Ramesh R, Asta M, Graetzel M. Lead-free halide perovskite solar cells with high photocurrents realized through vacancy modulation, Adv. Mater. 2014, 26(41), 7122-7.

[67] Sabba D, Mulmudi HK, Prabhakar RR, Krishnamoorthy T, Baikie T, Boix PP, Mhaisalkar S, Mathews N. Impact of anionic $\mathrm{Br}$-substitution on open circuit voltage in lead free perovskite ( $\mathrm{CsSnI}_{3-\mathrm{x}} \mathrm{Br}_{\mathrm{x}}$ ) solar cells, $J$. Phys. Chem. C. 2015, 119(4), 1763-7.

[68] Gupta S, Bendikov T, Hodes G, Cahen D. $\mathrm{CsSnBr}_{3}$, a lead-free halide perovskite for long-term solar cell application: insights on $\mathrm{SnF}_{2}$ addition, ACS Energy Lett. 2016, 1(5), 1028-33.

[69] Wang N, Zhou Y, Ju MG, Garces HF, Ding T, Pang S, Zeng XC, Padture NP, Sun XW. Heterojunction-Depleted Lead-Free Perovskite Solar Cells with Coarse-Grained B- $\gamma$-CsSnI 3 Thin Films, Adv. Energy Mater. 2016, 6(24), 1601130.

[70] Qiu X, Jiang Y, Zhang H, Qiu Z, Yuan S, Wang P, Cao B. Lead-free mesoscopic Cs2SnI6 perovskite solar cells using different nanostructured $\mathrm{ZnO}$ nanorods as electron transport layers, Phys. Status Solidi RRL, 2016, 10(8), 587-91.

[71] Qiu X, Cao B, Yuan S, Chen X, Qiu Z, Jiang Y, Ye Q, Wang H, Zeng H, Liu J, Kanatzidis MG. From unstable $\mathrm{CsSnI}_{3}$ to air-stable $\mathrm{Cs}_{2} \mathrm{SnI}_{6}$ : A lead-free perovskite solar cell light absorber with bandgap of 1.48 eV and high absorption coefficient, Sol. Energy Mater. Sol. Cells, 2017, 159, 227-34.

[72] Wu B, Zhou Y, Xing G, Xu Q, Garces HF, Solanki A, Goh TW, Padture NP, Sum TC. Long minority-carrier diffusion length and low surface-recombination velocity in inorganic lead-free $\mathrm{CsSnI}_{3}$ perovskite crystal for solar cells, Adv. Funct. Mater. 2017, 27(7), 1604818.

[73] Heo JH, Kim J, Kim H, Moon SH, Im SH, Hong KH. Roles of $\mathrm{SnX}_{2}(\mathrm{X}=\mathrm{F}, \mathrm{Cl}, \mathrm{Br})$ Additives in Tin-Based Halide Perovskites toward Highly Efficient and Stable Lead-Free Perovskite Solar Cells, J. Phys. Chem. Lett. 2018, 9(20), 6024-31. 
[74] Song TB, Yokoyama T, Aramaki S, Kanatzidis MG. Performance enhancement of lead-free tin-based perovskite solar cells with reducing atmosphere-assisted dispersible additive, ACS Energy Lett. 2017, 2(4), 897-903.

[75] Ke W, Stoumpos CC, Zhu M, Mao L, Spanopoulos I, Liu J, Kontsevoi OY, Chen M, Sarma D, Zhang Y, Wasielewski MR. Enhanced photovoltaic performance and stability with a new type of hollow 3D perovskite \{en $\mathrm{FASnI}_{3}$, Sci. Adv. 2017, 3(8), e1701293.

[76] Ke W, Stoumpos CC, Spanopoulos I, Mao L, Chen M, Wasielewski MR, Kanatzidis MG. Efficient leadfree solar cells based on hollow \{en\} MASnI 3 perovskites, J. Am. Chem. Soc. 2017, 139(41), 14800-6.

[77] Ke W, Priyanka P, Vegiraju S, Stoumpos CC, Spanopoulos I, Soe CM, Marks TJ, Chen MC, Kanatzidis MG. Dopant-free tetrakis-triphenylamine hole transporting material for efficient tin-based perovskite solar cells, J. Am. Chem. Soc. 2018, 140(1), 388-93.

[78] Vegiraju S, Ke W, Priyanka P, Ni JS, Wu YC, Spanopoulos I, Yau SL, Marks TJ, Chen MC, Kanatzidis MG. Benzodithiophene Hole-Transporting Materials for Efficient Tin-Based Perovskite Solar Cells, Adv. Funct. Mater. 2019, 29(45), 1905393.

[79] Liu J, Ozaki M, Yakumaru S, Handa T, Nishikubo R, Kanemitsu Y, Saeki A, Murata Y, Murdey R, Wakamiya A. Lead-Free Solar Cells based on Tin Halide Perovskite Films with High Coverage and Improved Aggregation, Angew. Chem. 2018, 130(40), 13405-9.

[80] Zhao Z, Gu F, Li Y, Sun W, Ye S, Rao H, Liu Z, Bian Z, Huang C. Mixed-Organic-Cation Tin Iodide for Lead-Free Perovskite Solar Cells with an Efficiency of 8.12\%, Adv. Sci. 2017, 4(11), 1700204.

[81] Liu X, Yan K, Tan D, Liang X, Zhang H, Huang W. Solvent engineering improves efficiency of lead-free tin-based hybrid perovskite solar cells beyond 9\%, ACS Energy Lett. 2018, 3(11), 2701-7.

[82] Wang Z, Ganose AM, Niu C, Scanlon DO. First-principles insights into tin-based two-dimensional hybrid halide perovskites for photovoltaics, J. Mater. Chem. A. 2018, 6(14), 5652-60.

[83] Jiang J, Onwudinanti CK, Hatton RA, Bobbert PA, Tao S. Stabilizing lead-free all-inorganic tin halide Perovskites by ion exchange, J. Phys. Chem. C. 2018, 122(31), 17660-7.

[84] Jokar E, Chien CH, Tsai CM, Fathi A, Diau EW. Robust Tin-Based Perovskite Solar Cells with Hybrid Organic Cations to Attain Efficiency Approaching 10\%, Adv. Mater. 2019, 31(2), 1804835.

[85] Kamarudin MA, Hirotani D, Wang Z, Hamada K, Nishimura K, Shen Q, Toyoda T, Iikubo S, Minemoto T, Yoshino K, Hayase S. Suppression of Charge Carrier Recombination in Lead-Free Tin Halide Perovskite via Lewis Base Post-Treatment, J. Phys. Chem. Lett. 2019, 10(17), 5277-83.

[86] Yokoyama T, Cao DH, Stoumpos CC, Song TB, Sato Y, Aramaki S, Kanatzidis MG. Overcoming shortcircuit in lead-free $\mathrm{CH}_{3} \mathrm{NH}_{3} \mathrm{SnI}_{3}$ perovskite solar cells via kinetically controlled gas-solid reaction film fabrication process, J. Phys. Chem. Lett. 2016, 7(5), 776-82.

[87] Jung MC, Raga SR, Qi Y. Properties and solar cell applications of Pb-free perovskite films formed by vapor deposition, $R S C A d v$. 2016, 6(4), 2819-25.

[88] Hao F, Stoumpos CC, Cao DH, Chang RP, Kanatzidis MG. Lead-free solid-state organic-inorganic halide perovskite solar cells, Nat. Photonics. 2014, 8(6), 489. 
[89] Hao F, Stoumpos CC, Chang RP, Kanatzidis MG. Anomalous band gap behavior in mixed Sn and Pb perovskites enables broadening of absorption spectrum in solar cells, J. Am. Chem. Soc. 2014, 136(22), 8094-9.

[90] Hao F, Stoumpos CC, Guo P, Zhou N, Marks TJ, Chang RP, Kanatzidis MG. Solvent-mediated crystallization of $\mathrm{CH}_{3} \mathrm{NH}_{3} \mathrm{SnI}_{3}$ films for heterojunction depleted perovskite solar cells, J. Am. Chem. Soc. 2015, 137(35), 11445-52.

[91] Do Kim H, Miyamoto Y, Kubota H, Yamanari T, Ohkita H. Open-circuit voltage loss in $\mathrm{CH}_{3} \mathrm{NH}_{3} \mathrm{SnI}_{3}$ perovskite solar cells, Chem. Lett. 2017, 46(2), 253-6.

[92] Yokoyama T, Song TB, Cao DH, Stoumpos CC, Aramaki S, Kanatzidis MG. The origin of lower hole carrier concentration in methylammonium tin halide films grown by a vapor-assisted solution process, ACS Energy Lett. 2017, 2(1), 22-8.

[93] Tsai CM, Mohanta N, Wang CY, Lin YP, Yang YW, Wang CL, Hung CH, Diau EW. Formation of Stable Tin Perovskites Co-crystallized with Three Halides for Carbon-Based Mesoscopic Lead-Free Perovskite Solar Cells, Angew. Chem. 2017, 129(44), 14007-11.

[94] Zhao B, Abdi-Jalebi M, Tabachnyk M, Glass H, Kamboj VS, Nie W, Pearson AJ, Puttisong Y, Gödel KC, Beere HE, Ritchie DA. High Open-Circuit Voltages in Tin-Rich Low-Bandgap Perovskite-Based Planar Heterojunction Photovoltaics, Adv. Mater. 2017, 29(2), 1604744.

[95] Fujihara T, Terakawa S, Matsushima T, Qin C, Yahiro M, Adachi C. Fabrication of high coverage MASnI 3 perovskite films for stable, planar heterojunction solar cells, J. Mater. Chem. C. 2017, 5(5), 1121-7.

[96] Cao DH, Stoumpos CC, Yokoyama T, Logsdon JL, Song TB, Farha OK, Wasielewski MR, Hupp JT, Kanatzidis MG. Thin films and solar cells based on semiconducting two-dimensional ruddlesden-popper $\left(\mathrm{CH}_{3}\left(\mathrm{CH}_{2}\right)_{3} \mathrm{NH}_{3}\right)_{2}\left(\mathrm{CH}_{3} \mathrm{NH}_{3}\right)_{\mathrm{n}-1} \mathrm{Sn}_{\mathrm{n}} \mathrm{I}_{3 \mathrm{n}+1}$ perovskites, ACS Energy Lett. 2017, 2(5), 982-90.

[97] Moyez SA, Roy S. Thermal engineering of lead-free nanostructured $\mathrm{CH}_{3} \mathrm{NH}_{3} \mathrm{SnCl}_{3}$ perovskite material for thin-film solar cell, J. Nanopart. Res. 2018, 20(1), 5.

[98] Liu X, Yang Z, Chueh CC, Rajagopal A, Williams ST, Sun Y, Jen AK. Improved efficiency and stability of $\mathrm{Pb}-\mathrm{Sn}$ binary perovskite solar cells by Cs substitution, J. Mater. Chem. A. 2016, 4(46), 17939-45.

[99] Kayesh ME, Chowdhury TH, Matsuishi K, Kaneko R, Kazaoui S, Lee JJ, Noda T, Islam A. Enhanced photovoltaic performance of $\mathrm{FASnI}_{3}$-based perovskite solar cells with hydrazinium chloride coadditive, ACS Energy Lett. 2018, 3(7), 1584-9.

[100] Liu X, Wang Y, Xie F, Yang X, Han L. Improving the performance of inverted formamidinium tin iodide perovskite solar cells by reducing the energy-level mismatch, ACS Energy Lett. 2018, 3(5), 1116-21.

[101] Xi J, Wu Z, Jiao B, Dong H, Ran C, Piao C, Lei T, Song TB, Ke W, Yokoyama T, Hou X. Multichannel Interdiffusion Driven $\mathrm{FASnI}_{3}$ Film Formation Using Aqueous Hybrid Salt/Polymer Solutions toward Flexible Lead-Free Perovskite Solar Cells, Adv. Mater. 2017, 29(23), 1606964.

[102] Moghe D, Wang L, Traverse CJ, Redoute A, Sponseller M, Brown PR, Bulović V, Lunt RR. All vapordeposited lead-free doped $\mathrm{CsSnBr}_{3}$ planar solar cells, Nano Energy, 2016, 28, 469-74. 
[103] Li W, Li J, Li J, Fan J, Mai Y, Wang L. Addictive-assisted construction of all-inorganic CsSnIBr 2 mesoscopic perovskite solar cells with superior thermal stability up to $473 \mathrm{~K}$, J. Mater. Chem. A. 2016, 4(43), 17104-10.

[104] Li XL, Gao LL, Chu QQ, Li Y, Ding B, Yang GJ. Green Solution-Processed Tin-Based Perovskite Films for Lead-Free Planar Photovoltaic Devices, ACS Appl. Mater. Interfaces, 2018, 11(3), 3053-60.

[105] Ke W, Stoumpos CC, Spanopoulos I, Chen M, Wasielewski MR, Kanatzidis MG. Diammonium cations in the $\mathrm{FASnI}_{3}$ perovskite structure lead to lower dark currents and more efficient solar cells, ACS Energy Lett. 2018, 3(7), 1470-6.

[106] Lee B, Shin B, Park B. Uniform $\mathrm{Cs}_{2} \mathrm{SnI}_{6}$ thin films for lead-free and stable perovskite optoelectronics via hybrid deposition approaches, Electron. Mater. Lett. 2019, 15(2), 192-200.

[107] Yang WF, Igbari F, Lou YH, Wang ZK, Liao LS. Tin Halide Perovskites: Progress and Challenges, Adv. Energy Mater. 2019, 1902584.

[108] Feng J, Xiao B. Effective masses and electronic and optical properties of nontoxic $\mathrm{MASnX} 3(\mathrm{X}=\mathrm{Cl}, \mathrm{Br}$, and I) perovskite structures as solar cell absorber: a theoretical study using HSE06, J. Phys. Chem. C. 2014, 118(34), 19655-60.

[109] Diau EW, Jokar E, Rameez M. Strategies to Improve Performance and Stability for Tin-Based Perovskite Solar Cells, ACS Energy Lett. 2019, 4(8), 1930-7.

[110] Mosconi E, Umari P, De Angelis F. Electronic and optical properties of mixed $\mathrm{Sn}-\mathrm{Pb}$ organohalide perovskites: a first principles investigation, J. Mater. Chem. A. 2015, 3(17), 9208-15.

[111] Liu M, Chen Z, Xue Q, Cheung SH, So SK, Yip HL, Cao Y. High performance low-bandgap perovskite solar cells based on a high-quality mixed $\mathrm{Sn}-\mathrm{Pb}$ perovskite film prepared by vacuum-assisted thermal annealing, J. Mater. Chem. A. 2018, 6(34), 16347-54.

[112] Tong J, Song Z, Kim DH, Chen X, Chen C, Palmstrom AF, Ndione PF, Reese MO, Dunfield SP, Reid OG, Liu J. Carrier lifetimes of $>1 \mu$ in $\mathrm{Sn}-\mathrm{Pb}$ perovskites enable efficient all-perovskite tandem solar cells, Science, 2019, 364(6439), 475-9.

[113] Wang R, Wang J, Tan S, Duan Y, Wang ZK, Yang Y. Opportunities and challenges of lead-free perovskite optoelectronic devices, Trends Chem. 2019.

[114] Konstantakou M, Stergiopoulos T. A critical review on tin halide perovskite solar cells, J. Mater. Chem. A. 2017, 5(23), 11518-49.

[115] Chung I, Song JH, Im J, Androulakis J, Malliakas CD, Li H, Freeman AJ, Kenney JT, Kanatzidis MG. $\mathrm{CsSnI}_{3}$ : semiconductor or metal? High electrical conductivity and strong near-infrared photoluminescence from a single material. High hole mobility and phase-transitions, J. Am. Chem. Soc. 2012, 134(20), 857987.

[116] Stoumpos CC, Malliakas CD, Kanatzidis MG. Semiconducting tin and lead iodide perovskites with organic cations: phase transitions, high mobilities, and near-infrared photoluminescent properties, Inorg. Chem. 2013, 52(15), 9019-38. 
[117] Saparov B, Sun JP, Meng W, Xiao Z, Duan HS, Gunawan O, Shin D, Hill IG, Yan Y, Mitzi DB. Thin-film deposition and characterization of a Sn-deficient perovskite derivative $\mathrm{Cs}_{2} \mathrm{SnI}_{6}$, Chem. Mater. 2016, 28(7), 2315-22.

[118] Lee B, Stoumpos CC, Zhou N, Hao F, Malliakas C, Yeh CY, Marks TJ, Kanatzidis MG, Chang RP. Airstable molecular semiconducting iodosalts for solar cell applications: $\mathrm{Cs}_{2} \mathrm{SnI}_{6}$ as a hole conductor, J. Am. Chem. Soc. 2014, 136(43), 15379-85.

[119] Weiss M, Horn J, Richter C, Schlettwein D. Preparation and characterization of methylammonium tin iodide layers as photovoltaic absorbers, Phys. Status Solidi A. 2016, 213(4), 975-81. 